


\title{
A HOLOGRAPHIC FUTURE: \\ COMPARING AN AR HEADSET TO \\ TRADITIONAL CONSTRUCTION METHODS
}

BY

TAYLER HUBBER-DAVIS

\begin{abstract}
A thesis
submitted to the Victoria University of Wellington in fulfilment of the requirements for the degree of Master of Building Science
\end{abstract}

Victoria University of Wellington

2019 



\section{ABSTRACT}

New Zealand's construction industry has seen a profound uptake in the use of Building Information Modelling (BIM) in recent years. BIM has proven to be beneficial to individuals during moments of the lifecycle of a building, but it has yet to play a significant role in the actual construction stage of a project.

In recent years, researchers have become increasingly interested in the use of Augmented Reality (AR) to provide support for BIM implementation and productivity on-site. However, current research has yet to prove the effectiveness of integrating the information from the BIM model into an AR environment. With international AR applications emerging and the improvement on AR and BIM software, it has now become feasible to test the integration of these two technologies dynamically.

This paper utilises recent developments in technology to provide a comparison of the effectiveness of information retrieval methods. A three-phase, mixed method experiment was conducted and evaluated over a one-year time frame in Wellington, New Zealand. By using a mixed method approach, the research gained multiple forms of data drawing on all possibilities. One phase involved a focus group with a variety of construction industry professionals exploring the use of BIM and how their teams work together to solve problems and tasks on-site. The second phase had twenty-four construction industry tradesmen randomly assigned to three control groups to complete clash detection tasks using different visualisation mediums. The control groups used either twodimensional paper drawings, a BIM model on a laptop, or a BIM model in a Microsoft HoloLens to complete the information retrieval tasks. Following the task-based experiment, the control groups participated in a focus group to understand tradesmen's perceptions of the different visualisation mediums and how current processes could be improved for their understanding. Each group was assessed on a usability framework model of effectiveness, efficiency and satisfaction.

Based on the results of the experiments and focus groups, this research can produce evidence for determining the most effective methods for information retrieval and clash detection on-site. Can AR provide a more powerful system for construction productivity and information retrieval than paper or computerbased systems? The research does not provide a detailed solution but instead demonstrates the potential marriage between AR and BIM technologies to help evolve future building processes. 



\section{ACKNOWLEDGEMENTS}

I would first like to acknowledge the support of my supervisor, Kevin Sweet. Your enthusiasm, patience and continuous support throughout this last year have helped me to reach this goal competently. I also want to express my appreciation for providing access to a Microsoft HoloLens for my research. I cannot thank you enough!

I would like to extend my thanks to Kevin Thickett and Chris Welch, from Aurecon. Both have also been a tremendous support to this thesis. Without their guidance, skills and industry knowledge, I would not have been able to put this research together.

A special thank you to Michael Donn and Nigel Isaacs for taking the time to give guidance and feedback throughout my university years. You have allowed me to challenge myself, enrich my ideas and achieve goals I wouldn't have thought I was capable of!

I am grateful to all of those that participated in my research. Each member of the focus groups and experiments delivered valuable feedback and information for my research. Regrettably, I cannot acknowledge you all by name.

A huge thank you to the Building Research Levy for funding this research and offering their guidance.

I wish to acknowledge a friendship that began at Victoria University of Wellington and continued to grow over the last five years. A massive thank you to my partner in crime, Dan! Thank you for being a friend before a colleague, for always willing to read my writing and lend an ear when I was stressed, and for continually reminding me that "We've got this!". You da best!

On another personal note, I would like to acknowledge the support from my parents, family and friends. Also, a special shout-out to the flock at Shepherd (shaka's all round)! You have all been supportive and understanding of the commitments and responsibilities of completing my thesis. Without your support during the highs and the lows of this past year, it would have been a much more difficult time. You are the ones who have ultimately helped me get this far and I am so thankful for all of you. I hope I have made all of you proud! :) 



\section{CONTENTS}

ABSTRACT

ACKNOWLEDGEMENTS

VIII

LIST OF FIGURES

$\mathbf{X I}$

LIST OF TABLES

XIII

LIST OF ABBREVIATIONS

\subsection{INTRODUCTION}

1.1 Statement of the Problem 5

1.2 Research Questions, Aims \& Objectives $\quad 5$

$\begin{array}{ll}1.3 \text { Significance of the Study } & 6\end{array}$

$\begin{array}{ll}1.4 \text { Summary of the Research Methodology } & 7\end{array}$

1.5 Thesis Roadmap 9

1.6 Limitations $\quad 11$

2.0 LITERATURE REVIEW 13

2.1 Chapter Introduction $\quad 15$

2.2 Building Information Modelling $\quad 15$

2.2.1 Definition of BIM 16

2.2.2 Benefits \& Drawbacks of BIM 19

2.2.3 BIM Implementation Challenges $\quad 20$

2.3 Augmented Reality in the Construction Industry 22

2.3.1 Previous Examples in the Construction Industry 22

2.4 Technological Requirements of AR \& BIM Integration 27

2.5 HoloLens $\quad 29$

2.5.1 HoloLens Hardware $\quad 29$

2.5.2 HoloLens Software \& Tools 33

2.5.3 HoloLens Application Examples $\quad 34$

$\begin{array}{ll}2.6 \text { Concluding Remarks } & 37\end{array}$

3.0 RESEARCH METHODOLOGY $\quad 39$

3.1 Chapter Introduction $\quad 41$

3.2 Research Design $\quad 41$

3.2.1 Rational \& Theoretical Framework 42

3.3 Participants \& Recruitment $\quad 44$

3.4 Data Collection $\quad 46$

3.4.1 Instruments $\quad 46$

3.4.2 Data Collection Procedures $\quad 49$

3.5 Data Analysis $\quad 53$

3.5.1 Qualitative Data Analysis $\quad 54$

3.5.2 Quantitative Data Analysis $\quad 56$ 
3.5.3 Data Integration $\quad 58$

3.6 Concluding Remarks $\quad 59$

4.0 RESULTS

4.1 Chapter Introduction $\quad 63$

4.2 Initial Focus Group $\quad 63$

4.2.1 Focus Group Discussion $\quad 64$

4.2.2 Focus Group Lessons Learned $\quad 67$

4.3 Task Development \& HoloLens Application Design 68

4.3.1 Model Clashes $\quad 68$

4.3.2 Paper Drawings $\quad 70$

4.3.3 Three-dimensional Laptop Model $\quad 71$

4.3.4 HoloLens Model Application Workflow $\quad 72$

$\begin{array}{ll}4.4 \text { Experiments } & 78\end{array}$

4.4.1 Effectiveness (Accuracy) $\quad 79$

$\begin{array}{ll}4.4 .2 \text { Efficiency (Speed) } & \mathbf{8 1}\end{array}$

4.5 Post-Experiment Focus Groups $\quad 84$

4.5.1 Focus Group Discussion $\quad 85$

$\begin{array}{ll}5.0 \text { DISCUSSION } & 89\end{array}$

5.1 Chapter Introduction $\quad 91$

$\begin{array}{ll}5.2 \text { Effectiveness } & 91\end{array}$

5.3 Efficiency $\quad 92$

$\begin{array}{ll}5.4 \text { Satisfaction } & 94\end{array}$

6.0 SUMMARY \& CONCLUSIONS $\quad 97$

6.1 Chapter Introduction $\quad 99$

6.2 Review of Thesis $\quad 99$

$\begin{array}{ll}6.3 \text { Limitations } & 102\end{array}$

6.4 Future Research Recommendations $\quad 103$

$\begin{array}{ll}\text { REFERENCES } & 105\end{array}$

APPENDICES

Appendix A - Mixed Methods Diagram $\quad 113$

Appendix B - Health Screening Questionnaire $\quad 115$

Appendix C - Initial Focus Group Information Sheet 117

Appendix D - Post Experiment Focus Group Question Guide 121

Appendix E - Focus Group Rules $\quad 127$

Appendix F - Initial Focus Group Question Guide 129

Appendix G - Post-Experiment Focus Group Question Guide 131

Appendix H - Experiment Answer Sheet 133

Appendix I - Model Legends 135 


\section{LIST OF FIGURES}

Figure 1 - Data Process \& Integration

Figure 2 - Research Chapters \& Methodology Process 10

Figure 3 - BIM Kiosk (Bråthn \& Moum, 2016) 22

Figure 4 - Vaai's Gantt Chart Visualisation (Vaai, 2014) 23

Figure 5 - "BIM-Phase" (Zaher, Greenwood, \& Marzouk, 2018) 24

Figure 6 - iHelmet (Yeh, Tsai, \& Kang, 2012) 26

Figure 7 - Martin Bros Framing Study (Rubenstone, 2016) 26

Figure 8 - TAM Framework (Adapted from Davis, 1989) 28

Figure 9 - Microsoft HoloLens (Washington University in St. Louis, 2018) 29

Figure 10 - How to Fit the HoloLens (Adapted from Microsoft, 2018b) 30

Figure 11 - HoloLens Cursor Interactions (Hodgson, 2018) 31

Figure 12 - Air Tap Gesture (Adapted from Microsoft, 2018f) 32

Figure 13 - Tap \& Hold Gesture (Adapted from Microsoft, 2018f) 32

Figure 14 - Bloom Gesture (Adapted from Microsoft, 2018f) 32

Figure 15 - HoloLens Lenses (Jana, Sharma, \& Rai, 2017) 33

Figure 16 - BIM HoloView HoloLens Model (Microsoft, 2018a) 36

Figure 17 - HoloLive Mockup HoloLens Model (Microsoft, 2018d) 36

Figure 18 - Trimble Connect HoloLens Collaboration (Microsoft, 2018e) 36

Figure 19 - Hourglass Design of Focus Group Discussion (Hennick, 2014) 47

Figure 20 - Data Analysis Process $\quad 54$

Figure 21 - Usability Framework Model (ISO, 2018) 56

Figure 22 - Cafe \& Kitchen Floor Plan 69

Figure 23 - Clashes in Model $\quad \mathbf{7 0}$

Figure 24 - 3D Revit Model $\quad 71$

Figure 25 - Revit to Unity Workflow 72

Figure 26 - Layers of the Model $\quad 73$

Figure 27 - Mixed Reality Toolkit $\quad 73$

Figure 28 - Build Settings in Unity $\quad 75$

Figure 29 - Visual Studio Solutions Configuration Settings $\quad 75$

Figure 30 - HoloLens Functions Menu 77

Figure 31 - HoloLens Model $\quad 77$

Figure 32 - Total Number of Clashes Answered Per Group $\quad \mathbf{8 0}$

Figure 33 - Comparison of Total Clashes Detected \& Correct Answers $\quad \mathbf{8 0}$

Figure 34 - Overall Time Spent on Experiment $\mathbf{8 2}$

Figure 35 - Time Per Clash (Group 1) 83

Figure 36 - Time Per Clash (Group 2) 83

Figure 37 - Time Per Clash (Group 3) 84 



\section{LIST OF TABLES}

Table 1 - BIM Definition Comparison (Adapted from Sun et al., 2015)

Table 2 - BIM Benefit Analysis

Table 3 - HoloLens Application Features

Table 4 - Experiment \& Focus Group Participants Schedule

Table 5 - Experiment Statistics

81

Table 6 - Time (seconds) Spent on Each Clash

82

Table 7 - Advantages \& Disadvantages of Each System 



\section{LIST OF ABBREVIATIONS}

$\begin{array}{ll}\text { AECO } & \text { Architecture, Engineering, Construction, } \\ \text { AR } & \text { Augmented Reality } \\ \text { BAC } & \text { BIM Acceleration Committee } \\ \text { BIM } & \text { Building Information Modelling } \\ \text { CAVE } & \text { Cave Automatic Virtual Environment } \\ \text { MEP } & \text { Mechanical, Electrical, Plumbing } \\ \text { MR } & \text { Mixed Reality } \\ \text { UI } & \text { User Interface } \\ \text { VR } & \text { Virtual Reality }\end{array}$





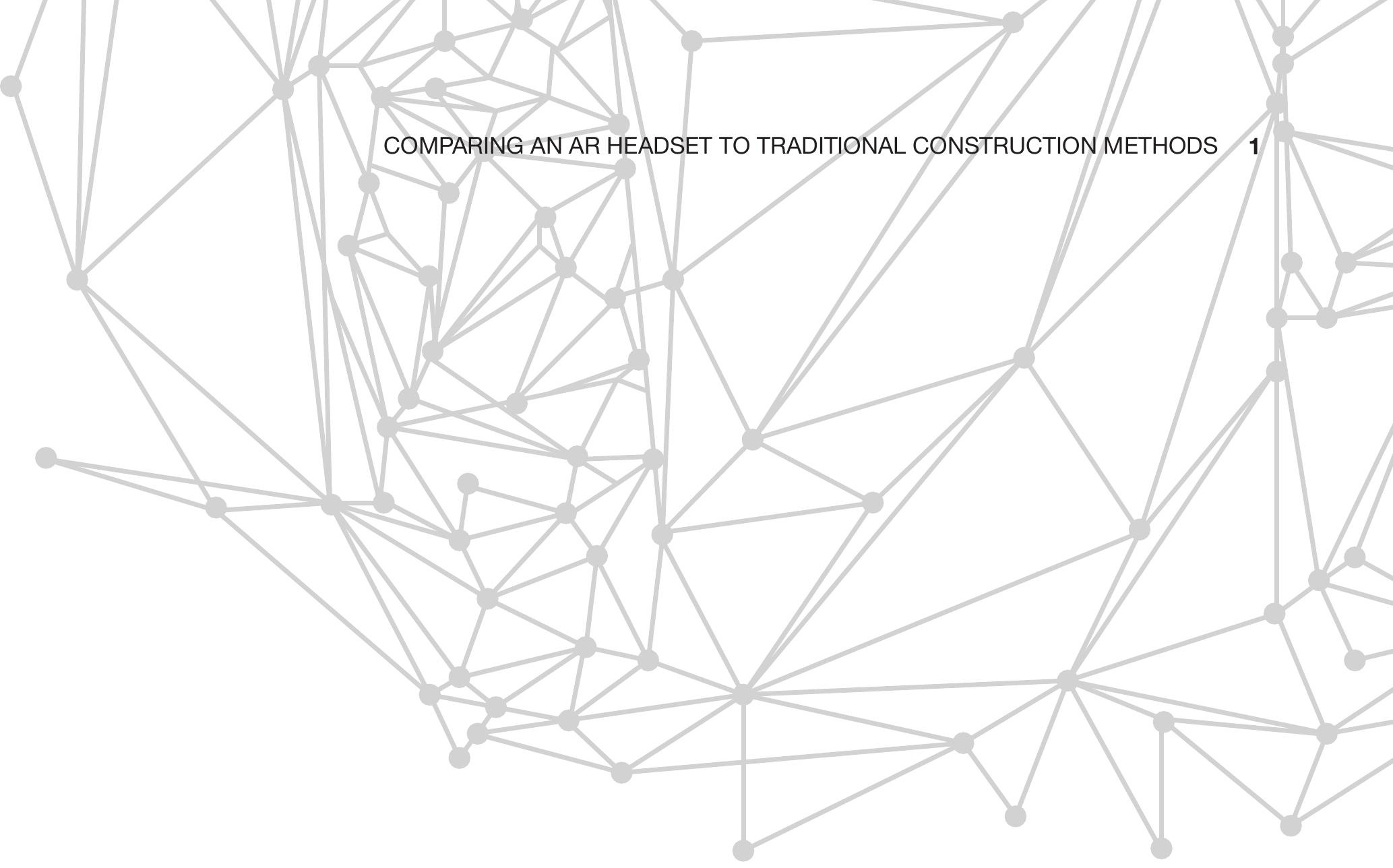

CHAPTER ONE

INTRODUCTION 

"Any sufficiently advanced technology is indistinguishable from magic." - Arthur C. Clark, Profiles of the Future, 1962 



\subsection{STATEMENT OF THE PROBLEM}

Building Information Modelling (BIM) has had a significant effect on the way that we build, both in New Zealand and worldwide. Studies have confirmed that BIM can provide multiple benefits to construction projects. However, at present, BIM is not being utilised to its full potential, and there are limited examples of successful implementation.

In recent years researchers have become increasingly interested in the use of Augmented Reality (AR) to provide support for BIM implementation and productivity on construction sites (Zaher, Greenwood \& Marzouk, 2018).

Nonetheless, AR is still a developing research area for the construction industry. As technology continues to evolve this process will become more streamlined. What if it were possible to see a hologram of a building project on-site and use it to compare the actual construction in place? Could this provide a visual advantage for project development and alignment to BIM expectations?

There is a need for better BIM implementation strategies, and with the improvement of technology, it is now feasible to test the integration of $A R$ and BIM dynamically. A considerable amount of research has examined the use of mobile phones or tablets for BIM/AR use on-site, but there is little research on the use of AR headset technologies. This thesis takes advantage of recent technologies by using a Microsoft HoloLens for the testing phase of the research.

\subsection{RESEARCH QUESTIONS, AIMS \& OBJECTIVES}

The research questions for this thesis are:

$R Q \# 1$ : To what extent can Augmented Reality provide a more effective system for productivity and information retrieval for Building Information Modelling in comparison to traditional methods?

$R Q$ \#2: What are the relative advantages and disadvantages of using an AR headset for information retrieval on construction sites? 
The main aim of this thesis research is:

To quantify the effectiveness of Augmented Reality as an information retrieval tool for Building Information Modelling in comparison to traditional paper drawing or computer-based methods.

With this aim in mind, the objectives of this study are:

1) To critically assess previous literature about BIM and its implementation, precedent $A R$ applications and studies to identify background information, and the technological requirements and characteristics of integrating BIM and AR technology.

2) To identify common issues that arise during the construction stage of a project and understand how construction industry professionals work together to solve them.

3) To develop the framework for implementing a Microsoft HoloLens application on a construction project.

4) To demonstrate AR's potential in comparison to other systems through experiments and focus group sessions.

5) To make industry recommendations for $A R$ 's potential future based on the results of the study.

\subsection{SIGNIFICANCE OF THE STUDY}

Companies both internationally and within New Zealand have begun the exploration of how AR can integrate with BIM. Although AR's use in the Architecture, Engineering, Construction and Owner-Operated (AECO) world has been of interest for over ten years, the applied research on this technology in the construction industry is only in its adolescence (Gheisari, Williams, Chen, \& Irizarry, 2014).

AR can be used on a mobile device or via wearable technology such as a headset (Chu, Matthews \& Love, 2018). The portability of AR makes it useful for the AECO industry as most workers need a view of the spaces or buildings to perform their everyday tasks (Gheisari, Williams, Chen, \& Irizarry, 2014). Wang and Chong (2015) state that "Augmented Reality, a technology that presents virtual information into the workers' real-world views, can extend BIM to the site for transiting the digital information onto physical workpieces". They suggest that the integration of BIM and AR could help manage on-site 
activities through instant feedback on design decisions and plans. Despite this conclusion, few studies, including Wang and Chong's study, have yet to demonstrate its effectiveness or usability on construction sites successfully. Chu, Matthews \& Love's (2018) study is a recent example that addresses this gap. They developed a mobile BIM AR system and had participants compare it with existing paper information retrieval methods. However, they acknowledge that the research surrounding the integration of BIM and AR is limited and that further research should use updated technologies to address task-based processes with BIM and AR.

The current advancements in AR technology are changing how we see a building model and access the information held within it. AR could provide a clear, visual understanding for workers on site with virtual objects overlaid on the real environment. This element of visualisation could optimise communication systems on a project and improve project workflows to increase productivity. AR could give images not only of what should be present but also what is missing or is in place in advance of planning. This information suggests that a combination of AR and BIM could address implementation issues as well as improving construction and delivery methods.

The findings from this research aim to provide information and further understanding of AR and BIM benefits and aid the broader industry in developing BIM/AR implementation strategies. Companies within New Zealand and on a global scale could find the results beneficial if they are considering implementing AR into their projects or have faced issues with the current information systems they are using.

\subsection{SUMMARY OF THE METHODOLOGY}

This mixed methods study addresses the effect of using AR as an information retrieval tool for construction in comparison to other visualisation methods. Mixed methods research can be defined as "a research design (or methodology) in which the researcher collects, analyses, and mixes (integrates or connects) both quantitative and qualitative data in a single study or a multiphase program of inquiry" (Johnson, Onwuegbuzie \& Turner, 2007). In this study, several phases work sequentially to collect both qualitative and quantitative data. It is essential for a mixed methods approach to be used because it allows the study to capture an individual's experiences and opinions of $A R$ as well as measurable comparisons to other visualisation techniques. 
Further information about mixed methods research is detailed in section 3.1.

In order to achieve this aim, an initial focus group provided a preliminary qualitative exploration into how construction industry professionals currently collaborate and use visualisation tools on construction sites. Following the initial focus group, a combination of experiments and focus groups collected quantitative and qualitative data concurrently. The experiments asked three groups of participants to complete tasks using either two-dimensional paper construction drawings, a three-dimensional model on a laptop, or an AR model on a Microsoft HoloLens. Measures recorded during the experimental userbased study identified the speed and accuracy of answers. Consecutively after each experiment, a focus group provided a detailed insight into the participant's experience with the assigned resource.

In examining the integrated results of the experiments and focus groups, conclusions can draw the advantages of using AR for information retrieval in a construction environment and where this stands as a tool relative to traditional methods. Figure 1 explains the sequential process of collecting and integrating the data.

\begin{tabular}{|c|}
\hline Initial Focus Group \\
\hline Qualitative Data Collection and Analysis \\
\hline 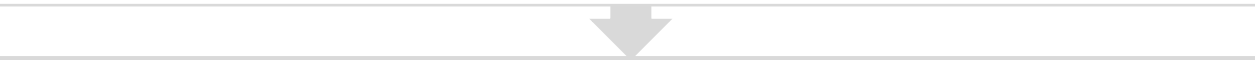 \\
\hline Initial Focus Group Results \\
\hline Obtain Qualitative Results \\
\hline 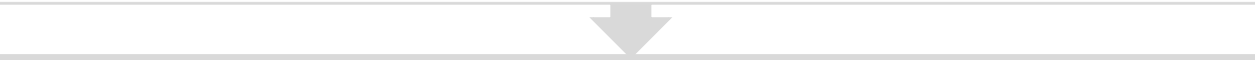 \\
\hline Data Integration \\
\hline Use Focus Group Results to Form Variables, Instruments \& Interventions for Experiments \\
\hline 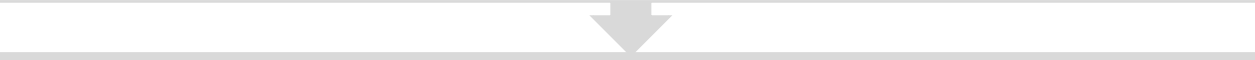 \\
\hline Experiments and Focus Group \\
\hline Quantitative (Experiments) and Qualitative (Focus Group) Data Collection \\
\hline 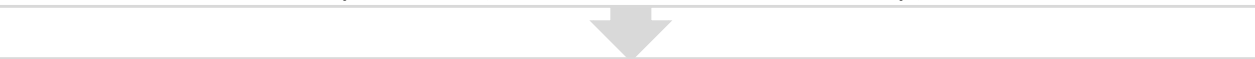 \\
\hline Experiment and Focus Group Results \\
\hline Obtain Quantitative (Experiments) and Qualitative (Focus Group) Results \\
\hline+2 \\
\hline Data Interpretation \\
\hline How Qualitative Data explains Quantitative Results \\
\hline
\end{tabular}




\subsection{THESIS ROADMAP}

This thesis contains six chapters and is structured as follows. Figure 2 explains the connection between each section and the methodology process.

Chapter 1 introduces the research topic and outlines the aims, objectives and significance of the research.

Chapter 2 contains a systematic literature review of BIM and AR applications in the construction industry, information specific to the Microsoft HoloLens, and technology implications for integrating AR and BIM.

Chapter 3 introduces the research methodology and gives the rationale and theoretical framework for the chosen methodology.

Chapter 4 provides the results of the initial focus groups, experiments and postexperiment focus group sessions. It also provides the workflow for converting a BIM into an AR application for the Microsoft HoloLens.

Chapter 5 analyses and discusses the results of the research.

Chapter 6 provides a review of the thesis with some concluding remarks, limitations and recommendations for future research. 


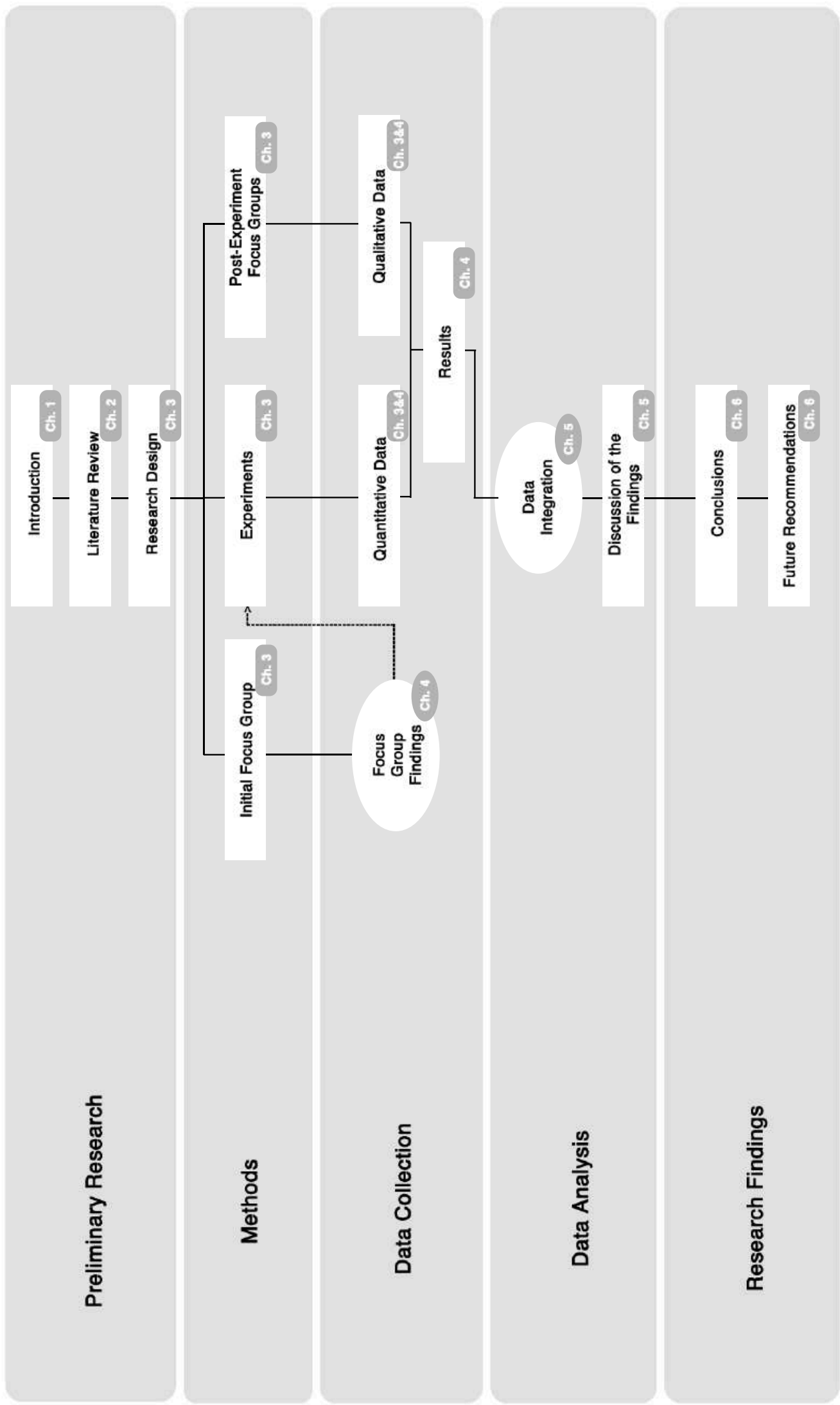

Figure 2 - Research Chapters \& Methodology Process 


\subsection{LIMITATIONS}

A limitation of this research was that the experiments ran during the December period when most of the construction industry is typically unavailable. Due to time constraints, this was the only time that the experiments could be completed. In turn, this caused limited ability to gain access to participants meaning that the sample sizes were small. However, in using a smaller population, it can aid as a test for the research hypothesis in the short allocated space of time.

The focus group discussions with construction industry professionals could also result in different interpretations. With focus groups, it is improbable to get the same discussion twice, and each session starts with an unbiased point of knowledge. The benefit of this is that each participant can contribute to the discussion equally and develop their concepts further. In selecting an appropriate population of participants, the researcher can again, gain a collective insight into the study time-frame.

Another limitation is that the researcher had limited programming knowledge before starting the research, so, the AR application had simple capabilities. It is not the purpose of this study to find a detailed solution to BIM implementation but rather to demonstrate how AR could benefit the construction industry. 




\subsection{CHAPTER INTRODUCTION}

Augmented Reality is "a technology whereby real and live images can coexist with virtual information through the medium of a mobile interface" (Zaher, Greenwood \& Marzouk, 2017). There is a consensus across most literature that AR can be a positive tool for the construction industry (Ghaffarianhoseini et al., 2017, Yeh, Tsai, \& Kang, 2012, Zaher, Greenwood \& Marzouk, 2017, Bråthen \& Moum, 2016, Vaai, 2014, and Wang, Kim, Love, \& Kang, 2013). It is said to enhance the information extraction process leading to increased productivity. This widely accepted view that AR can produce more efficient and effective results has led to an increased interest of AR in recent years (Zaher, Greenwood \& Marzouk, 2017). However, as technology develops, it needs to be assessed and re-assessed for usability purposes.

This chapter presents a review of the literature related to BIM, AR and the issues with integrating the two technologies to lead the way for this research. Information about the Microsoft HoloLens is also examined to develop an understanding of how it can be of use to this research. This literature review aims to determine what has already been written on AR and BIM, to identify gaps in previous studies and to provide a foundation for this research. The chapter starts with a detailed review of BIM, with a specific interest in the implementation of it in the construction phase of a project. It then analyses some precedents of $A R$ in the construction industry. Following this section, the chapter points out the technological requirements and concerns regarding effective AR and BIM integration. Finally, as one of the main components of this research is to develop an application for the Microsoft HoloLens, information about the software requirements are also examined to assist this research.

\subsection{BUILDING INFORMATION MODELLING}

Building Information Modelling (BIM) began roughly in the 1970s when threedimensional modelling emerged, and Chuck Eastman created a working BIM prototype (Ghaffarianhoseini et al., 2017, and Sun, Jiang, Skibniewski, Man, \& Shen, 2015). Nowadays, it is rare to find companies that are not using BIM in some aspect. Although it is a popular term in the construction industry and has had significant technological advancements, it has not yet been fully adopted (Ghaffarianhoseini et al., 2017). 


\subsubsection{Definition of BIM}

The definition of BIM has been thrown around across professions, and there is no precise answer for what it is (Miettinen \& Paavola, 2014). Consequently, this is one of the main reasons why BIM has not yet reached its full potential. The BIM Acceleration Committee (2017), conducted an industry survey in 2017 on people's views of BIM views in New Zealand. In the survey, $25 \%$ of respondents mentioned that there is a lack of clarity around what BIM is and is not.

Sun, Jiang, Skibniewski, Man and Shen (2015) compared definitions of BIM across key organisations and researchers for their study investigating the factors limiting the application of BIM. Table 1 shows the definitions that they compared. The definition that they developed and chose to use for their study was "the processes of modelling, collaboration and integration and "building information model" to refer to the object-based model or group of datasets". However, Miettinen and Pavola (2014), Matějka and Tomek (2017), and Latiffi, Brahim and Fathi (2014), all established that the definition of BIM is continuously evolving as the technology improves. An exploration of current definitions adds to Sun et al.'s research and determines an appropriate definition of BIM for this research.

The International Organisation for Standardisation (ISO) defines BIM as "the use of a shared digital representation of a built object (including buildings, bridges, roads, process plants, etc.) to facilitate design, construction and operation processes to form a reliable basis for decisions" as part of their BIM standard ISO 29481-1:2016 (International Organisation for Standardisation, 2016). 
This content is unavailable.

Please consult the print version for access. 
The International BIM Implementation Guide believes that there are two definitions of BIM dependent on whether it is acting as a product or process. The BIM Implementation Guide was developed by the Royal Institute of Chartered Surveyors (RICS) independently with Autodesk. Their product definition is "A digital representation of the physical and functional characteristics of a facility using a collection of elements or information that serves as a shared knowledge resource for design, construction, operation and retrofit/demolition of a built environment asset" (Royal Institute of Chartered Surveyors, 2016). Also, their process definition is where BIM is "used to both describe the process and the philosophy that enables the input, sharing, maintenance and output of (electronic) information used in the built environment sector" (Royal Institute of Chartered Surveyors, 2016).

New Zealand shares similar views to the International BIM Implementation Guide as they believe it is essential to consider that BIM is not a single act or process (BIM Acceleration Committee, 2016). The first definition refers to BIM as a product and defines it as "an object-based digital representation of the physical and functional characteristics of a facility. The Building Information Model serves as a shared knowledge resource for information about a facility, forming a reliable basis for decisions during its life cycle from inception onward" (BIM Acceleration Committee, 2016). However, the BIM Acceleration Committee also defined BIM as a process where it is "a collection of defined model uses, workflows and modelling methods used to achieve specific, repeatable and reliable information results from the model. Modelling methods affect the quality of the information generated from the model. When and why a model is used and shared impact on the effective and efficient use of BIM for desired project outcomes and decision support" (BIM Acceleration Committee, 2016).

All of these definitions share similarities where most can agree that BIM:

- Is a digital representation of a building;

- Is used to interchange data;

- Creates collaborate workflows;

- Can be used for the lifecycle of a building.

For this research, BIM will be defined using the United Kingdom Government's 2016 definition as it is more up-to-date, simply put, and encompasses all the above qualities. BIM's use is mandated on all public sector projects in the U.K., and this definition was part of their Level 3 BIM Strategic Plan (Eynon, 2016). 
BIM is defined merely as a process through the following definition: "BIM is a collaborative way of working underpinned by digital technologies, which allow for more efficient methods of designing, delivering and maintaining physical built assets throughout their entire lifecycle" (Eynon, 2016).

\subsubsection{Benefits \& Drawbacks of BIM}

At present, two-dimensional drawings are frequently used on site to locate building information (Yeh, Tsai, \& Kang, 2012). However, they present several drawbacks to workers including inconvenient portability and handling, difficulty in understanding spatial relationships, and browsing and readability problems (Yeh, Tsai, \& Kang, 2012). BIM can be more beneficial as it provides an "intelligent model" that contains the two-dimensional and three-dimensional drawings of a building, and specific building information within a singleintegrated file (Wei, \& Othuman Mydin, 2017). It could also be used throughout the entire lifecycle of a building from pre-design stages through to handover (Sun, Jiang, Skibniewski, Man, \& Shen, 2015).

There are notable benefits of BIM across the construction industry, with most relating to productivity (Zaher, Greenwood \& Marzouk, 2018). An analysis of some of the universal benefits across multiple studies is shown in Table 2.

The most common benefits identified in the studies were improved construction planning and scheduling capabilities, improved digital representation and collaboration, improved communication and collaboration, and accurate cost estimates. From the analysis of these studies, it seems that as time goes on and BIM develops, there is a broader realisation of the benefits it can have in a project.

Despite the overwhelming number of benefits BIM can provide, research shows that changes made during construction are rarely input into the model for future use (Chu, Matthews \& Love, 2018). Theraefore, this confirms that the full potential utilisation of BIM has not been realised (Chu, Matthews \& Love, 2018). 
Table 2 - BIM Benefit Analysis

\begin{tabular}{|c|c|c|c|c|c|c|c|c|c|c|}
\hline & 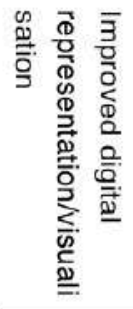 & $\begin{array}{l}\frac{\rho}{90} \\
\frac{0}{5} \\
\frac{0}{0} \\
\frac{0}{10} \\
\frac{0}{0} \\
\frac{0}{1}\end{array}$ & 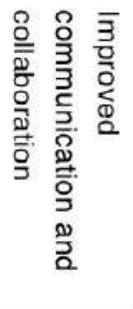 & 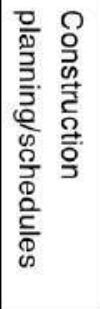 & 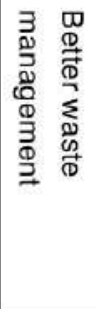 & 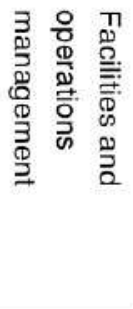 & 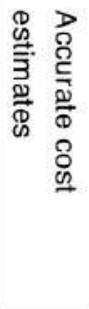 & 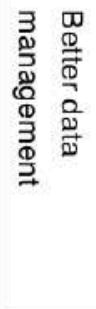 & 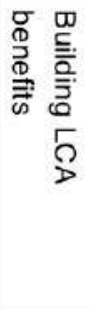 & 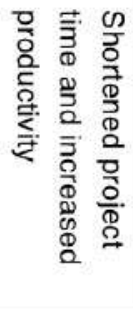 \\
\hline $\begin{array}{l}\text { Wang, Love, } \\
\text { Kim, Park, } \\
\text { Sing \& Hou } \\
\text { (2012) }\end{array}$ & $\bullet$ & & $\bullet$ & $\bullet$ & & & $\bullet$ & $\bullet$ & & \\
\hline $\begin{array}{l}\text { Yeh, Tsai \& } \\
\text { Kang (2012) }\end{array}$ & $\bullet$ & & $\bullet$ & $\bullet$ & & & $\bullet$ & $\bullet$ & $\bullet$ & $\bullet$ \\
\hline $\begin{array}{l}\text { Danker, \& } \\
\text { Oliver (2014) }\end{array}$ & & $\bullet$ & $\bullet$ & $\bullet$ & & $\bullet$ & $\bullet$ & & • & \\
\hline $\begin{array}{l}\text { Sun, Jiang, } \\
\text { Skibniewskki } \\
\text { Man, and } \\
\text { Shen (2015) }\end{array}$ & $\bullet$ & $\bullet$ & $\bullet$ & $\bullet$ & & & $\bullet$ & $\bullet$ & $\bullet$ & $\bullet$ \\
\hline $\begin{array}{l}\text { Wei \& } \\
\text { Othuman } \\
\text { Mxdin (2017) }\end{array}$ & $\bullet$ & $\bullet$ & & 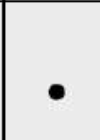 & - & $\bullet$ & $\bullet$ & & & $\bullet$ \\
\hline $\begin{array}{l}\text { Ghaffarianhos } \\
\text { eini et al. } \\
\text { (2017) }\end{array}$ & $\bullet$ & $\bullet$ & 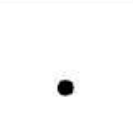 & . & 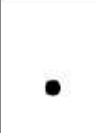 & 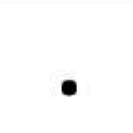 & 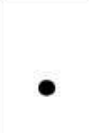 & 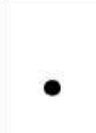 & $\bullet$ & $\bullet$ \\
\hline
\end{tabular}

\subsubsection{BIM Implementation Challenges}

With technology developing and three-dimensional models gaining popularity on sites, BIM seems like the logical solution to improve information retrieval (Chu, Matthews \& Love, 2018). Despite this, the benefits of BIM currently seem to outweigh its usage, and the portability of computers is impractical (Ghaffarianhoseini et al., 2017, and Yeh, Tsai, \& Kang, 2012).

A common theme regarding BIM implementation across all studies was the interoperability challenge. Interoperability could be primarily due to the temporary affiliations between companies causing a "complex communication environment" in the construction industry (Bråthen \& Moum, 2016).

In the survey that was conducted by the BIM Acceleration Committee in 2017, they found that one of the obstacles to using BIM in New Zealand was the 
"perceived lack of clarity among industry stakeholders around processes required for BIM to be efficient". One respondent stated "As the main contractor, the most obstacles or issues from outside is the different format of the information from consultants and subcontractors. For example, the architect uses ArchiCAD, the structural engineer Revit, MEP consultant uses DDS-cad... This makes the collaboration process very hard.”. Therefore, for BIM to be successful and have a consistent understanding, all parties should work in the same format (Wei, \& Othuman Mydin, 2017).

Additionally, Chu, Matthews and Love (2018) noted that workers could be overwhelmed at the amount of information that is available. Rather than utilising the information for productivity, they can be found spending more time managing the data. Ultimately the perception of BIM is of lesser value because of this. Vass and Gustavsson (2017) even identified that project managers, who were sceptical of BIM, would not implement it because it showed "lack of interoperability".

Other critical issues of BIM implementation are lack of knowledge or skill in using BIM, the ease of software and insufficiency of hardware which could be mainly due to the lack of BIM standardisation for projects (Gheisari, Williams, Chen, \& Irizarry, 2014, and Wei, \& Othuman Mydin, 2017). Successful BIM implementation would require companies to train employees on BIM skills and awareness (Wei, \& Othuman Mydin, 2017). Ghaffarianhoseini et al. (2017) noted that the influence of major contractors could determine the full adoption of BIM in a project and so they must have knowledge and skill in using BIM. However, for companies to use BIM and become trained successfully, they must have up-to-date software and hardware as BIM software is usually complicated (Wei, \& Othuman Mydin, 2017).

To ensure a common goal is achievable, it is vital that the information is correct and communicated effectively (Bråthen \& Moum, 2016). Even though BIM seems to be a better solution to retrieving information, two-dimensional drawings are still predominant at sites all around the world (Bråthen \& Moum, 2016). Ghaffarianhoseini et al. (2017) mentioned that BIM could provide more efficient interoperability than two-dimensional drawings. However, there are currently no appropriate tools to make use of BIM on sites, and there are challenges associated with training site workers (Bråthen \& Moum, 2016). With BIM implementation as a current industry challenge and research still limited, 
construction industry professionals may find it difficult to exploit the benefits of BIM. The information extraction process needs to be improved to make effective use of BIM (Chu, Matthews \& Love, 2018). As technology develops, possible implementation solutions can become more feasible to test (Chu, Matthews \& Love, 2018).

\subsection{AUGMENTED REALITY IN THE CONSTRUCTION INDUSTRY}

AR usage in the Architecture, Engineering, Construction and Owner-Operated (AECO) world has been of interest for over ten years (Gheisari, Williams, Chen, \& Irizarry, 2014). AR can be used on a mobile device or via wearable technology (Chu, Matthews \& Love, 2018). The portability of AR makes it useful for this industry as most workers need a view of the spaces or buildings to perform their everyday tasks (Gheisari, Williams, Chen, \& Irizarry, 2014). It has seen an increase in use within the last decade with many researchers investigating its effectiveness for productivity (Zaher, Greenwood \& Marzouk, 2018). Although, few studies have successfully demonstrated its effectiveness or usability on site (Chu, Matthews \& Love, 2018). Recent research has taken case study approaches to implementing AR technology in construction (Yeh, Tsai, \& Kang, 2012).

\subsubsection{Previous Examples in the Construction Industry}

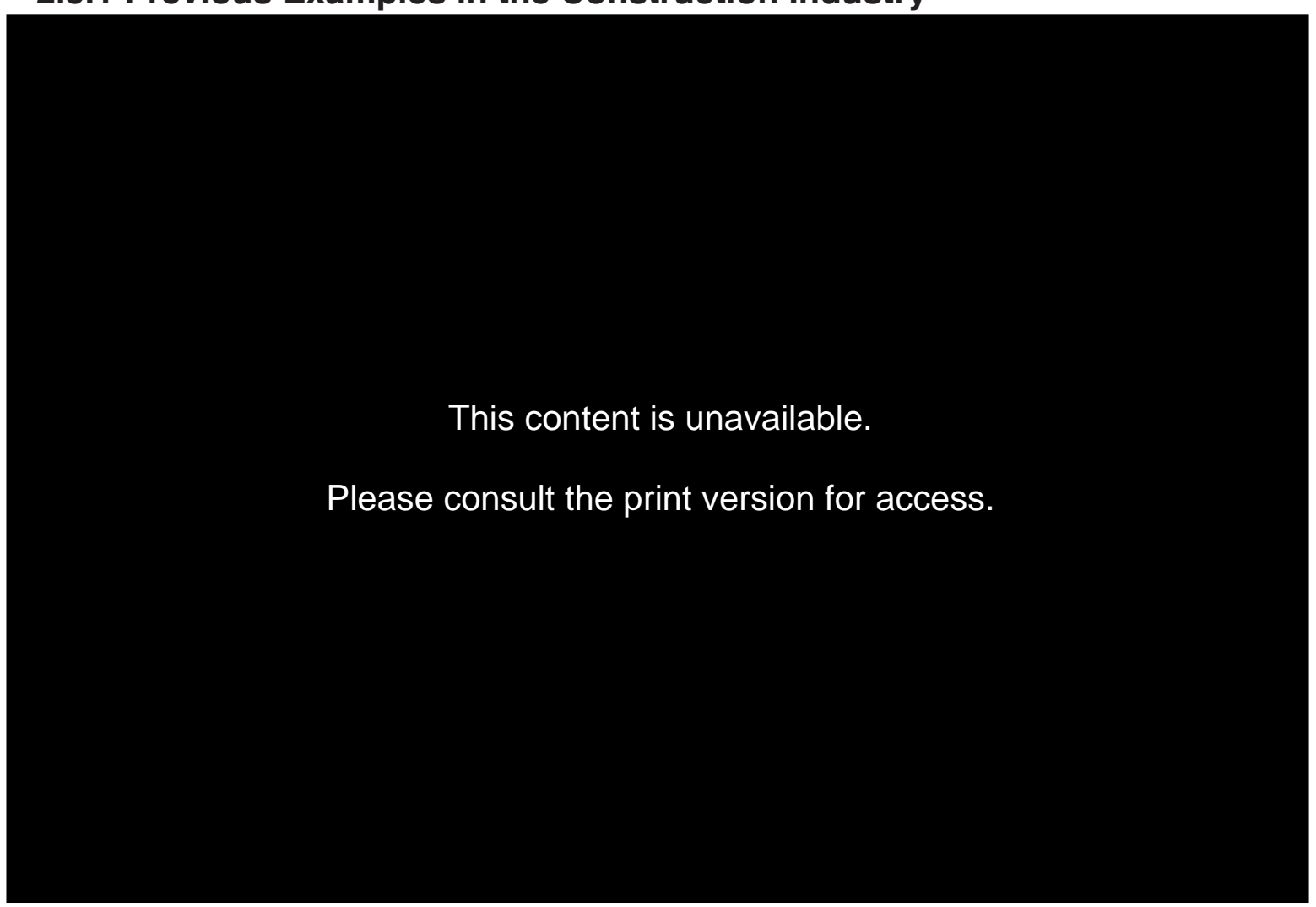

Figure 3 - BIM Kiosk (Bråthen \& Moum, 2016) 
Bråthen \& Moum (2016) took a different approach to AR and used stationary BIM booths called "BIM-kiosks" on a construction site. "BIM-kiosks", shown in Figure 3, allows the site workers to view BIM and get on-site, up-to-date access to BIM information on site. By using electronic media, it offers the opportunity to deliver BIM information in dynamic views that can be manipulated and queried. A local contractor installed five BIM-kiosks on one site. After analysing how site workers used the kiosk, they discovered that having BIM available for site workers meant that complex situations could be handled more efficiently and that there was greater collaboration between the workers. The limitations of this research are that the study was performed in Norway and that it was a single case study. Another limitation is that these kiosks, although transportable from site-to-site, cannot be moved easily around the site. Instead, they are a semipermanent display.

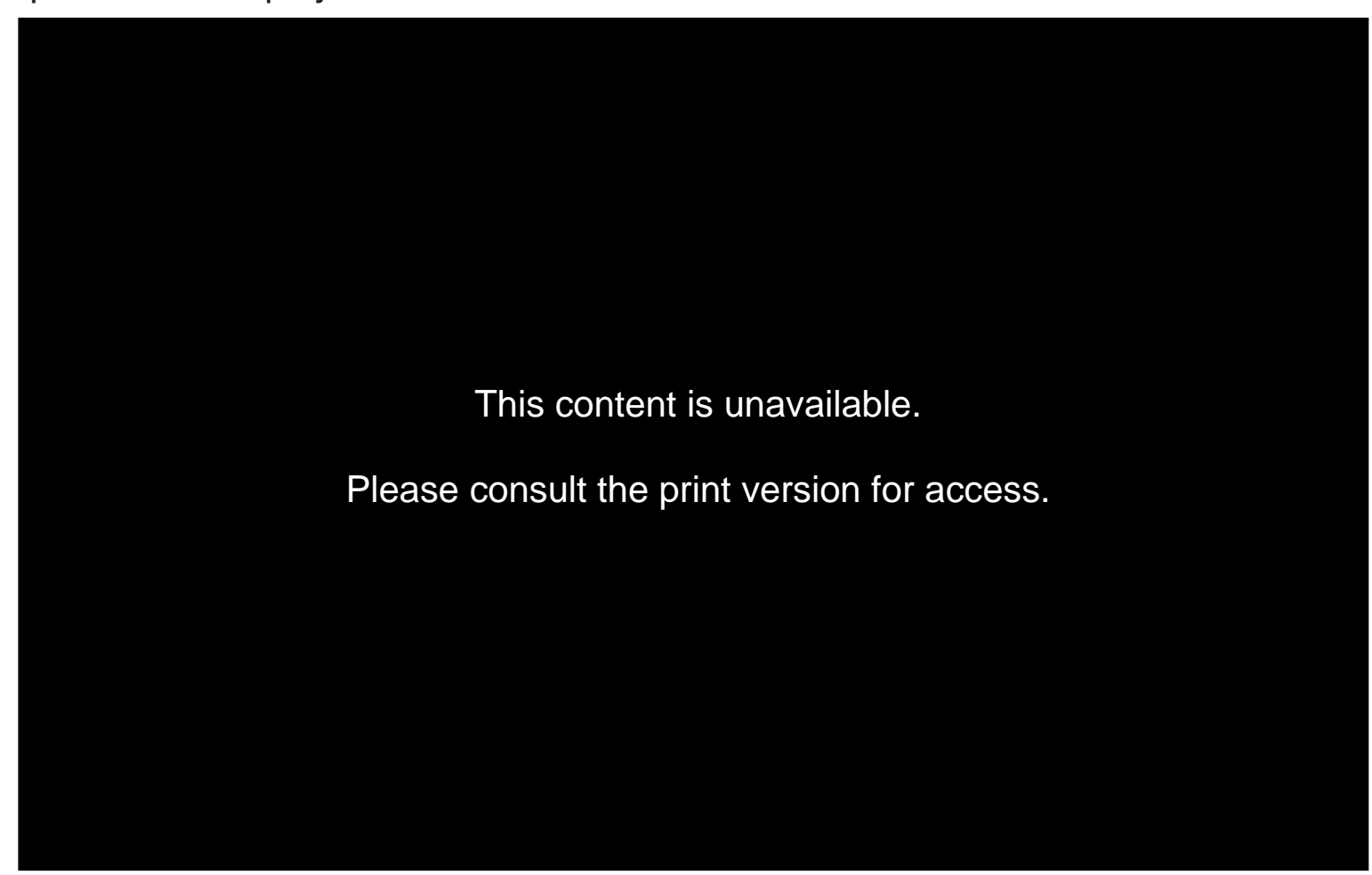

Figure 4 - Vaai's Gantt Chart (Vaai, 2014)

Vaai (2014) researched the potential AR had on mobile devices to enable the use of 4D BIM. He developed an AR application for an Android tablet, which showcased a three-dimensional model of the real project. He initially anticipated having ten functions for his application that could provide value to construction projects. After analysing interviews with construction industry professionals, he determined that within the timeframe he had, he could only demonstrate four. 
The application's four functions were:

- Gantt chart visualisation - links tasks to three-dimensional model components;

- Deactivation - ability to switch different construction layers on and off;

- Timeline - construction of the building in three-dimensional along a timeline;

- And immersive walkthrough - enables the user to view the inside of the building.

An example of Vaai's Gantt chart visualisation is shown in Figure 4. Once the application was developed, he demonstrated it to a range of construction industry professionals and interviewed them about their opinions. Due to time constraints, he was only able to demonstrate some of the uses and obtain feedback from a small percentage of stakeholders.

This content is unavailable.

Please consult the print version for access.

Figure 5 - “BIM-Phase” (Zaher, Greenwood, \& Marzouk, 2018) 
Similarly, Zaher, Greenwood \& Marzouk (2018) created an AR system through the development of an Android application, "BIM-U", and demonstrated it on a real construction project. This study was to explore the advantages of using handheld mobile devices on construction sites. They hypothesised that "handheld mobiles devices combined with AR and BIM provide a powerful system for construction progress monitoring". Figure 5 shows their application with their "BIM-Phase" feature. Once a BIM model has been updated, "BIMPhase" divides the project into phases. In the case of Figure 5, this project contained six phases. A video of the actual project progress is displayed behind the AR model. They concluded that the next step in improving their research would be to use more effective hardware. They suggested using hardware, such as the Microsoft HoloLens, to conduct user-based studies through user reactions to AR applications or accurate measurements.

Some researchers have also investigated the use of wearable devices to display augmented building information more effectively. An earlier example of this is Yeh, Tsai and Kang's (2012) study. They developed a lightweight device, iHelmet, that could "project construction drawings and related information on the basis of the location of the user". The iHelmet, pictured above in Figure 6, has considered the safety element of construction sites by basing their AR device around the design of the construction helmet. They altered a construction helmet to allow for an iPod-Touch to be installed and could project an image in front of them. Their study involved a usability test where participants completed tasks using the iHelmet and were compared based on the time it took to complete the task and the success rates of the information retrieval. Some of the issues identified with the design of this device were that the helmet did not fit everyone's line of vision; some users felt uncomfortable wearing the electronic device. The participants of the research all concluded that it was better than using two-dimensional drawings as it provided a practical, handsfree observation of the information in a precise and productive manner. Yeh, Tsai, and Kang (2012) believed that there were limitations from the hardware available at the time and that the helmet may not comply with safety regulations. Improved hardware with clearer displays and user control should be used to validate AR's potential for building information retrieval. 
This content is unavailable.

Please consult the print version for access.

This content is unavailable.

Please consult the print version for access.

Figure 7 - Martin Bros Framing Study (Rubenstone, 2016) 
In a magazine article by Jeff Rubenstone (2016), Martin Bros., a drywall contractor in California, described their demonstration of a proof-of-concept for AR (Rubenstone, 2016). Using a Microsoft HoloLens and Autodesk Revit, they had a participant put together the steel framing for a bathroom pod in a Cave Automatic Virtual Environment (CAVE). Figure 7 shows the participant using the Microsoft HoloLens to construct the bathroom pod. Although the participant had a construction background, he had not built anything in over 20 years. With outlines of the materials and connections projected through the HoloLens, the participant was able to build the bathroom pod like a puzzle. One of the issues Martin Bros. identified was the implementation of AR on site. If AR hardware improves then the information BIM provides could be displayed in a holographic overlay in a specified location. However, at the time of the demonstration, they found that the HoloLens lost tracking during use and the level of detail was limited.

\subsection{TECHNOLOGICAL REQUIREMENTS OF AR \& BIM INTEGRATION}

Wang, Kim, Love, \& Kang (2013) established in a literature review of 120 studies that AR and BIM are complementary, but their integration has tended to be examined rather than proof of concept or feasibility testing. Sanchez, Hampson and Vaux (2016) had similar views on this in later years. They stated in their book that there were "few mature AR industrial applications in the construction industry, with most existing work being prototypes with limited commercialization". They also said that with the current rate of technology development, AR may now be mature enough to be implemented into the AECO industry. Even though AR may produce sufficient benefits to BIM, there are still issues with technical issues and problems with implementation.

A major technological issue identified for AR technology is drift (Gheisari, Williams, Chen, \& Irizarry, 2014). Drift is where there is a misalignment between the real world and the virtual world (Gheisari, Williams, Chen, \& Irizarry, 2014). The virtual elements should be simplified to avoid overloading the system and to provide a simple interface to minimise drift. (Gheisari, Williams, Chen, \& Irizarry, 2014). However, a study performed by Gheisari, Williams, Chen, and Irizarry (2014) determined that the effectiveness of AR could still be established despite drift problems. Their user-based experiment concluded that AR could correctly locate objects but solving the drift problems would enhance the overall user experience. 


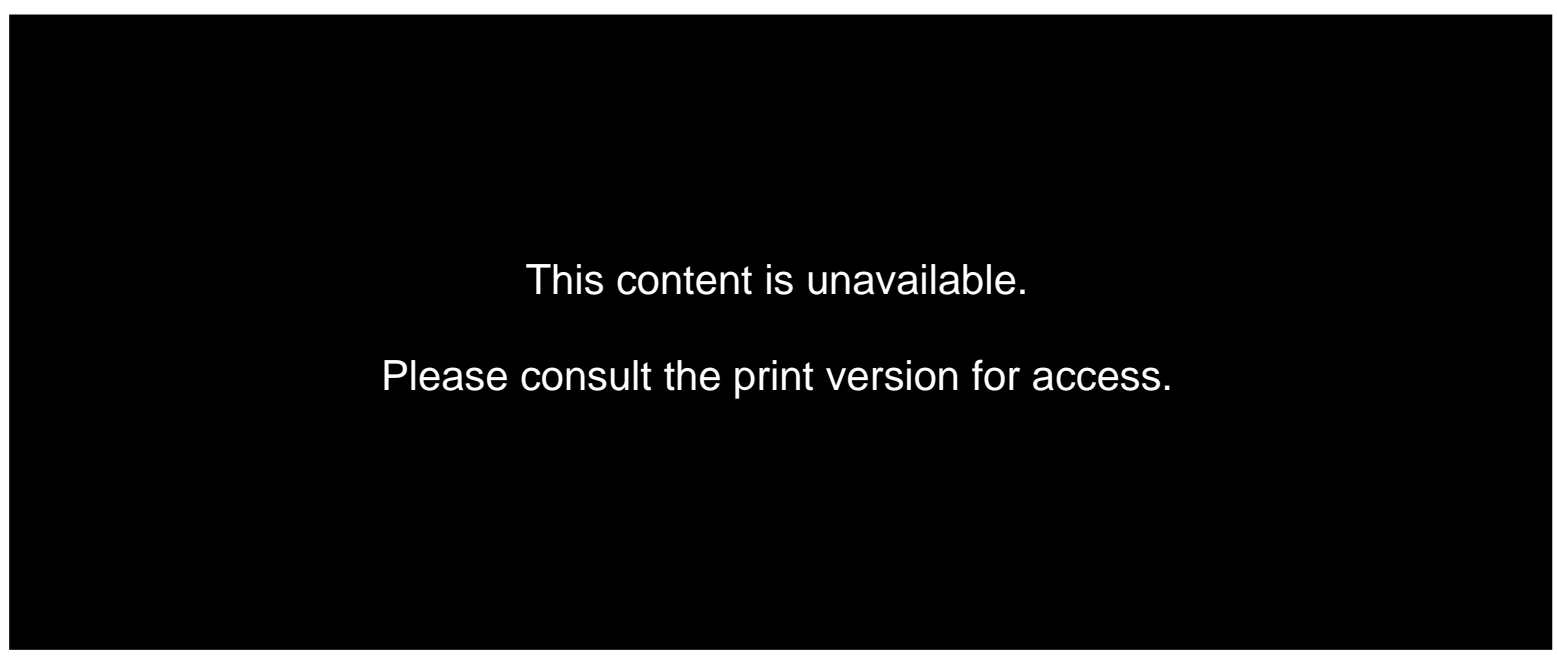

Figure 8 - TAM Framework (Adapted from Davis, 1989)

A potential solution to enhance the user experience could be to design the application using the Technological Acceptance Model (TAM). The TAM framework developed by Davis (1989) is beneficial when implementating an application or system. The factors that influence a user's acceptance to an application or system are perceived usefulness, perceived ease of use and the attitude towards using the system. Figure 8 shows the user acceptance process. Perceived usefulness refers to "the degree to which a person believes that using a particular system would enhance his or her job performance" (Davis, 1989). Perceived ease of use is "the degree to which a person believes that using a particular system would be free of effort" and attitude toward using an application or system is "the mediating affective response between usefulness and ease of use beliefs and intentions to use a target system" (Davis, 1989). "Perceived usefulness" is difficult to determine due to varying personalities (Davis, 1989).

Although, the main deciding factors that dictate how beneficial a system is to a user are the information systems it provides, the marketing of the system and the psychological qualities regarding flow and environmental psychology. Davis believes that these mainly involve the examining of emotional or cognitive responses and ultimately relates to consumer behaviour. In terms of getting to "perceived ease of use", the use of an application or system should be a simple process that requires little cognitive effort when interacting with it. Therefore, a successful application or system should have a simple interface design. The technological limitations remain a significant obstacle in using $A R$, but with further research and developments in technology, it could be resolved. 


\subsection{HOLOLENS}

One of the main parts of this thesis is converting a Building Information Model into an AR application for the Microsoft HoloLens. To do this, it requires an understanding of how the HoloLens functions and the different software needed to develop an application. Since the researcher had limited skills in coding for a HoloLens, it was essential to keep the application as simple as possible.

\subsubsection{HoloLens Hardware}

The Microsoft HoloLens, shown in Figure 9, is a wireless, AR headset that has a self-contained computer, multiple sensors and advanced optics to display holographic images and information onto the real world (Washington University in St. Louis, 2018). The optical sensors allow the holograms to "blend seamlessly with the environment" for optimal user experience (Washington University in St. Louis, 2018). There are two sensors on each side of the HoloLens for environmental scanning, a camera at the front to detect hand motions, speakers on each side of the headset, light sensors, microphones and an HD camera to record what the user sees (Grand Valley State University, 2018). The headband can be adjusted to fit the circumference of someone's head and the position of someone's eyes as shown in Figure 10.

This content is unavailable.

Please consult the print version for access.

Figure 9 - Microsoft HoloLens (Washington University in St. Louis, 2018) 
This content is unavailable.

Please consult the print version for access.

Figure 10 - How to Fit the HoloLens (Adapted from Microsoft, 2018b)

The computer itself runs on the Windows 10 Universal Platform (Taylor, 2016). Taylor (2016) describes a universal platform as having the ability to develop one application that can be run across multiple devices (e.g. an application for a Windows Phone could also be used on the HoloLens). Even so, it is essential for this study to design with the HoloLens in mind to ensure the app runs smoothly especially with UI (User Interface) qualities (Taylor, 2016).

There are four environment cameras on either side of the HoloLens and one infrared camera in the middle of the device (Vroegop, 2017). The infrared camera measures the depth of space to create a three-dimensional scan of the environment by "calculating the time it takes for the light to return to the HoloLens (Vroegop, 2017).

One form of interacting with the holograms is to use hand gestures. With the use of the camera, a dot appears continuously in the centre of the view. This dot is what Microsoft calls "Gaze". When someone is interacting with a hologram, the dot will turn into a hollowed circle, shown in Figure 11, to indicate that this object is interactive. 
This content is unavailable.

Please consult the print version for access.

Figure 11 - HoloLens Cursor Interactions (Hodgson, 2018)

The specified HoloLens gestures must be used to interact with objects. There are only three gestures that are recognised by the HoloLens: Air-Tap, Tap and Hold, and Bloom (Jana, Sharma, \& Rao, 2017). Air-Tap is similar to a mouseclick on a computer, where someone taps to select objects (Jana, Sharma, \& Rao, 2017). To perform the Air-Tap gesture, shown in Figure 12, the user needs to make a fist with either hand then point an index finger towards the sky and then move that same finger forward, bend it down and release it back up to the sky (Jana, Sharma, \& Rao, 2017). Tap and Hold, shown in Figure 13, is similar to clicking and dragging a mouse button (Jana, Sharma, \& Rao, 2017). This gesture can be used to move an object (Jana, Sharma, \& Rao, 2017). A user begins this gesture by performing the Air-Tap gesture. However, they then have to pinch an index finger and thumb together and hold it there until they are happy with the position of the object (Jana, Sharma, \& Rao, 2017). Bloom is used when a user wants to exit an application and return to the home screen or bring up a menu (Vroegop, 2017). To perform the bloom gesture, shown in Figure 14, the user starts with a closed fist with the palm facing upwards, then mimic a flower opening by spreading their fingers wide (Vroegop, 2017).

Microphones and spatial speakers allow further interaction with the HoloLens. The microphones allow the user to give commands to the HoloLens via their voice. Voice is another form of interacting with the HoloLens features rather than the use of gestures or a remote. The spatial speakers, on the other hand, 
add to the three-dimensional experience by placing sounds in the holographic world. However, the spatial speakers are not utilised in this research as sound could be a distracting factor for detecting clashes.

This content is unavailable.

Please consult the print version for access.

Figure 12 - Air-Tap Gesture (Adapted from Microsoft, 2018f)

This content is unavailable.

Please consult the print version for access.

Figure 13 - Tap \& Hold Gesture (Adapted from Microsoft, 2018f)

This content is unavailable.

Please consult the print version for access. 


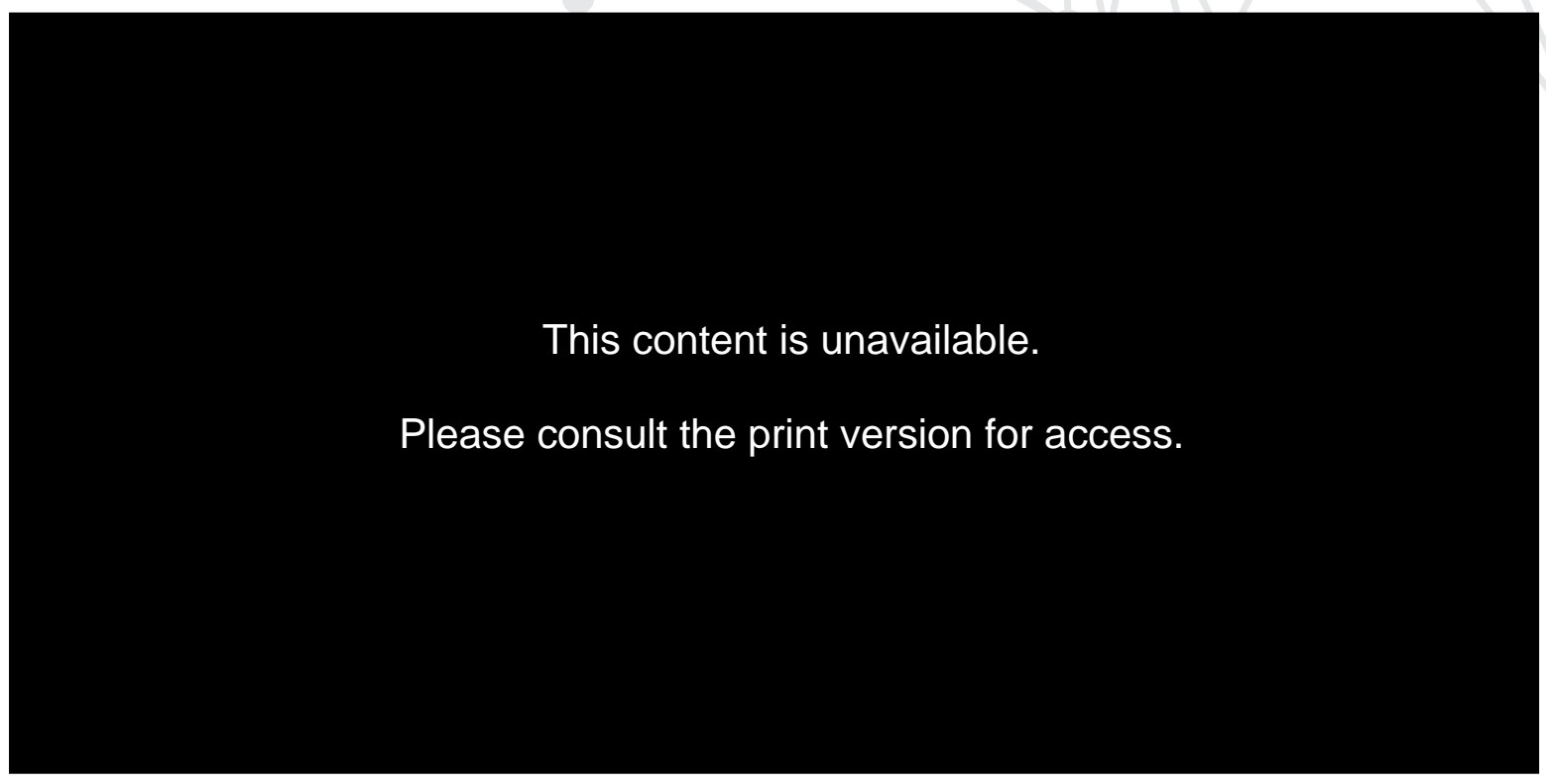

Figure 15 - HoloLens Lenses (Jana, Sharma, \& Rao, 2017)

The transparent eye coverings, shown in Figure 15, are the "holographic lenses" which creates the graphic of the game and acts as two computer screens (Taylor, 2016). Light is emitted from the camera and passed through the eyes to project a hologram at 30 frames per second (Taylor, 2016).

\subsubsection{HoloLens Software \& Tools}

Specific equipment, software, programs and tools are needed to develop HoloLens applications (Taylor, 2016). Microsoft recommends that a Windows 10 PC is used to run all the appropriate tools (Taylor, 2016). This research used, an ASUS TUF Gaming FX504 Series laptop with a Windows 10 Education operating system so that it could be transported easily to the experiments. The laptop was tested by computer specialist before use to ensure it was fit for purpose.

Other than the PC, the necessities for developing HoloLens applications are:

- Unity;

- Mixed Reality ToolKit;

- Visual Studio;

- And HoloLens Emulator (Microsoft, 2018b).

Unity is "a gaming engine that is used to build three-dimensional worlds" (Vroegop, 2017). It allows the user "to take two-dimensional graphics, threedimensional models, particle systems, and sound to make them interact with each other" (Odom, 2017). Unity is used to build the application. 
The Mixed Reality Toolkit is an add-on to Unity developed by Microsoft. The Mixed Reality Toolkit contains samples, scripts and components that can help with the HoloLens application development (Odom, 2017).

Visual Studio is an Integrated Development Environment (IDE) which is used to program the HoloLens application to code changes in the behaviour of objects (Odom, 2017). Visual Studio works in-sync with Unity to create the scripts in C\# language. Visual Studio also works with the HoloLens Emulator and HoloLens to deploy the model.

The HoloLens Emulator is used "to test the code as you make an update or change it without having to upload it to a HoloLens every time" (Taylor, 2016). It is an "extension to Visual Studio that will simulate how a program will run on the HoloLens" (Odom, 2017).

\subsubsection{HoloLens Application Precedents}

At present, only three BIM-related applications are available for the Microsoft HoloLens in New Zealand: BIM Holoview (Figure 16), HoloLive (Figure 17), and Trimble Connect (Figure 18). All applications contain similar qualities and functions. Table 3 compares each application's features. For clarity, the overall features are:

- 1:1 scale - where the BIM model can be overlaid onto a building at the correct size.

- Revit conversion - ability to convert a Revit model to HoloLens.

- Revit plugin - direct Revit to application

- Marker system - ensures that the BIM model is aligned to the real environment.

- Tag-along - allows the user interface to follow you as you go through the building.

- Downloadable model - models are cached so they can be downloaded before going onto a site.

- Colour coding - enables identification of different building elements through a colour.

- Adjustable viewing - ability to view model on a tabletop or to true scale.

- Transparency - view model in $\mathbf{x}$-ray mode. 
- Toggle holograms on/off - make holograms appear or disappear.

- Sharing capabilities - ability to share model with other HoloLens users.

- Texture/material application - apply realistic materials to model buildings to understand what they may look like in reality.

- Measurement tool - use a ruler to measure the environment virtually.

- Object information link - links object to Revit data/BIM information.

- Voice commands - retrieve menus/objects using your voice.

- Clash checking - run clash check to see if any objects intersect.

Table 3 - HoloLens Application Features

\begin{tabular}{|c|c|c|c|}
\hline 1:1 Scale & 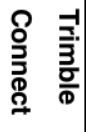 & $\begin{array}{l}\text { T. } \\
\text { 응 } \\
\frac{\text { C. }}{\Phi}\end{array}$ & 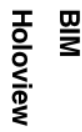 \\
\hline Revit Conversion & • & • & • \\
\hline Revit Plug-in & ? & ? & 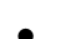 \\
\hline Marker System & & 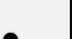 & \\
\hline Tag-along interface & ๑ & 9 & 9 \\
\hline Downloadable model & & & 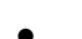 \\
\hline Colour coding & 9 & & $\bullet$ \\
\hline Adjustable viewing distances & $\bullet$ & • & $\bullet$ \\
\hline Transparency & $\bullet$ & $\bullet$ & $\bullet$ \\
\hline Toggle holograms on/off & 9 & 9 & ๑ \\
\hline Sharing capabilities & 9 & 9 & ๑ \\
\hline Texture/Material Application & 9 & 9 & \\
\hline Measurement Tool & ๑ & 9 & \\
\hline Object information link & 9 & e & \\
\hline Voice Commands & 9 & 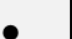 & \\
\hline Clash checking & - & & \\
\hline 1:1 Scale & & & \\
\hline
\end{tabular}


This content is unavailable.

Please consult the print version for access.

Figure 16 - BIM HoloView HoloLens Model (Microsoft, 2018a)

This content is unavailable.

Please consult the print version for access.

Figure 17 - HoloLive Mockup HoloLens Model (Microsoft, 2018d)

This content is unavailable.

Please consult the print version for access.

Figure 18 - Trimble Connect HoloLens Collaboration (Microsoft, 2018e) 


\subsection{CONCLUDING REMARKS}

The use of $A R$ and BIM on-site has gained significant interest within the AECO industry, but current research has yet to prove the effectiveness of integrating these two technologies. Most studies have used a static approach with studies showing that AR, when integrated with BIM, could potentially provide an effective solution BIM implementation and productivity on site. However, the most detailed studies were completed several years ago when the technology was not as advanced as it is today. The implementation of AR and BIM still requires validation.

Due to the time constraints of the research, all the technical issues cannot be addressed. Current research is still developing towards fixing these issues. The development of the application can follow the guidelines of recent research around developing AR systems and precedent HoloLens applications.

This research extends previous research by using more advanced technologies and hardware. What sets this research apart from other research, apart from the use of the HoloLens, is that it provides an example of how it may be used in the construction environment. This research could ultimately produce an innovative example of how an AR headset can increase productivity on-site. 

COMPARING AN AR HEADSET TO TRADITIONAL CONSTRUCTION METHODS 39

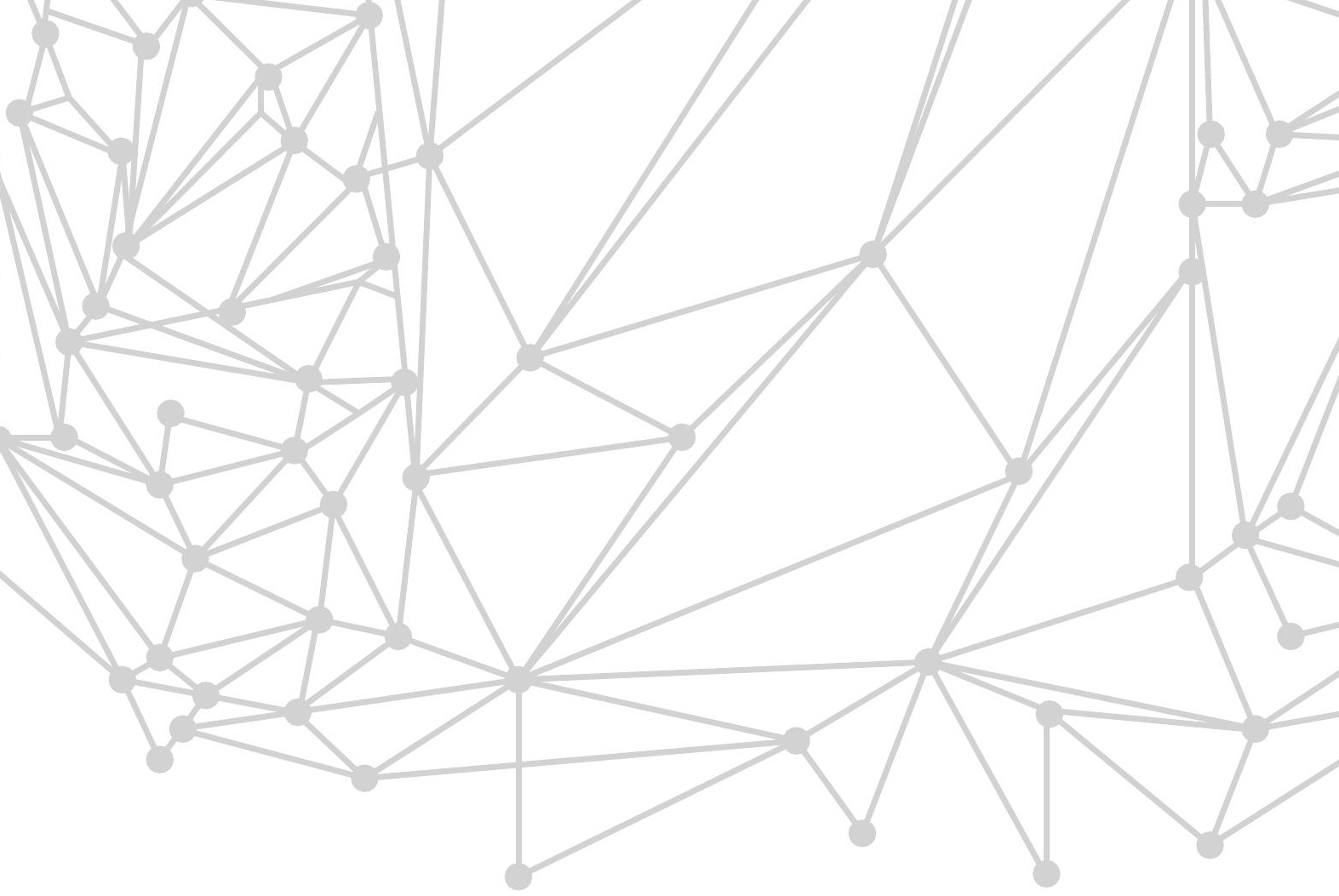

CHAPTER THREE

RESEARCH METHODOLOGY 



\subsection{CHAPTER INTRODUCTION}

The previous chapter presented some fundamental insights into research on BIM implementation, the use of $A R$, and the technical requirements of developing an AR application. Most importantly, the literature review identified that the Microsoft HoloLens is an advanced visualisation device and confirmed that further research was necessary for the use of it on construction sites.

As an attempt to understand how the Microsoft HoloLens could be useful for information retrieval, this research question, as mentioned in Chapter One, is used to guide the study:

To what extent can Augmented Reality provide a more effective system for productivity and information retrieval for Building Information Modelling in comparison to traditional methods?

The purpose of this three-phase, mixed methods study was to compare the effectiveness of $A R$ for information retrieval against other information retrieval methods. A combination of qualitative and quantitative research methods was used to quantify the efficacy of AR. This chapter outlines the robust research methodology implemented in this study to evaluate the use of the Microsoft HoloLens for information retrieval. The chapter first explains the research design and rationale for the approach. Following this, it provides information about the participants and recruitment techniques, the data collection process and the process of data analysis. It was hypothesised that the Microsoft HoloLens could provide a more powerful system for construction productivity for information retrieval than paper or computer-based systems.

\subsection{RESEARCH DESIGN}

The study comprised of three phases as a mixed methods approach: an initial focus group, experiments, and a final focus group. There are various viewpoints on what is considered the correct definition of mixed methods research (Johnson, Onwuegbuzie \& Turner, 2007). Researchers like Creswell, Tashakkori, and Teddlie (as cited in Kumar, 2014) believe that mixed methods research involves the mixing of both qualitative and quantitative paradigms. However, other researchers such as Formosa and Morse (as cited in Johnson, Onwuegbuzie, \& Turner, 2007) believe mixed methods can also mix multiple methods within one research paradigm, e.g., the inclusion of 
quantitative surveys and quantitative experiments. For this research, mixed methods research is defined using Creswell's 2007 definition. Creswell defines mixed methods research as "a research design (or methodology) in which the researcher collects, analyses, and mixes (integrates or connects) both quantitative and qualitative data in a single study or a multiphase program of inquiry" (Johnson, Onwuegbuzie \& Turner, 2007).

This specific study employed a multiphase sequential methods design (qual $\rightarrow$ quan + qual). The first phase of the study was a qualitative exploration of common issues that arise on a construction site in regard to the changes in construction drawings, and how construction industry professionals work together to solve these issues. Data from a focus group session was collected from various construction industry professionals in New Zealand. From this initial exploration, the qualitative findings were used to develop the tasks and HoloLens application design for a set of experiments in the second phase of the study. In the second phase, quantitative data was collected from three task-based experiments to test the theory that AR can increase productivity and information retrieval in comparison to traditional visualisation methods. The third phase worked successively with the second phase where the same three control groups were involved in a focus group session regarding the experiments. The quantitative and qualitative data from phase two and three respectively were compared and integrated to form an answer to the research question. (See Appendix A for a diagram of the research design for this study with the process and product outputs.)

\subsubsection{Rationale \& Theoretical Framework}

In order to determine how useful AR can be for information retrieval, it should be compared against two-dimensional and three-dimensional computer drawings. Two-dimensional and three-dimensional drawings are typical information retrieval methods in the current construction industry. Two-dimensional drawings are paper drawings where plans, sections, elevations and details are laid out. Occasionally there will be an axonometric drawing. Three-dimensional drawings are typically known as "BIM models" which are three-dimensional drawings on laptops, desktop computers or tablets. Previous studies use a range of research methods to compare different information systems. 
Ryan's (2007) thesis "Enhancing 3D Models with Urban Information" is based on Cockburn and McKenzie's research techniques. She used a case study approach where focus groups, questionnaire and a guided discussion were employed. These research methods allowed her to gain sufficient evidence to investigate the usefulness of three-dimensional methods of information over alternative two-dimensional methods.

A mixed methods approach is essential for thesis study because of the use of advanced technology and the lack of information surrounding it. Creswell and Plano Clark (2011) consider it suitable to use mixed methods research when:

- Qualitative research or quantitative research alone is insufficient to understand the problem fully;

- There is a need to explore before research instruments are administered;

- Statistical results need to be explained by talking to people;

- It is necessary to see if the quantitative results match the qualitative results;

- Experiments need to be enhanced by talking to people;

- New instruments need to be developed by gathering qualitative data (Creswell \& Plano Clark, 2011).

Lucas (2016) describes quantitative research methods as "methods where closed-ended information produces measurable data" whereas qualitative research methods are described as "the use of open-ended information to understand qualities or subjective data". The rationale for using a combination of qualitative and quantitative data was that the research could exploit the benefits of each technique and produce more detailed results than if a single technique were used (Creswell, 2002). In this case, a mixed method approach is suitable to explore and enhance the experiments and to provide a comparison of the quantitative and qualitative results. By using a mixed method approach, the research could gain "multiple forms of data drawing on all possibilities" (Creswell, 2002).

Focus groups allow for the generation of ideas and multiple views in a short period (Courage \& Baxter, 2005). These were used instead of individual interviews or surveys because of time constraints and the need to understand similarities among different professions. By using focus groups at the beginning 
of the research, it helped to inform the requirements for the experiments and later focus groups. The data collected from the post-experiment focus groups were used for gaining feedback and opinions about each information system. These focus groups allowed a data comparison to validate the experiment results.

\subsection{PARTICIPANTS \& RECRUITMENT}

The first focus group aimed to recruit between four and eight participants of varying professions within the construction industry. The ideal professions of focus group participants were project managers, builders, structural, mechanical or building service engineers, BIM managers or architects. These professions were selected as they were the most common professions on site that would utilise the plans and drawings. Four to eight is the ideal number of participants for a focus group (Courage \& Baxter, 2005). Courage and Baxter (2005) state that if there are more than ten participants, then the focus groups can be challenging to manage and not all participants may have the time to speak. By limiting the participants to four to eight participants, it allows each participant to have seven to fifteen minutes each to discuss their opinions. Courage and Baxter also suggest that if there are less than four participants, it is challenging to gather valuable information.

Initially, at the beginning of the study process, the participants for the final two phases were the same as the first focus group. Instead, the demographic information of the participants in the final stages developed from the results of the initial focus group. Although this still used a purposive sampling technique, it became iterative, and the participants' requirements evolved during the research process. The participants for the experiments, however, were the same participants for the final focus group. The participants were the same in order to gain their perspectives on the information tools after completing the task. The experiment and final focus group participants were divided into three groups where each used a different medium of visualisation. Based on Courage and Baxter's participant recommendations, and the three experimental groups, twelve to twenty-four participants was the optimal number for the final phases. Therefore, each group contained between four and eight participants.

Participants in the experiments were excluded if they were familiar with AR as they could bear a significant advantage in comparison to the other participants. 
As the Microsoft HoloLens can present participants with some discomfort, participants were also excluded if they experience the following conditions:

- Migraine headaches;

- Motion sickness;

- Inner ear disorder;

- Binocular disorder;

- Fear of heights;

- Epilepsy/seizures;

- Eye problems;

- Or any other serious health concerns (Microsoft, 2018b).

All participants were recruited via email voluntarily. Emails were sent out to various industry professionals using a purposive sampling method. Purposive sampling is where "the researcher decides what needs to be known and sets out to find people who can and are willing to provide the information by virtue of knowledge or experience" (Etikan, Musa, \& Alkassim, 2016). Due to time constraints, the researcher's internal and external supervisors helped to recruit the participants by providing the names of experienced construction industry professionals in Wellington, New Zealand. It was near impossible to recruit participants that did not know each other in some instance because of the smaller population and tight community of the industry in Wellington. On this occasion, purposive recruitment was useful as they could be targeted based on having specific characteristics and experience that define them as "information rich" participants (Hennink, 2014). Participants were included if they were currently working in the New Zealand construction industry and were willing to share their experiences. The recruitment emails provided potential participants with an information sheet, consent form, focus group rules and any further details about the project for recruitment. (See Appendix B, C, D \& $E$ for the recruitment documents). A detailed health screening questionnaire, shown in Appendix $B$, was distributed via email during recruitment for the experiment participants. This questionnaire outlined the health conditions and any symptoms that they could bear during the tasks. The health questionnaire was to ensure participants had enough time to read over the document and respond that they were fit to participate. The participants were also asked to read over the health screening questionnaire in person before participating in the experiment. 


\subsection{DATA COLLECTION}

\subsubsection{Instruments}

The first phase involved the use of semi-structured, open-ended questions in a focus group setting. The focus group was a qualitative exploration of how different construction industry professionals work in teams to solve problems and tasks on-site. This information was collected through answers from various current New Zealand construction industry professionals in Wellington. The focus group gained preliminary data to inform the tasks for the second phase experiments through open-ended questions regarding their experiences of working on construction sites and problem-solving techniques. As this is an exploratory part of the research, the use of the semi-structured questions allowed the researcher to inquire for more information where it was necessary.

An audio recording was used to collect data from the focus group session. In addition, the discussion was transcribed verbatim. By recording the session, it provides a more precise, unobtrusive way of data collection in comparison to fleeting memories or field notes (Krueger, 2006). Each participant was given a number in the transcription to ensure anonymity and keep track of contributions. During the focus group, the questions were guided by the researcher who was acting as the facilitator. The participants were asked the questions shown in Appendix $\mathrm{F}$ during this discussion.

Question 1 asked each participant what their name was and a brief overview of their "typical" day at work to distinguish who each participant was in the audio recording and what were everyday tasks they completed in their roles.

Question 2 asked them what visual tools they use on their current projects to determine what the most common form of information retrieval tools was used on construction sites.

Question 3 examined if participants found they had to change the drawings of a building often during the construction stage of a project. This question was asked to confirm the commonality of revised drawings.

Question 4 was the most important question as it queried common issues that appear on projects when on site to determine relevant clash detection issues for the experiment tasks.

Question 5 continued from question 4 by asking how they fix the issues that they run into on site and how they work with others to fix the issues. This question was to determine how construction industry professionals work in 
groups to understand and mitigate construction issues.

Question 6 discussed their thoughts on what technology could do to help them with their projects on site. This question was to help formulate ideas for future research in developing initial thoughts.

Participants were also asked if they had any other comments to add to this discussion or relating to the topic of the focus group. This question was to indicate to the participants that it was the final question but also to ensure that no relevant information was missed.

By having a set of questions for the focus group, it prevents the researcher from deviating from the research objective. Figure 19 depicts a useful structure for the focus group discussion guides. The first question in the list acts as the introductory question, while the last question provides closure to the discussion. By having an introductory question, it allows the participants "to feel more comfortable in the group environment" whereas the closing question indicates to the participants that the discussion is coming to an end. (Hennick, 2014).

This content is unavailable.

Please consult the print version for access.

Figure 19 - Hourglass Design of Focus Group Discussion Guide (Hennick, 2014) 
In the second phase, usability experiments were used to explore and generate themes about construction industry tradesmen's use of three different information retrieval systems. Participants were placed into three groups where they used different information retrieval systems to solve a task. The participants in Group 1 acted as the control group by using a set of twodimensional paper drawings of the building. Group 1 was the control group because paper drawings are the most traditional method of information retrieval. Group 2 and 3 acted as the experimental groups. Group 2 used a laptop with a three-dimensional model of the building. Group 3 used a Microsoft HoloLens with a holographic model of the structure.

In the usability experiments, the participants were given the drawings or model of a building and were asked to detect clashes in the building together in a group. The task design was based on the results of the initial focus group explicitly questions four, five and six. A HoloLens C\# application was developed from those results to use for the experiment. The outputs of the tasks were used to measure quantitative data through a comparison of performance data variables. Participants were video recorded during this time for the researcher to observe and understand how they decided on a clash detection answer. The video recording aided in understanding the location of their clash detection answer.

The third phase was in combination with the experiments and involved three focus groups with the same participants of the experiments. The three focus group sessions provided a qualitative analysis of the experiment to understand tradespeople's perceptions of the information retrieval methods and how current processes could be improved for their understanding. Similarly to the initial focus group, these sessions used open-ended questions. These focus groups added a qualitative element to the experiments, enhancing the interpreted information through a satisfaction variable. The researcher acted as the facilitator again and based the discussion around eight questions as shown in Appendix G.

Question 1 asked what the overall benefits of the visualisation resource were. Conversely, question 2 asked about the drawbacks of the visualisation system. Question 3 queried how easy it was to work together in a group to identify the clashes and how confident they were with their answers. 
Question 4 examined how the current resource compares with what they currently use on projects.

If the group was using the laptop or Microsoft HoloLens, question $\mathbf{5}$ was asked to explore whether or not the participants thought the system would assist them in saving time for decision making.

Again, if the group was using the laptop or Microsoft HoloLens, question 6 was asked to explore how willing they would be to use the allocated system during the construction stage of a project.

Question 7 looked into what would make them more likely to use the allocated resource.

Finally, question $\mathbf{8}$ concludes the focus group by asking if there are any general comments to make. This exit question was designed to see if anything was missed during the discussion.

\subsubsection{Data Collection Procedures}

Contact was made with the professionals through email invitations explaining the research aims and requesting their assistance with gaining information for the focus group. The information and consent documents were also attached to this email. Some of the recipients of the recruitment email never responded, making it difficult to gain participants for the session. The participants that did respond were given a location, including a map, and confirmation of time. Participants were emailed the day before the focus group session to remind them and confirm their attendance.

The initial focus group study was conducted in a meeting room at Victoria University of Wellington's Te Aro Campus. The focus group session was held in mid-July 2018. It is important to set up focus groups appropriately so that it does not influence the content of the discussion (Barbour, 2007). Liamputtong (2011) suggests that the table and chairs should be arranged in a circle in order to facilitate interaction and allow the participants to have equal access to each other. A round table acts as a psychological influence as it creates a less-dominant environment and provides a "protective barrier for insecure participants" (Liamputtong, 2011). Refreshments of cakes, pastries, tea, coffee and juice were provided to encourage a relaxed and comfortable atmosphere as well as showing appreciation for their participation. The focus group session began at 10:00 am; however, the participants were asked to arrive at 9:30 am. The extra half-an-hour before the discussion meant that they had enough time 
to read and sign the consenting documents, mingle and feel comfortable with each other, and mitigate any participants that were running late to the session.

The discussion ran for one hour. The session was cut to one hour to ensure the engagement of participants as well as facilitating their schedules (Redmond \& Curtis, 2009). "Any more than two hours is the physical and psychological limit for people", and the topic was specific enough to limit it to one hour (Redmond \& Curtis, 2009).

Once the recruited participants arrived for the focus group, they were asked to read over the information sheet, consent form and focus group rules. After consent, the participants were asked to sit around the table and sign the consent form. Consenting is an essential step in the focus group process to "minimise any potential risk to participants from their involvement" in the research (Hennick, 2014). Ethical boundaries mean that the information that was disclosed in the discussion remains confidential and participants can remove themselves from the study before a specific date.

The researcher then led with a brief introduction of the project and what was expected for the focus group. Once the research had been explained, the ethical documents had been signed, and the participants' questions had been answered, the researcher started the audio recording, and the focus group discussion began. The first question asked started by having the participants answer it clockwise around the table; however, the questions following this were free for anyone to respond. Once all the questions had been answered, and no one had anything else to add, the audio recording was stopped, and the participants were thanked and were welcome to leave the session. The consent forms and audio recording were collected and ready for data analysis. Once the data analysis was complete, the information was used sequentially for the development of the experiments in phase two.

The first step for the experiments was to develop the building model. A three-dimensional representation of the building model was obtained from a construction industry professional. Due to ethical reasons, the source of the model could not be named. The model was developed using Autodesk Revit, a BIM software that allows the user "to design and document a virtual representation of a project" with parametric and drafting elements" (Davis, 1989). A model with complex Mechanical, Electrical and Plumbing (MEP) 
layouts was requested. Once the researcher had access to the building model, clashes were added to it for the experiment tasks. For this research, clashes are when problems occur in the building where building components are interfering (Tommelein \& Gholami, 2012). These clashes were based on the initial focus group discussion. The model was then constructed for the HoloLens, by exporting it to a Unity file. Unity is "a game-development platform" which is "endorsed and recommended by Microsoft for the development of HoloLens applications (Taylor, 2016). Further information about the design of the building model is outlined in Chapter 4.

The experiment participants were recruited at the same time as the development of the building model. They were sent emails outlining the reason for the experiment, what was expected of them and the time-frame that they would need to be available to participate. The information sheet, consent form, health screening questionnaire and focus groups rules were attached to the emails for their perusal. Once all the participants had responded, they were divided into the groups based on their days of availability. As it was difficult to find participants, the days were selected based on the availability of the participants. The twelve to twenty-four participants of the experiment research were divided into three groups. The three groups had equal numbers, ranging from four to eight participants per group, where each used a different medium of visualisation.

The experiments and focus groups were held in three separate sessions and all held in a large meeting room in Christchurch, New Zealand. All the sessions were held at the beginning of December 2018. Participants were sent reminder emails the morning of the day before the experiment to confirm their attendance. Extra participants were also recruited as a back-up plan. The reminder email and back-up participants were to mitigate no-shows.

When the participants arrived at the experiment, they were asked to read over the information sheet and sign the consent form. Group 3 participants that were using the Microsoft HoloLens were first asked to complete the Health Screening Questionnaire and inform the researcher if they experienced any of the symptoms. If they did experience any of the symptoms, they could not participate. The participants were also provided with an information sheet about the study, which gives details about the project and what data will be used. Once the participants completed the forms, the researcher explained the 
research and was given time to ask questions. This first started with an introduction of the researcher, a brief explanation of the research and what the study was trying to achieve. Following this, the researcher outlined the task and explained the definition of clash detection and that they were to look for mainly mechanical based clashes. It was important to describe what the researcher was asking them to look for as they may not be fully aware of what clash detection is. The focus group rules were outlined at this time as well. Group 2 and Group 3 were given a few minutes to familiarise themselves with the technology at this time. All groups were informed that it was not a full set of drawings or model as only part of the building could be used. If the whole building was in the model, then it may be identifiable. It was important to state that it was only part of the building as they may think the lack of certain elements were clashes such as fire egresses or the fact that there was no roof. The roof was excluded because the cropped view of the building was on the ground floor of a multiple story building.

Once the participants felt comfortable and understood the experiment process, they were asked to begin the experiment. The video recording started at this time. The participants were given a 30-minute time frame to find as many clashes as they could. Group 1 was supplied two-dimensional drawings that were placed in the middle of the table in the meeting room. A laptop was provided to Group 2 to which they huddled around to complete the task. The laptop was set at the end of the table so that all participants could be grouped around it. A Microsoft HoloLens was supplied to Group 3. The HoloLens display was live streamed to a laptop to ensure collaborative interaction between participants. This live stream was also recorded. All groups were given a sheet, shown in Appendix $\mathrm{H}$, for them to write their answers. They were also all given a colour key to identify what each of the mechanical, electrical and plumbing elements were.

The use of a Microsoft HoloLens may cause drowsiness or symptoms of motion sickness. Participants were informed in the briefing and information sheet that they should tell the researcher if they bear any signs of nausea so that they can stop the experiment. For ethical reasons, Group 3's participants using the Microsoft HoloLens, were checked every five minutes to ensure that they were not in any discomfort. 
After completing the experiment, the participants were invited to participate in the focus group discussion. The video recording was stopped, and an audio recording was started at this time. The length of both the experiment and focus group sessions depended on how long it took the participants to complete the experiment task. The focus group sessions ran for one hour each and participants were informed that the entire session would take no longer than two hours. Again, once all the questions had been answered and the audio recording was finished, the participants of Group 1 and Group 2 were thanked and were welcome to leave the session. Group 3, using the Microsoft HoloLens, were asked to stay behind for fifteen minutes to be observed of any discomfort signs. If they did experience any unusual symptoms, they were monitored until they returned to normal, or, further support was provided. The researcher had a first aid certificate and was able to assist with the treatment of common conditions and CPR. Alternatively, an ambulance would have been called if symptoms escalated. At the end of the focus group, the consent forms, answer sheets, and the video and audio recording were collected and ready for data analysis.

\subsection{DATA ANALYSIS}

The data analysis occurred in three phases as shown in Figure 20. The qualitative data from the initial focus group were analysed first, then the quantitative data from the experiments and finally the qualitative data from the experiment focus groups. The data from the initial focus group are integrated into the experiment design to enhance the quality of the experimental data. Once the data from the experiments and focus groups had been analysed, the findings were integrated, and relevant conclusions were made. 


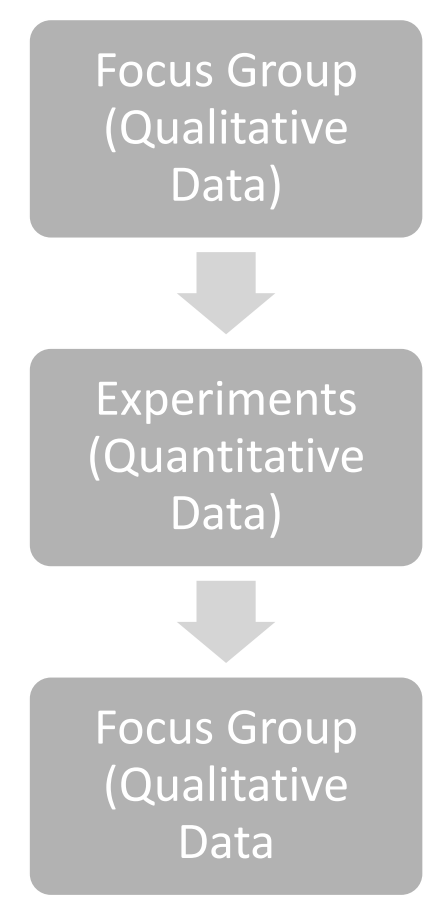

Figure 20 - Data Analysis Process

\subsubsection{Qualitative Data Analysis}

Qualitative data has a non-standardised and complex nature (Saunders, Lewis \& Thornhill, 2009). However, qualitative data can usually be grouped into three categories: summarising, categorisation and structuring (Saunders, Lewis \& Thornhill, 2009). All of these categories can be used individually or in combination for data analysis.

Summarisation involves the production of condensed vital points that emerge from a transcript (Saunders, Lewis \& Thornhill, 2009). The key points deliver principal themes, the relationships between them, and how these could be explored in future research (Saunders, Lewis \& Thornhill, 2009). Saunder, Lewis and Thornhill (2009) suggest that summarising the qualitative data is useful when further analysis is undertaken.

Categorisation involves the development of categories and associating it with essential data gathered from transcripts (Saunders, Lewis \& Thornhill, 2009). This is typically a three-step process where step one is to develop category codes or labels for the data; step two involves unitising the data to the categories; and finally, step three recognises relationships between the categories and data to draw well-grounded conclusions about the discussion (Saunders, Lewis \& Thornhill, 2009). Categorising is also useful when some of 
the qualitative data can be quantified (Saunders, Lewis \& Thornhill, 2009). This is completed by counting the frequency of certain events which can then be compared to create supplementary data (Saunders, Lewis \& Thornhill, 2009).

Structuring involves the "account of a participant's experience that is told in a sequenced way to convey meaning to the researcher" (Saunders, Lewis \& Thornhill, 2009). Interviews are suggested to be the primary method for this data analysis (Saunders, Lewis \& Thornhill, 2009). Generally, interviews are analysed this way because participants recount their own experiences and form a narrative (Saunders, Lewis \& Thornhill, 2009). Structuring can reduce or increase the amount of qualitative data as it could develop on what was said (Saunders, Lewis \& Thornhill, 2009).

As the qualitative data from the initial focus group is used as a basis for the continuing research, summarisation was used for the analysis procedure. The qualitative data from the post-experiment focus groups were analysed through the same processes as the initial focus group. The post-experiment data was also analysed through this method as it was integrated with the experimental data.

Once the focus group discussions had been completed, the analysis of the qualitative data commenced through the process of organising the data from the audio recordings. The recordings were listened to multiple times and then transcribed verbatim by the researcher. The questions were added into the transcript to reduce the likelihood of misinterpreting the response to the question. Following this, the transcripts were read several times and analysed using summarisation and thematic content analysis. In this study, the focus groups use an inductive approach where the data is first collected and then explored to see which themes should be concentrated on. This approach was appropriate as the area of research is only on the cusp of exploration.

Although the post-experiment focus groups used the same analysis approach, there was an additional step for data analysis. The summarisation of each of the three focus group sessions were linked through pattern identification. Pattern identification was to compare the information said about each information retrieval system and subsequently determine what was the most satisfying system in the overall participants' opinions. As these are subjective measures, they cannot be quantified. 


\subsubsection{Quantitative Data Analysis}

Unlike qualitative data, quantitative data has a more structured approach to data analysis as it produces numerical data (Saunders, Lewis \& Thornhill, 2009). The experiments used a quantitative approach by collecting discrete data. Discrete data is where the data is measured in separate, whole units (Saunders, Lewis \& Thornhill, 2009).

The experiment data was analysed based on usability testing. The most widely used definition of usability is The International Organisation for Standardisation's (ISO) definition for their usability standard ISO 9241-11. ISO (2018) defines usability as "the extent to which a system, product or service can be used by specified users to achieve specified goals with effectiveness, efficiency and satisfaction in a specified context of use". Figure 21 shows the ISO's usability framework model.

This content is unavailable.

Please consult the print version for access.

Figure 21 - Usability Framework Model (ISO, 2018) 
Usability is measured in terms of effectiveness, efficiency and satisfaction. The combination of these variables can determine "the extent to which a product is usable in a particular context" (ISO, 2018). ISO 9241-11:2018 defines these usability measures as the following:

Effectiveness: "the accuracy and completeness with which users achieve specified goals".

Efficiency: "the resources used in relation to the results achieved" e.g. time, human effort, or cost.

Satisfaction: "the extent to which the user's physical, cognitive and emotional responses that result from the use of a system, project or service meet the user's needs and expectations".

For the quantitative part of the research, the experiments were analysed and evaluated based on the effectiveness and the efficiency of each information retrieval system. With Group 1's data acting as the baseline, the data obtained from Group 2 and Group 3 can be measured and the variances compared to evaluate the usability of each system. The data collected from the experiments can be analysed through triangulation.

Once the experiments had been completed, the analysis of the qualitative data was completed by watching the video recordings to determine how much time was spent answering each task. The answer sheets provided an idea of what each clash detection answer was, but the video supplemented this by understanding exactly how they came to the answer. The video recordings were watched several times to confirm these answers.

The first step of the quantitative data analysis was through the effectiveness variable. Effectiveness was measured in terms of the number of correct clash detection answers each group gave. This variable measured which system was the most difficult to use for problem-solving. An analysis was performed by counting the number of correct answers each group solved - the higher number of correct clashes, the better the accuracy of the system.

The second step was to analyse the efficiency variable. Efficiency was measured by the elapsed time it took for each group to identify the clashes. The analysis was based on the speed at which groups discussed and answered individual clash detections and the time it took to complete the entire task. 
The longer the time that a group spends on the clash detection task, the less confident they are with their answers. If the group takes a significant amount of time, whether it be on a specific clash or the total time, then it indicates that the system was less efficient.

\subsubsection{Data Integration}

As the research has an exploratory sequential design, the quantitative and qualitative data was discussed separately as well as together. By integrating both the qualitative and quantitative data, it strengthens the validity and quality of the research data and findings.

The initial focus group qualitative findings were used to develop the experimental design and HoloLens application in a sequential manner. The answers from the initial focus group determined the participants of the experiments, the design of the clashes, and an indication of how they believe technology could aid the construction industry. The Technology Acceptance Model (TAM) discovered in the literature review also aided in the development of the HoloLens application. To recapitulate information from the literature review, the application should have a simple interface design and provide a convincing argument that it would be useful to them. After the focus group results had been collected and analysed, they were integrated into the experiment design.

After the quantitative data from the experiments and the qualitative data from the focus groups had been analysed, the data from both respective stages was integrated. As explained in the previous section, the combination of the three usability measures can determine how usable a product can be in a particular context. While the efficiency and effectiveness variables were measured in the experiments, the satisfaction variable was measured in the post-experiment focus group sessions through their experience and attitude towards the use of each information retrieval system. In evaluating the usability variables of each group, the relationship between effectiveness, efficiency and satisfaction can be examined. The subjective satisfaction measures of the post-experiment focus group in combination with the experiment variables can supplement and indicate the effectiveness and efficiency performances. In triangulating these results and finding a correlation between these variables, it was possible to determine the most usable information retrieval system and whether the use of $A R$ was feasible in this context. 


\subsection{CONCLUDING REMARKS}

This chapter described the research methodologies and the specific methods of focus groups and experiments that were used in this research. The research followed a mixed methods approach through a combination of qualitative and quantitative data methods. The qualitative research was provided through the initial focus group and post-experiment focus group to deliver descriptive analyses of participants perspectives. The quantitative research was supplied solely through the experiments. This data provided a comparative, triangulated analysis of the task completed by the three user groups. Consequently, the chapter discussed focus groups and experiments. 




\subsection{CHAPTER INTRODUCTION}

The following chapter presents the results of the thesis. The aim of this research is:

To quantify the effectiveness of Augmented Reality as an information retrieval tool in comparison to traditional paper drawing or computer-based methods

The results are split into four parts. The first part of the results presents the initial focus group discussion and consequent lessons learned analysis. The analysis and conclusions of the initial focus group were presented in this chapter to continue sequentially with the second phase of the research. The second part is the development of clash detection tasks and the HoloLens application. The third part is the experiment results. Finally, the last section of the results presents the post-experiment focus group discussions.

\subsection{INITIAL FOCUS GROUP}

The first phase set out to investigate the second research objective through a small focus group session. It explored common issues that arise during the construction stage of a project and how industry professionals work in teams to solve them. The primary purpose of this focus group was to understand problem-solving from their perspective so to inform the tasks for the experiments. While current research, such as those identified in the literature review, explores common issues during the construction stage of projects, there is limited information about this in a New Zealand context. Another purpose of this focus group was to understand how to run a successful focus group. This focus group was essentially a trial so that the lessons learned could be taken from this and applied to the future focus groups.

The focus group participants arrived at 9:30 am on Tuesday 17th July 2018. When the participants arrived, they were greeted by the researcher and were asked to read the information sheet, focus group rules and consent form. The first half an hour provided the participants with a chance to talk with other participants, read and sign the consent form, and have tea, coffee and snacks. The focus group started at 10:00 am and ran for one hour. There were five participants from varying professions within the construction industry. Once all participants had signed the consent form, the researcher briefly introduced the project then continued with the questions. 


\subsubsection{Focus Group Discussion}

The participants first introduced themselves, their role and a brief overview of their everyday tasks. The professions were a consultant project manager, a director of an architecture firm, sales support engineer, a design technology director of a software sales support company, and a mechanical engineer. The project manager's everyday tasks coordinate the project for clients. The director of the architecture firm spends most of his time running the company but has been in the construction industry for over 40 years. He has had previous experience with quantity surveying and spends much time promoting BIM around New Zealand. The sales support engineer mainly works with BIM on projects. The design technology director is predominantly implementing software sales support. However, the focus is to fill in gaps in knowledge by providing software training support and BIM support. The mechanical engineer has had experience in building sites both in New Zealand and overseas. His main tasks involve monitoring the design as it gets constructed on site, ensuring that the specifications of the drawings are adhered to and resolving any coordination issues that arise.

When asked about what visual tools each participant mainly uses on projects, all participants agreed that two-dimensional drawings were predominantly used. The participants agreed on this because two-dimensional drawings were considered a standard information retrieval method for everyone. They did also agree that the industry is slowly changing with the introduction of more experimental methods, but there will still be a need for paper. The project manager pointed out that during the design stage of a project he is more likely to use digital methods, but during the construction stage of a project, he is more likely to use paper. The architecture director said that there is a fundamental difference between producing the model and the production drawings. A project that he is currently working on has a purely model-based production, but, in the end, two-dimensional drawings still have to be produced. The industry will always have to go down to a two-dimensional system even though it is inefficient. He was unsure if we would ever be able to build things from threedimensional models. The architecture director also mentioned that in a recent project, some subcontractors are using pdf drawings on an iPad. This statement led to an additional question being included at this point. "How often is it that the subcontractors are taking mobile drawings to a site but still in two-dimensional format?" On his recent project, it was only one trade that was using iPad's. 
From there, the conversation went onto discuss the anticipated cost and the perceived benefits of using BIM or technology for a project. When technology is mentioned, most think about the costs and not the benefits. BIM and technology need to be considered an investment.

Do you find that you have to change the model or the drawings during the construction stage of a project? If so, approximately how often are you changing the model or drawings?

All participants agreed that it depends on how the job has been set up. If the client is prepared to pay the consultants to update the drawings regularly, then it would be less. It also depends on the skill level of the ones changing the model. The workers on site would not necessarily know how to modify a model. However, the project manager argued that in their experience this is changing fast as the subcontractors he has worked with are now better at interacting with models than main contractors or designers. He also mentioned that the tradesmen on site are taught how to read two-dimensional information and not translate three-dimensional information from a model to the real world. The architecture director said that his team must continue rebuilding their BIM systems and have rebuilt BIM systems a minimum of 3 times. The design technology director said that there needs to a level of skill that draftsman have, to produce a set of documentation or a model that can be used on site. The conversation then diverted around the training and education of people in the construction industry. The general discussion was around graduates coming in with digital knowledge but not having the same construction understanding as those who were trained in apprenticeships.

Thinking about recent projects that you have been involved with, what are common issues that arise onsite? Also, how do you work with others to fix these issues?

The design technology director said that one type of job where changes are always going to come up is alteration work where you do not know the existing conditions until someone gets on to the site. A considerable amount of time is spent assessing the conditions of the site, gathering and processing the information and coming together to make the right decision. Sometimes you cannot even go into the building before construction because of tenancy issues, and sometimes the council drawings are inaccurate. 
Other issues that were discussed were seismic restraints and ceiling services. Seismic restraints are sometimes left out of the design processes and therefore can become an issue later. There seems to be a lack of clarity around who is responsible for seismic restraints. Is it the designer's job? The service consultant's job? The installers? The mechanical engineer brought up that there is a project he is working on recently where the services are installed nicely, but when they come to do the seismic restraints, they have to adjust for clearances. The coordination was not done. Sometimes the model seems perfect but, once it is taken to site, clashes come up with services.

How do you think technology can develop to solve issues on site?

The project manager can visualise an installer going on site, putting a helmet on and making a phone call to the designer at the same time. This way the model and drawings could be integrated with real life and be discussed to solve problems. No one gets far solving problems on site until they are there in front of the problem. He also believed it would be beneficial for installers that have limited English as they can visually explain it.

The architecture firm owner said that he is already doing this. An example was someone went to the construction site with an iPad and video conferenced different members of the project team to discuss the site. He believes that there is a place for AR and Virtual Reality in the construction industry. He believed Virtual Reality would be beneficial for the start of a project for the visualisation point of view. At the start of a project, AR is not that helpful unless there is an existing building. However, going through to construction, once constructed has started, the AM/FM industry is a prime example of where AR would be massive. The most important thing is trust and people need to collaborate and ask, "what do you need so that you can trust this model and go on site with confidence?".

The design technology director said that the technology is available but, there needs to be a level of expertise to be about to set it up and use it. He thinks that there is currently nobody that is willing to invest or use it. However, as technology develops over time, it will become more comfortable to use. 


\subsubsection{Focus Group Lessons Learned}

Overall, the focus group was successful in identifying potential issues that could arise during the construction stage of a project and how technology may be able to aid in solving problems. It was also successful in understanding how to run a focus group.

An issue that could be present in the model for the experiment can be related to visualisation and clash detection. As the services in the ceiling were identified as having the most clashes across projects, then this can be integrated into the task problem. Seismic restraints could also be identified as a clash in the model. As the discussion was mainly around these two areas, it would be similar to a real issue for the participants to identify. As the changes of a model or drawings depended on how a project was set up, the model should be reviewed by professionals. This way, the model can be functional and understandable for the actual experiments.

The original intent was to have a range of different professions in the construction industry to participate in the experiments. However, after the initial focus group discussion, it seemed more valuable to have tradesmen as the participants. This was because it was identified that this profession showed a lack of knowledge in the training of software and three-dimensional models. If AR can help builders to understand three-dimensional drawings better then this could provide a valuable tool for tradespeople on site. A positive result of the focus group was that they all believed VR and AR could be useful for the construction industry concerning visualisation and collaboration. However, it will be essential to have training sessions on how to use the software before the experiment.

Despite the focus group's success, there were significant matters that could be adjusted for the future focus group sessions. These were related to the running of a focus group.

The recruitment of the focus groups was started only a few weeks before the session. This time constraint meant that only a limited number of people responded, which is why the focus group number was low. The recruitment for future focus groups should begin at least a month in advance to allow participants to fit it into their schedule and respond in time. 
During the session, participants would occasionally speak over each other. This overlap of speech would confuse when playing back the audio recording but also cuts off sentences that could have provided valuable information. In order to mitigate confusion in future focus groups, the rules should be stated in person by the researcher at the start of the focus group. If participants do speak over each other, the researcher should interrupt the conversation and go back to the original speaker.

\subsection{TASK DEVELOPMENT AND HOLOLENS APPLICATION DESIGN}

The second phase of the research was the experiments. The experiment phase used a model of a building and asked participants to use different mediums to identify clashes in the model. The participants were divided into three groups where each used a different medium of visualisation: two-dimensional paper drawings, a three-dimensional model on a laptop or the Microsoft HoloLens. The findings from the first phase helped to shape the task design.

For the task design to be functional, it went through a series of iterative design development stages. These stages are outlined below:

1. Clash designs added in Revit model

- Clashes reviewed by Architects

- Revit model complete and ready for paper drawings to be printed and for laptop group to use for the experiments

2. Polygon optimisation and grouping of objects in 3DS Max

3. User interface design and HoloLens function design in Unity and Visual Studio

4. Deploy to HoloLens

- HoloLens application ready for the experiment

\subsubsection{Model Clashes}

Once the building model was obtained from a construction industry professional, the model was cropped to two spaces. The model was cropped to two spaces so that the building could not be identified and to simplify the large model.

The final model was of a café and kitchen space as shown in the floor plan in Figure 22. The reason for choosing these two rooms was because it had a large number of mechanical services which could be used as clashes for the tasks. 


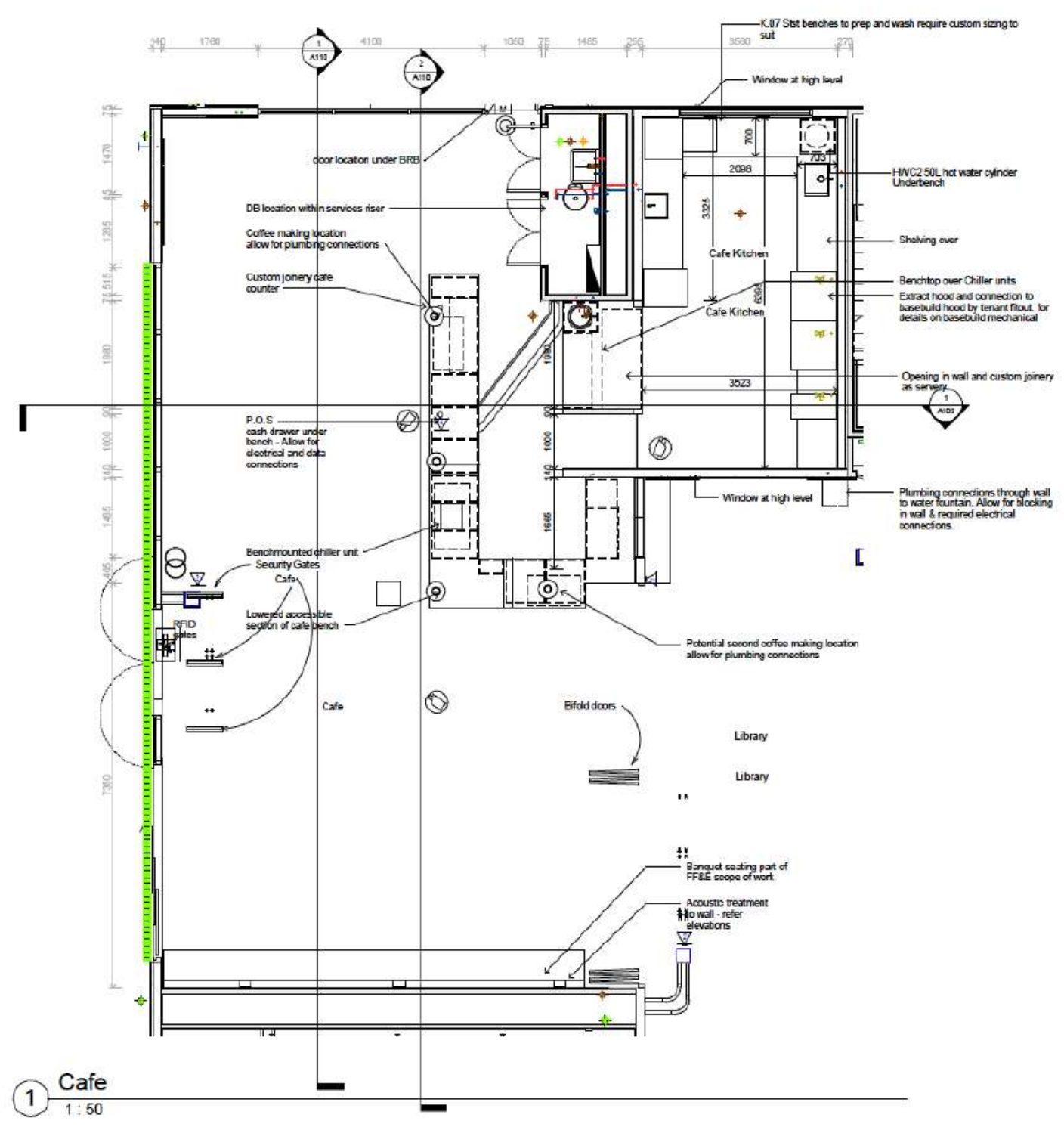

Figure 22 - Cafe \& Kitchen Floor Plan

Two architects reviewed the clashes before commencing with the development of the application. The clashes had to be completed in the base software, Revit because the clashes had to be consistent across all sets of drawings and systems. It was also difficult to change the clashes once developed in Unity. After the clashes had been reviewed and confirmed by the two architects, the building model was ready for development. The final model clashes, displayed in Figure 23, are as follows:

1. Sprinkler pipes clashing with cable tray

2. Hot and cold water pipes intersecting with cable tray

3. Sanitary pipes intersecting with supply air ducts

4. Duplicate columns intersecting 
5. A disconnected toilet exhaust duct

6. Kitchen exhaust duct intersecting with steel beam

7. Supply air duct intersecting with steel beam

8. Structural steel bracing intersecting with the window

9. Cable tray running through structural steel

10. Sanitary pipe intersecting with a sprinkler pipe

The clashes were mainly based on the MEP services; however, there were some structural clashes as well.

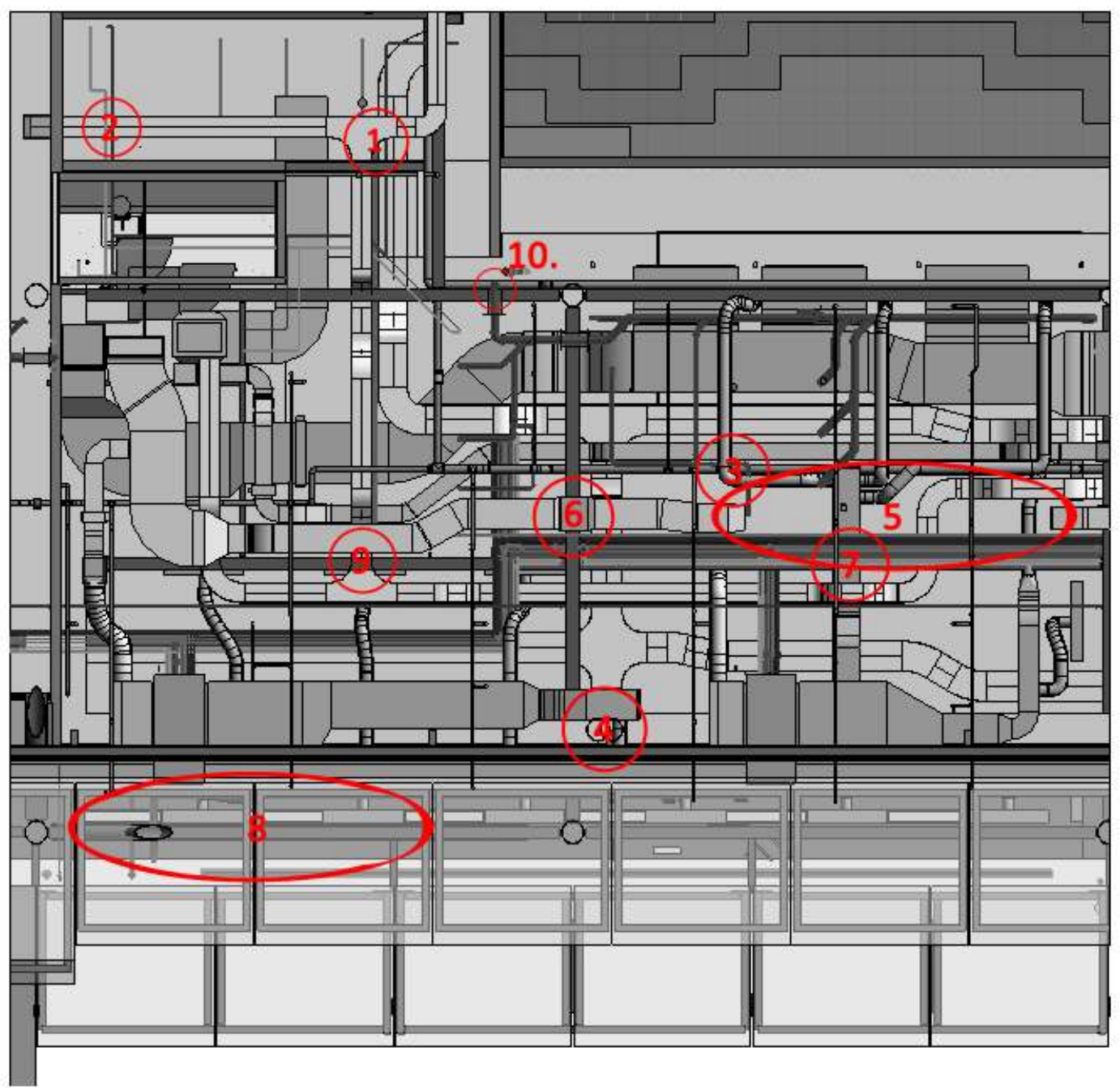

Figure 23 - Clashes in Model

\subsubsection{Paper Drawings}

The paper drawings were developed from the provided Revit Model and were presented in physical A3 paper formats, which is the most typical form of drawings on a construction site. 
The following set of drawings were presented to the control group:

- Café floor plan;

- Café MEP plan;

- Café fire plan displaying smoke detectors, fire alarms, sprinklers and sprinkler pipes.

- North, South, East and West Elevations;

- A longitudinal section;

- And a transverse section.

An example of one of these drawings is in Figure 22. The drawings displayed a MEP legend and fire legend as shown in Appendix I.

\subsubsection{Three-dimensional Laptop Model}

The three-dimensional laptop model was displayed in Revit and shown in a $3 \mathrm{D}$ viewing mode. Figure 24 shows a three-dimensional view of the model that the participants used for Group 2. The 3D viewing mode enabled the group to rotate the model and view it from whatever angle they preferred. The group was told how to rotate the model and were also explained how to hide and reveal different building elements.

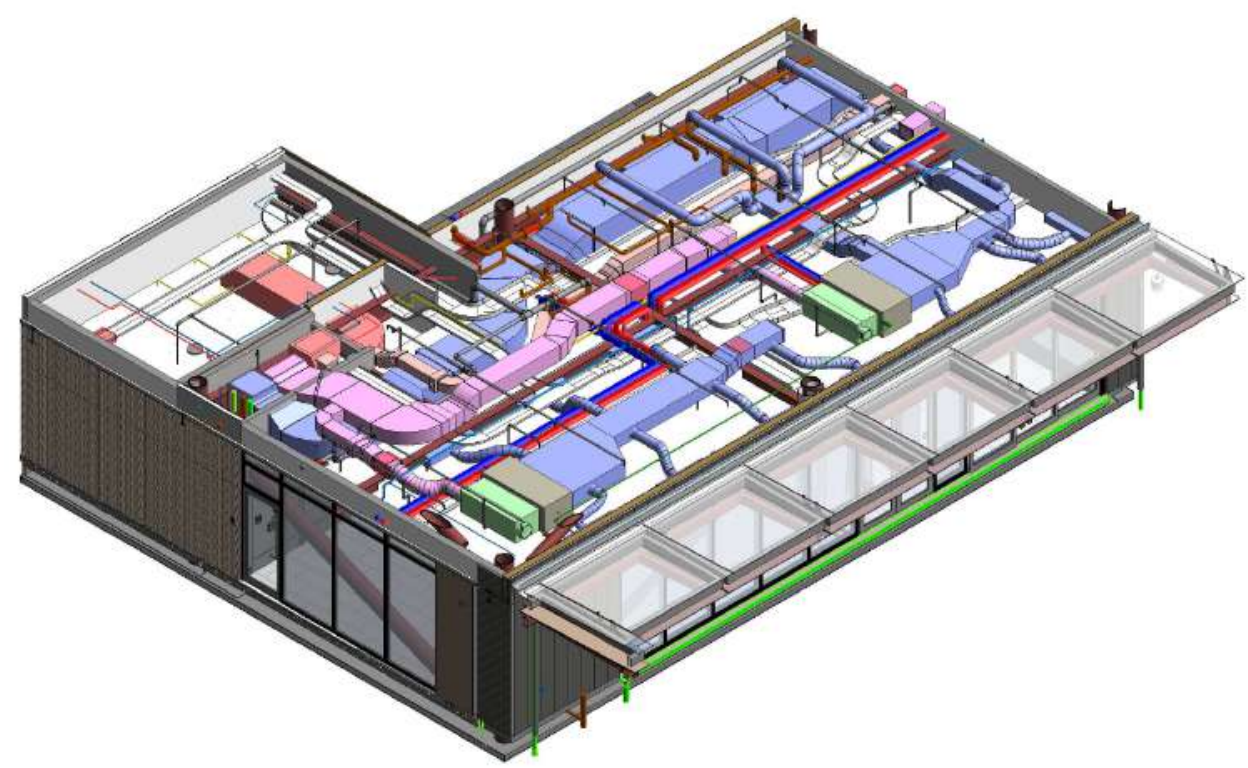

Figure 24 - 3D Revit Model 


\subsubsection{HoloLens Model Application Workflow}

In addition to Revit, 3DS Max and Unity were also used to construct the model for HoloLens. Figure 25 shows the workflow of the various software that was used.

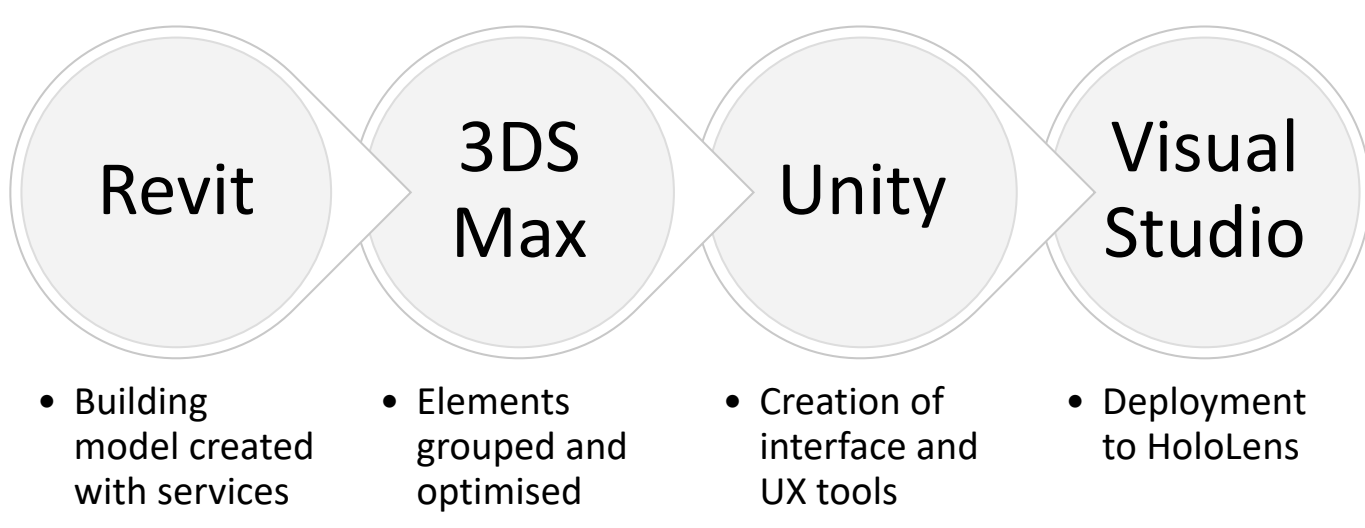

Figure 25 - Revit to Unity Workflow

The cropped model view was exported from Revit as an FBX file. The model was then imported to 3DS Max to optimise the file and group similar objects. If the Revit model was exported as an FBX file and imported directly into Unity, then it does not have materials associated with it. By grouping similar objects, it makes it easier to maintain and interact with them (Jana, Sharma, \& Rao, 2017).

When the building objects were imported into 3DS Max, they were individual objects. The objects were manually renamed to distinguish between each object and grouped into general construction processes. The model was optimised for Unity by deleting any unwanted layers, lights or cameras. The polygons of objects were optimised so that they perform better in Unity. Figure 26 shows the different layers of the model. Objects were grouped into the following categories:

- Foundation Slab

- External Walls

- Roof

- Internal Walls
- Windows

- Doors

- Plumbing

- HVAC 


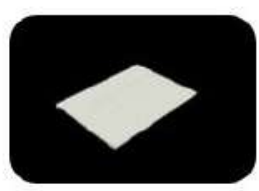

Concrete Slab Foundation

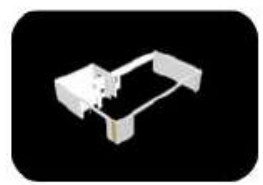

Walls

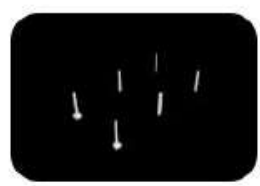

Concrete Columns

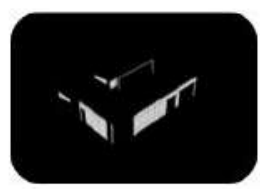

Windows

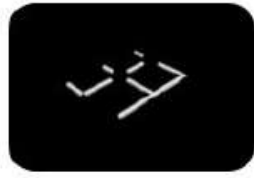

Concrete Beams

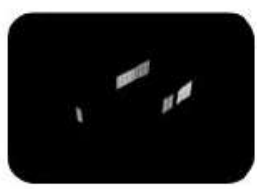

Doors

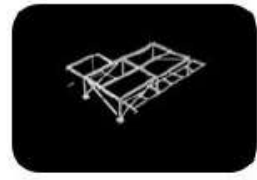

Steel Framing

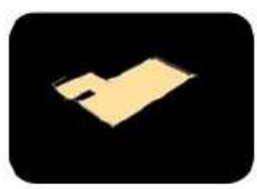

Ceiling

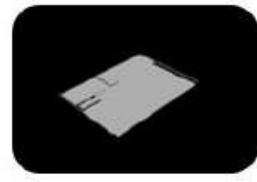

Flooring

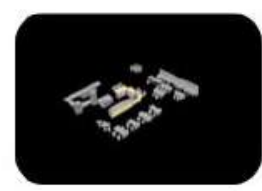

Fittings

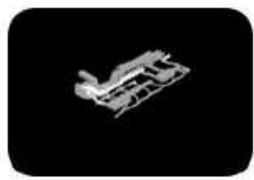

Mechanica Services

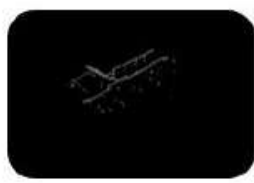

Fire Protection

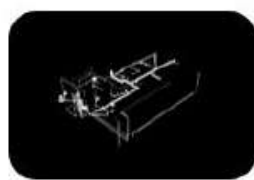

Plumbing and Drainage

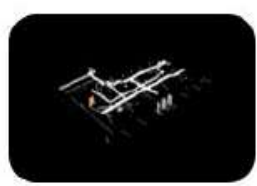

Electrical Services

Figure 26 - Layers of the Model

Once the layers were organised and elements were optimised, it was exported in FBX format for Unity. A new project was created in Unity, and the Mixed Reality Toolkit was imported into Unity as an asset package. Once the Mixed Reality Toolkit had been imported, it becomes a menu item, as shown in Figure 27. The Project, Scene and Universal Windows Platform (UWP) Capability settings were applied to the project. By applying these, it sped up the project development significantly.

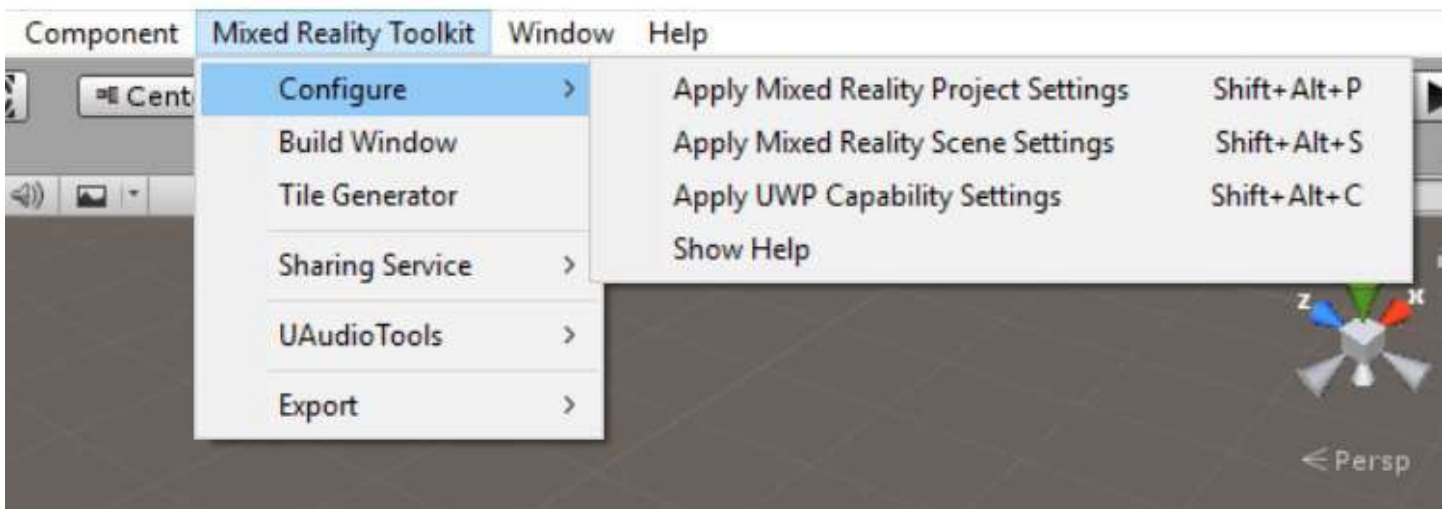


The following prefabs were added to the project's scene from the Mixed Reality Toolkit Folder:

- MixedRealityCameraParent - sets the appropriate camera settings and adds motion controller, teleportation and boundary components;

- InputManager - manages controls and the gaze, gesture and voice user inputs;

- DefaultCursor - "cursor the follows the users gaze around";

- SpatialMapping - maps out the room by detecting surfaces that holographic objects can be placed on;

- SpatialUnderstanding - provides a high level of environmental understanding and the ability to make decisions about what each detected surface is (Taylor, 2016).

SpatialMapping can be placed in Unity first to understand how it works without deploying it to the HoloLens (Odom, 2017). SpatialMapping is constructed into two main components - the Spatial Surface Observer and the Spatial Surface. The sensors in the HoloLens creates data about the surfaces through Spatial Surface and allows this information to be accessible through Spatial Surface Observer.

The FBX file of the building model was then imported into Unity as a GameObject and dragged into the project's hierarchy. The model was then saved and ready to be tested in the HoloLens Emulator. It was first tested to ensure that the model would appear in the HoloLens. The Unity building settings were set as per Figure 28. Once the build was complete, the solution was opened in Visual Studio to be deployed.

Once in Visual Studio, the Solutions Configurations selection was set to Debug, the process was set to $x 86$, and the target was set to HoloLens Emulator as per Figure 29. The last step to testing the model was to deploy the project to the HoloLens Emulator. 


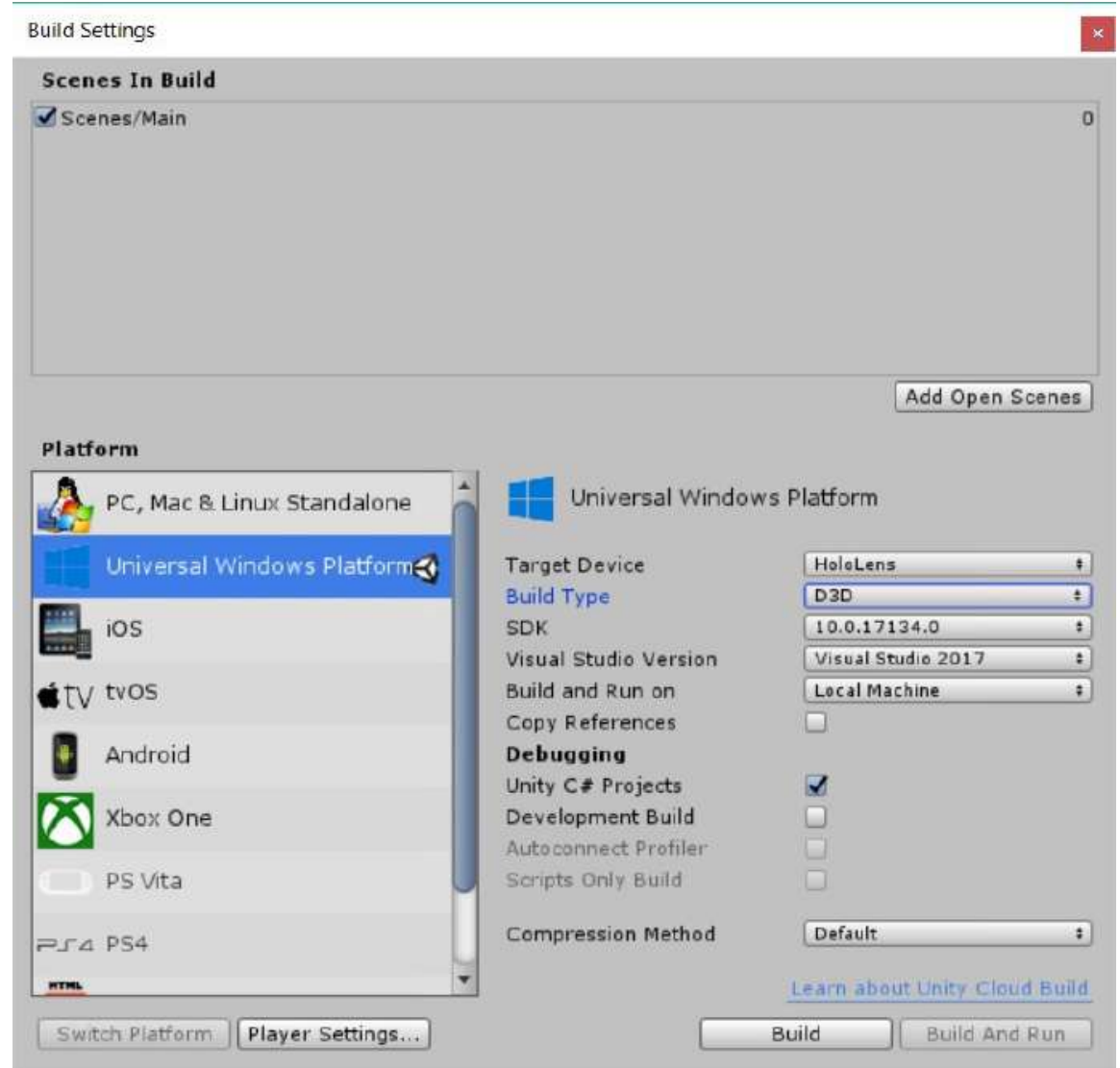

Figure 28 - Build Settings in Unity

\begin{tabular}{l|llll|l} 
Debug Team Tools Test Analyze Window Help \\
\hline
\end{tabular}

Figure 29 - Visual Studio Solutions Configuration Settings

Once the model appeared in the HoloLens Emulator, it was time to add the functional capabilities for the user interface design to the HoloLens model. As the researcher had limited knowledge in C\# programming, there was only one function that was designed for this application. As the task was mainly for visualisation purposes, the only function that was included was the ability to hide and reveal objects. Having the ability to hide and reveal objects on the building model means that the experiments can understand how different building elements are connected or intersecting.

The TAM framework described in the literature review had to be kept in mind when designing the user interface capabilities to ensure that the HoloLens application could be easily used. The functional capabilities should make use of interface elements in order to design a simple interface. In this case, a simple 
menu with Toggle buttons was designed (Figure 30). The toggles on this menu give a two-position button where one state is on, and one state is off. When the button is ticked, the elements are revealed, and when the button is toggled, it hides the associated elements.

A user interface Toggle element was added to the scene to enable this capability. In doing this, a Canvas element was added to the scene. The Canvas acts as the base for the user interface elements to be associated with as children elements, i.e. buttons. A Panel was added as a user visual element for the buttons to be placed on. An EventSystem was also added into the Canvas parent to handle inputs. The HoloLens Input Module was added to the EventSystem from the Mixed Reality Toolkit so that the HoloLens system can interact with the user interface. Other Mixed Reality Toolkit components, Tagalong and Billboard, were added to the canvas to improve the user interface. Tagalong is "a class that keeps the selected object within view of the user without locking it to their head" (Odom, 2017). Billboard ensures that the menu panel is facing the user at all times (Odom, 2017).

The Toggle buttons were renamed to the appropriate building elements. Within the Toggle button, there is a Toggle script in which behaviour functions can be added. A C\# object visibility script was added to the Toggle script as a the UnityEvent OnValueChanged. OnValueChanged is "a UnityEvent that is invoked when the Toggle is clicked" (Unity Technologies, 2018). The object visibility script needs to be added to the appropriate GameObject to associate the button with this script. After the scripts have been added to each relevant GameObject, the appropriate building element was added as an object to this event. This function works by locating the MeshRenderer of an object and passing it through the event function to turn the MeshRenderer on or off. The MeshRenderer is what makes an object appear on a screen. 


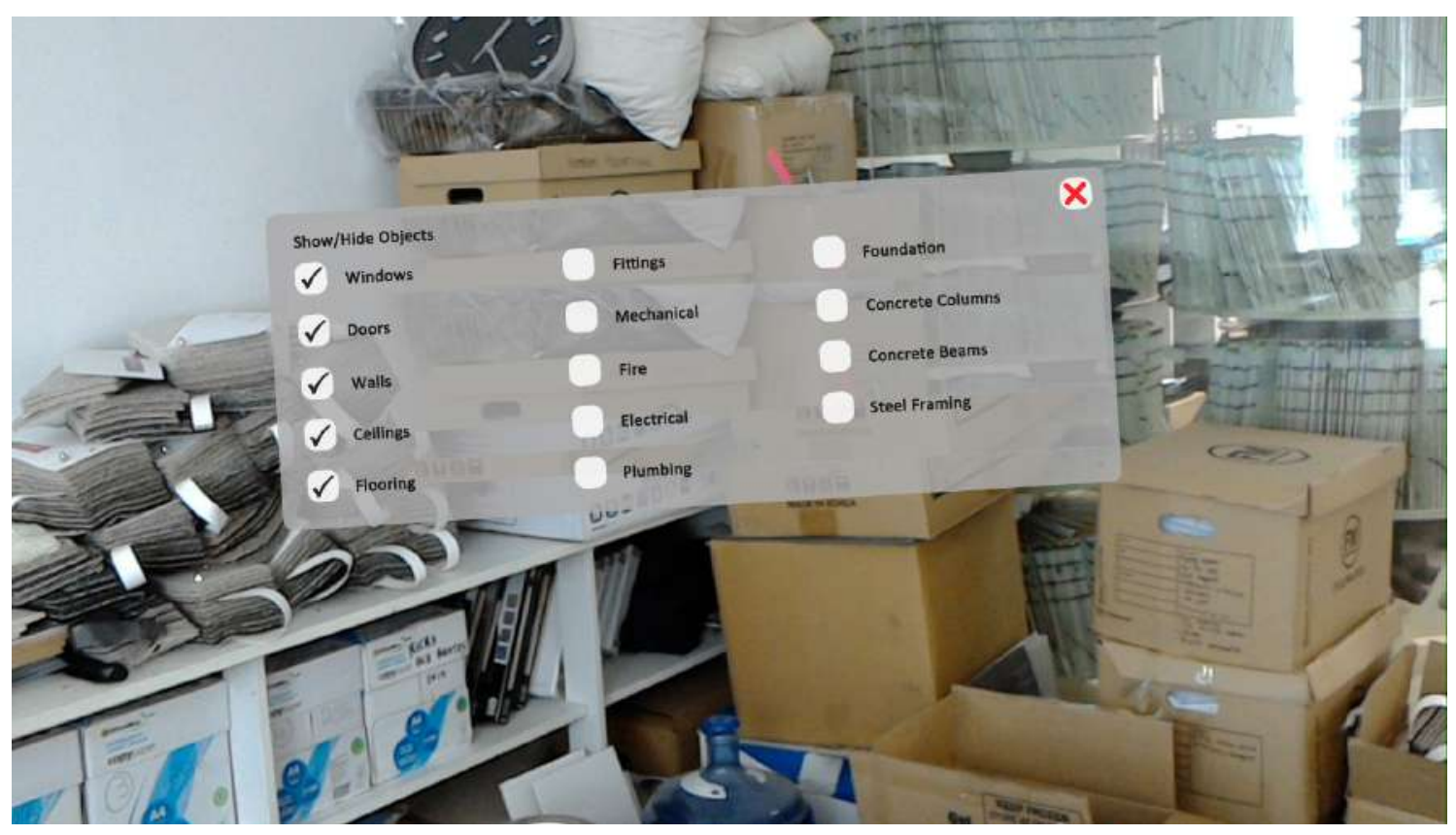

Figure 30 - HoloLens Functions Sidebar

Once the model was constructed, it was then built, compiled and deployed to Visual Studio. Instead of deploying the HoloLens to the Emulator, it was deployed to the HoloLens by Remote Machine. After it was deployed to the HoloLens, it was ready to be used for the experiment. Figure 31 shows the HoloLens model.

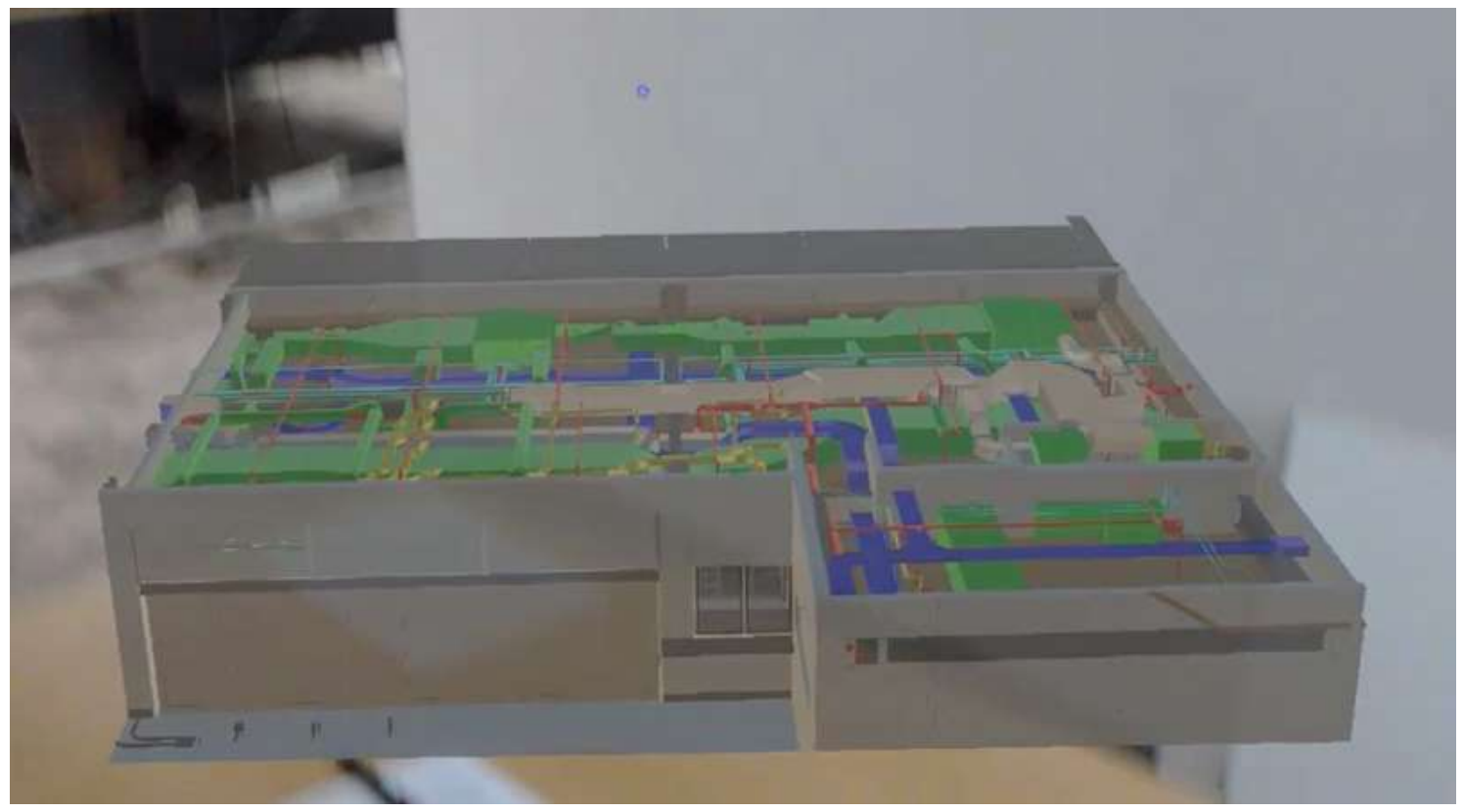

Figure 31 - HoloLens Model 


\subsection{EXPERIMENTS}

This section presents an overview of the experiments and the clash detection task results. The purpose of these experiments was to answer the first research question by comparing three different information retrieval systems for clash detection. The first research question was:

$R Q$ \#1: To what extent can Augmented Reality provide a more effective system for productivity and information retrieval in comparison to traditional paper or computer-based methods?

Based on the initial focus group discussion, the participants for the experiments were fifteen male builders. Studies have shown that $A R$ is equally effective for both males and females when using it for cognitive tasks (Hou \& Wang, 2013). As this has been proven, gender did not play a role in the recruiting of participants. The fifteen voluntary participants were divided evenly into three control groups for the experiments and focus group sessions. Due to the availability of participants, the three groups were made up of five participants each. None of the participants had previous experience with AR or Virtual Reality. They were divided into groups of five on a random basis except for one participant. Only one of the fifteen participants responded as experiencing one of the health conditions that could affect his comfort levels if using the Microsoft HoloLens. This participant was kept as a participant because of the small percentage of available participants but was purposefully placed in the paper drawing group for this reason.

Group 1 was assigned the two-dimensional paper drawings, Group 2 the three-dimensional model on a laptop and Group 3 the Microsoft HoloLens as resources. The experiments and focus groups were held in three separate sessions and all held in a meeting room at a venue in Christchurch, New Zealand during December 2018. Each session was completed in the afternoon of each day and ran from 2 pm - 4 pm. As it was difficult to find participants, the days were selected based on the availability of the participants. Table 4 outlines what day of the week each group completed the experiments and focus group session. 
Table 4 - Experiment \& Focus Group Participant Schedule

\begin{tabular}{|l|l|l|}
\hline Group & Resource & Day \\
\hline Group 1 & Paper drawings & Week 1 - Wednesday \\
\hline Group 2 & Laptop & Week 2 - Tuesday \\
\hline Group 3 & HoloLens & Week 2 - Wednesday \\
\hline
\end{tabular}

When the participants arrived, they were greeted by the researcher and were asked to read the information sheet, focus group rules and consent form. If using the Microsoft HoloLens, then they were asked to complete the health questionnaire form to ensure they were fit for the experiment. The first half an hour was spent reading and signing the consent form, explaining the research and introducing the task to each group. If the participants were using the laptop or Microsoft HoloLens then they were shown an explanation of how to use the technology. The experiment started at 2:30 pm and ran for a maximum of thirty minutes. The length of the experiments depended on how fast the groups completed the task. Following the experiment the focus group session started and ran for one hour.

\subsubsection{Effectiveness (Accuracy)}

This section presents the results of the clash detection answers. The participants were measured based off their correct or incorrect answers. The bar chart in Figure 32 shows total number of clashes that were detected within the 30-minute time-frame. The results showed that Group 1 was the only group that was unable to detect ten clashes in the 30-minute time-frame. Instead they answered seven within 30-minutes. Group 2 and 3 collected ten clashes within the 30-minute time-frame.

Figure 33 shows a bar chart comparing the total number of answers each group answered to the number of correct answers each group gave. Group 3 gave the highest number of correct answers with $80 \%$ of their answers labelled as correct. Similarly, Group 2 answered 70\% correct clashes. Group 1 was the least successful group in identifying clashes with only $40 \%$ of their answers being correct. 


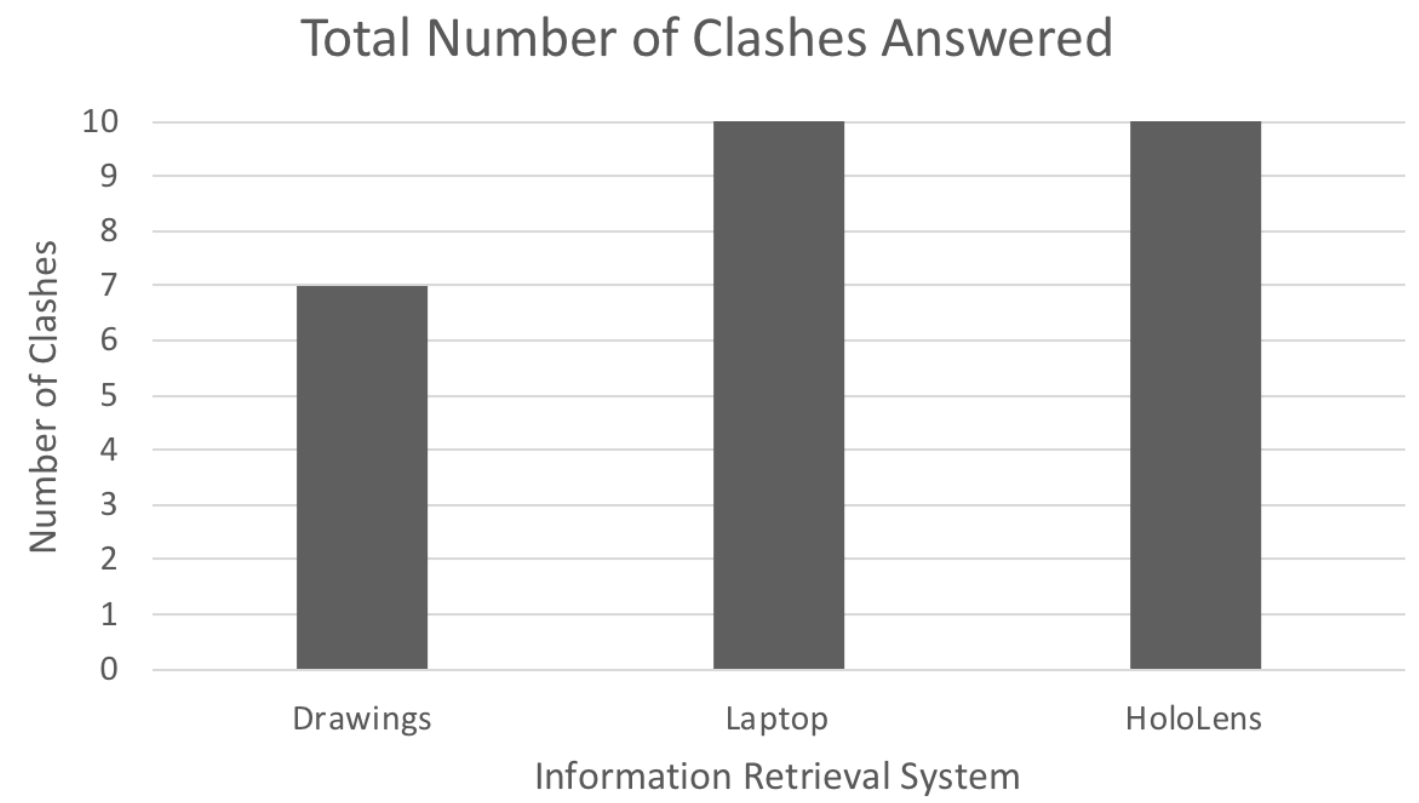

Figure 32 - Total Number of Clashes Answered Per Group

\section{Comparison of Clashes Detected to Correct} Answers

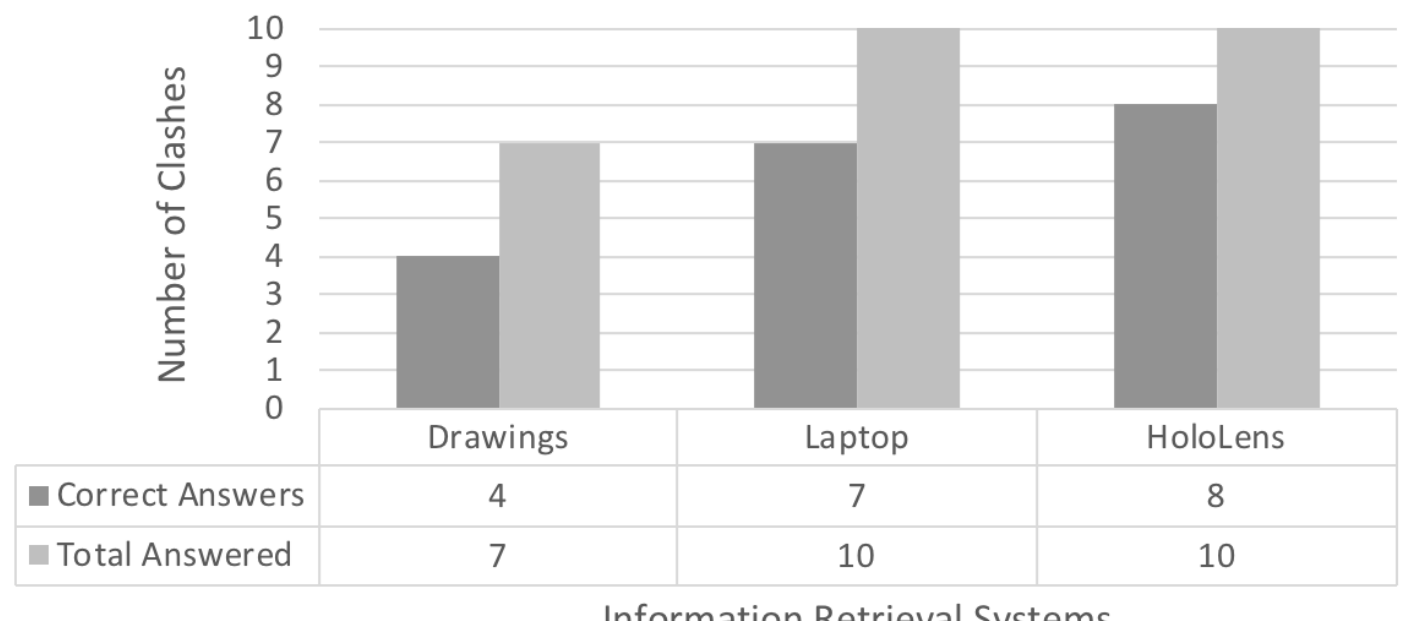

Information Retrieval Systems

Figure 33 - Comparison of Total Clashes Detected \& Correct Answers 


\subsubsection{Efficiency (Speed)}

This section describes the time each group spent on the task. The results included the overall time it took for a group to complete the task and the average time spent answering each clash. Table 5 displays the overall experiment statistics. These results represent the efficiency of time.

Figure 34 shows the overall time that each group spent on the experiment. It was measured in minutes. Group 2 was the fastest in collecting ten clashes at only 15 minutes and 23 seconds. Group 3 declined by approximately $17 \%$ in speed by collecting ten clashes in 18 minutes and 10 seconds. As previously stated, Group 1, did not detect all ten clashes in 30-minutes. Instead, they detected seven clashes in significantly lower time of 28 minutes and 22 seconds. This depicted a 60\% difference to Group 2's time and a 44\% difference between Group 3's time.

Table 5 - Experiment Statistics

\begin{tabular}{c|ccc} 
& PAPER & LAPTOP & HOLOLENS \\
\hline MEAN & $0: 04: 03$ & $0: 01: 52$ & $0: 01: 81$ \\
MEDIAN & $0: 04: 08$ & $0: 01: 05$ & $0: 01: 63$ \\
MODE & N/A & N/A & N/A \\
RANGE & $0: 4: 05$ & $0: 04: 20$ & $0: 02: 83$ \\
MIN & $0: 02: 20$ & $0: 00: 07$ & $0: 00: 43$ \\
MAX & $0: 06: 25$ & $0: 04: 32$ & $0: 03: 55$ \\
TOTAL & $0: 28: 22$ & $0: 15: 23$ & $0: 18: 10$ \\
ANSWER COUNT & 7 & 10 & 10
\end{tabular}




\section{Overall Time Spent on Experiment}

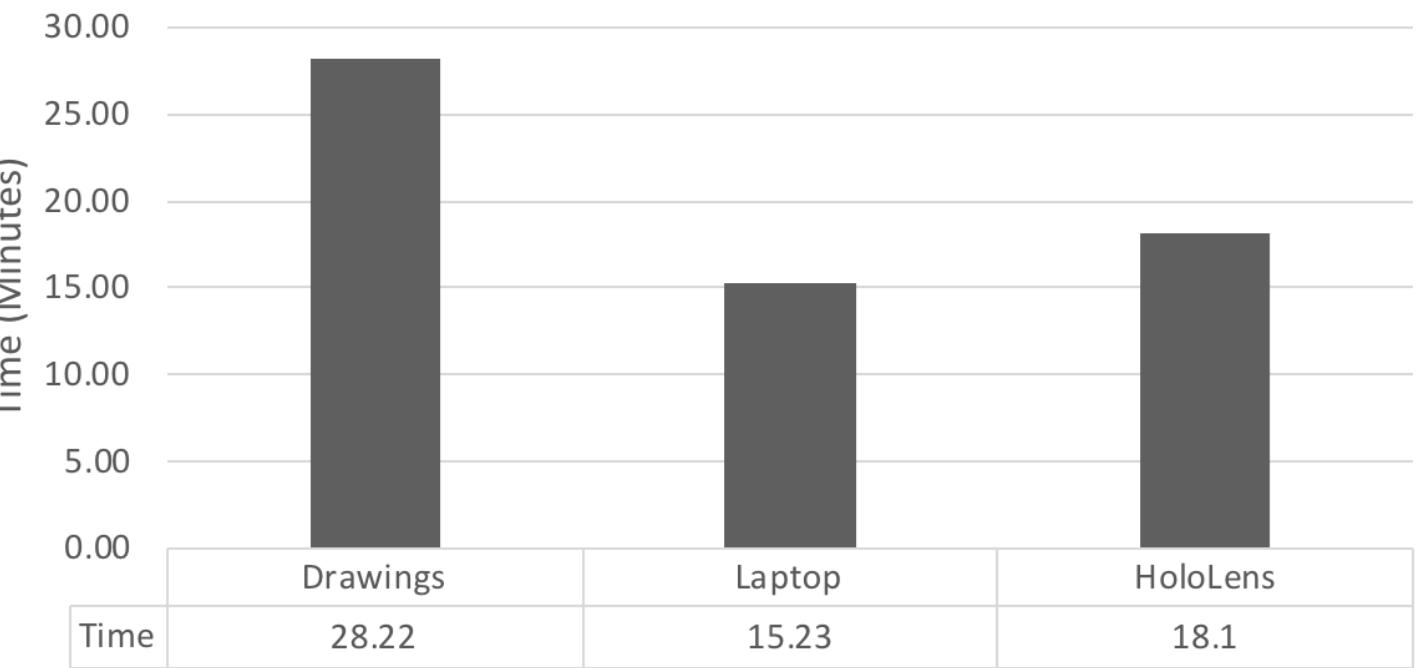

Information Retrieval Systems

Figure 34 - Overall Time Spent on Experiment

Table 6 - Time (seconds) Spent on Each Clash

\begin{tabular}{|c|c|c|c|}
\hline & $\begin{array}{c}\text { Group 1 - } \\
\text { Drawings }\end{array}$ & $\begin{array}{c}\text { Group 2 - } \\
\text { Laptop }\end{array}$ & $\begin{array}{c}\text { Group 3 - } \\
\text { HoloLens }\end{array}$ \\
\hline $\mathbf{1}$ & 245 & 7 & 195 \\
\hline $\mathbf{2}$ & 249 & 46 & 57 \\
\hline $\mathbf{3}$ & 205 & 54 & 213 \\
\hline $\mathbf{4}$ & 204 & 23 & 108 \\
\hline $\mathbf{5}$ & 132 & 131 & 102 \\
\hline $\mathbf{6}$ & 283 & 259 & $\mathbf{7 0}$ \\
\hline $\mathbf{7}$ & 375 & 45 & 94 \\
\hline $\mathbf{8}$ & $\mathrm{X}$ & 190 & 43 \\
\hline $\mathbf{9}$ & $\mathrm{X}$ & 72 & 122 \\
\hline $\mathbf{1 0}$ & $\mathrm{X}$ & 87 & $\mathbf{1 8 : 1 0}$ \\
\hline TOTAL TIME & $\mathbf{2 8 : 2 2}$ & $\mathbf{1 5 : 2 3}$ & \\
\hline
\end{tabular}




\section{Group 1 - Speed of Each Clash Detection}

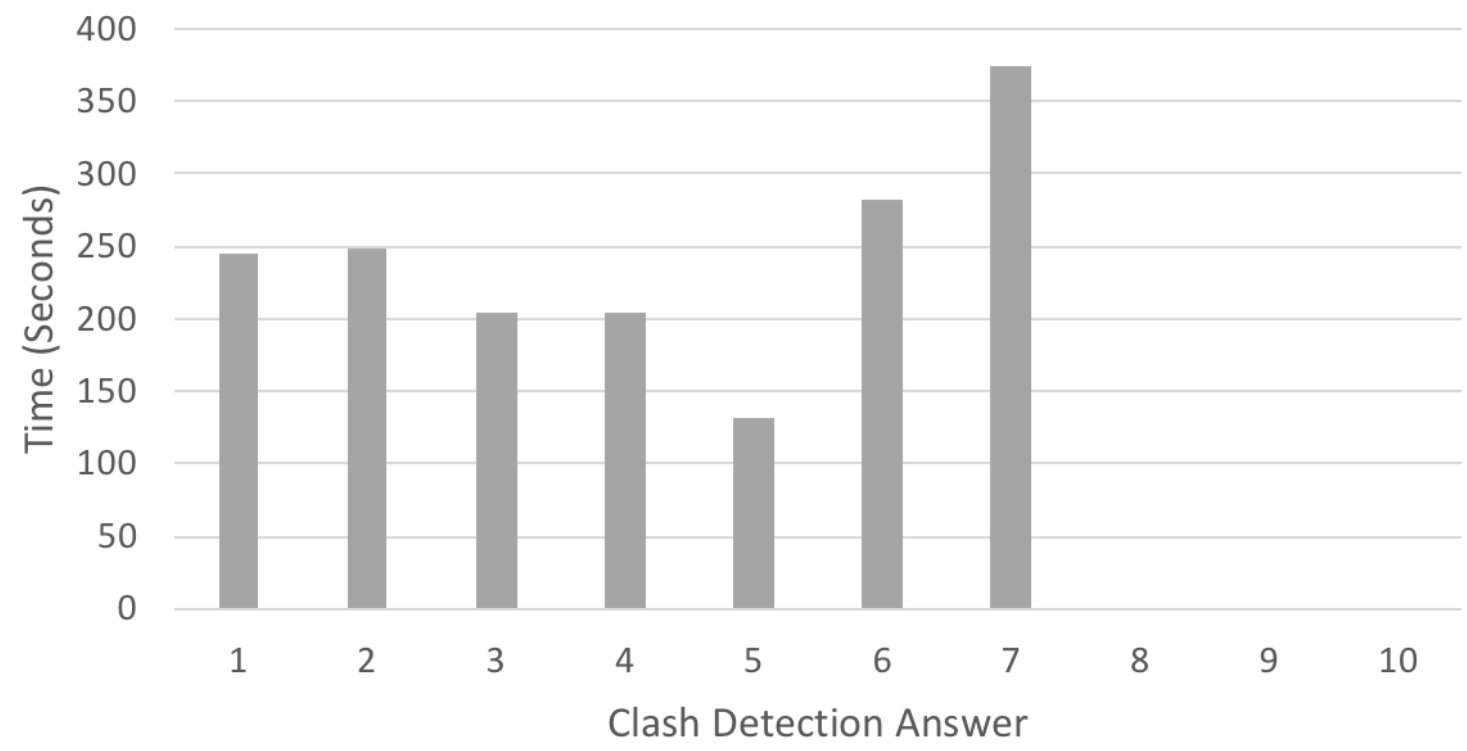

Figure 35 - Time Per Clash (Group 1)

The results showed that Group 1 (Drawings) was the slowest group in completing the task. They spent an average of 4 minutes and 3 seconds identifying each clash. The most amount of time spent on detecting a clash was 6 minutes and 15 seconds. The least amount of time spent on detecting a clash was 2 minutes and 12 seconds.

\section{Group 2 - Speed of Each Clash Detection}

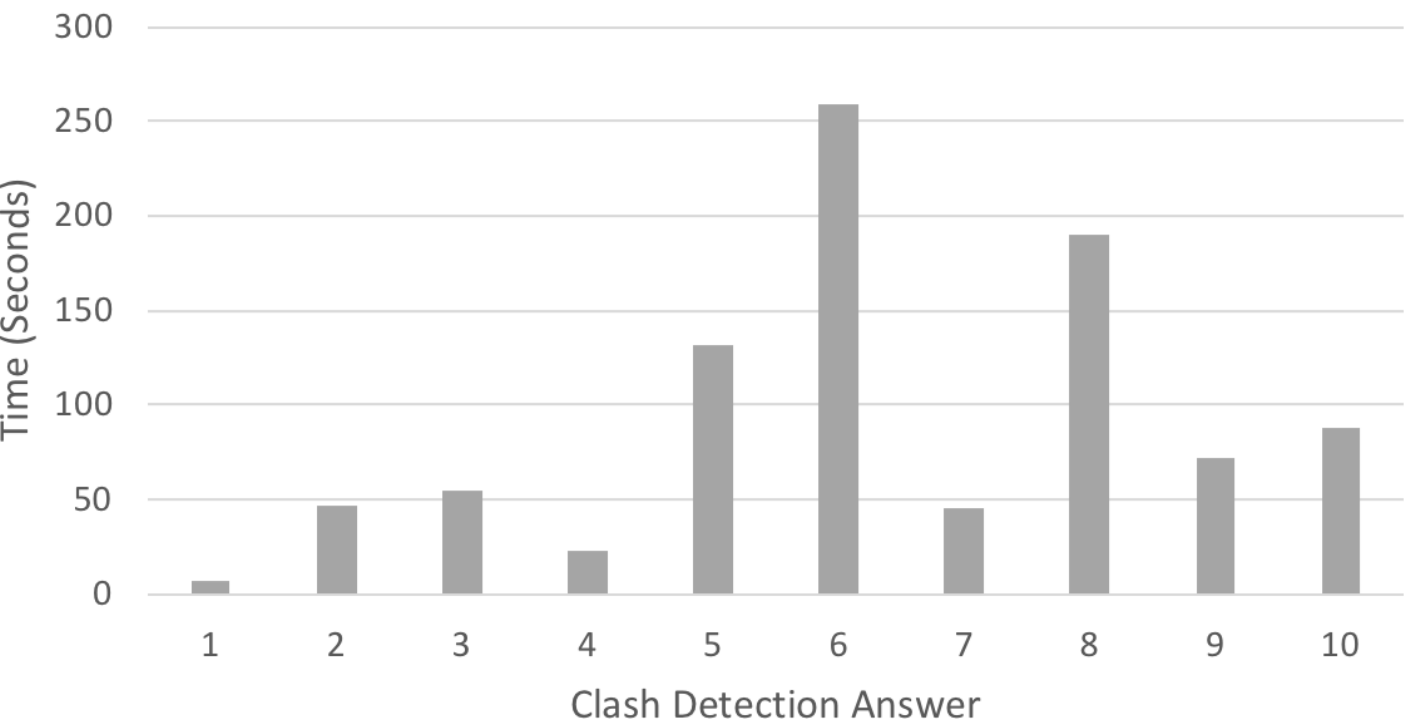

Figure 36 - Time Per Clash (Group 2) 
Group 2 (Laptop) was the fastest in detecting clashes. They averaged 1 minute and 31 seconds in retrieving each clash. The most amount of time spent on detecting a clash was 4 minutes and 19 seconds. The least amount of time spent on detecting a clash was 7 seconds.

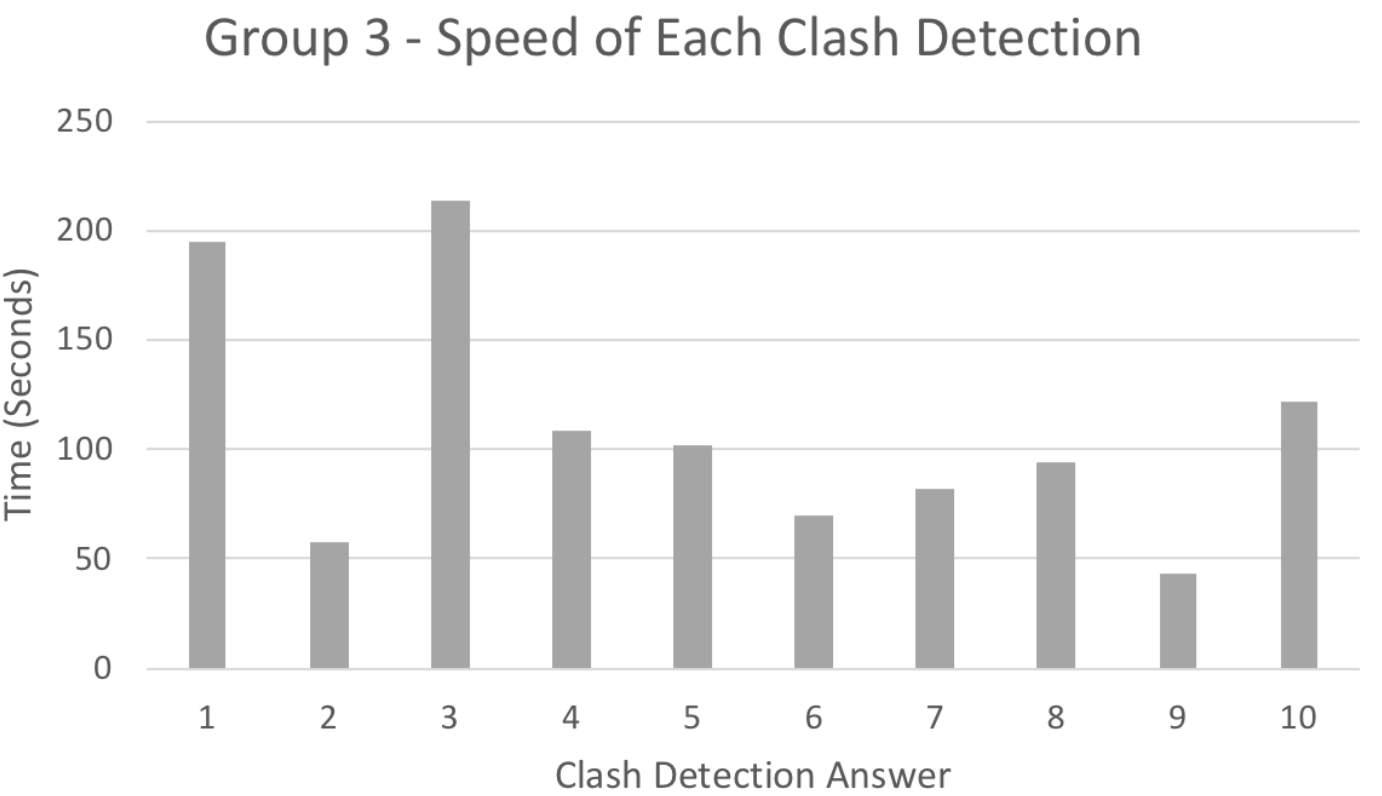

Figure 37 - Time Per Clash (Group 3)

Group 3 (HoloLens) followed closely behind Group 2 by collecting clashes at an average of 1 minute and 49 seconds. The most amount of time spent on detecting a clash was 3 minutes and 15 seconds. The least amount of time spent on detecting a clash was 43 seconds.

\subsection{POST-EXPERIMENT FOCUS GROUPS}

The final section of the results were the post-experiment focus groups. These focus group sessions aimed to answer the second research question:

$R Q$ \#2: What are the relative advantages and disadvantages of using a Microsoft HoloLens for information retrieval on construction sites?

The three focus groups correlated to the experiments by exploring the opinions and satisfaction levels of each group and their use of the information retrieval systems. Even though the research question looked specifically at the Microsoft HoloLens, it was useful to compare the answers to determine what was the most usable system. The focus groups were completed immediately after the experiments with the same participants and ran for one hour. 


\subsubsection{Focus Group Discussions}

The focus group sessions first began with asking about what the participant's thought the benefits and drawbacks were of their designated system. These advantages and disadvantages are displayed in Table 7. The participants had very similar thoughts to the initial focus group in regards to using paper drawings. All participants had been trained with paper drawings and felt that it would be difficult to switch to anything else as this is what everyone is comfortable with. When asked about the benefits and drawbacks of computer based drawings, it was mentioned that a laptop would be hard to use on site unless it was out of the back of a vehicle or in a site office. However, the participants that mentioned they have a computer available on site find that the drawings are still printed. Another participant mentioned that a laptop or computer may not be as useful but a tablet could be a better option. The tablet was identified as a better option because it could fit in someone's pocket. Phones were considered to be too small. The advantages and disadvantages of the HoloLens were very similar to the computer based responses. The only differences being that the HoloLens would be more useful if used at a 1:1 scale and that the cost of the HoloLens could be too high to be useful.

Following the advantages and disadvantages, the participants were asked about the ease of working together using their designated system. Participants of the paper drawing group said that it is easy because the drawings are easily accessible. They find it easy to use paper drawings to work together on site because they can easily give another tradesman a piece of paper for their own reference. Some of them said that they hardly ever look at the plans because they have more experience.

The computer based group said that it wasn't hard to work together but they had to think about the drawings more as they weren't used to the technology. They mentioned that it was easy to communicate together because of the colour coding and clarity of the 3D model.

The HoloLens group thought it had the potential to be useful for collaborative working but for this experiment it was difficult. They found it difficult to work together because there was a lag between the live stream and the HoloLens. If the stream feed was improved or if all participants were wearing a HoloLens then it would be easy to work together. 
In terms of the confidence levels of each groups answers, all groups had similar opinions in that they were fairly confident with their answers. One of the participants that found it difficult to use the HoloLens technology said that he did not feel confident with his answers.

All the participants across the groups said that they mainly use paper drawings on site currently. However, all participants said that either themselves or someone else they know on site have used iPads. The iPads are used to look at details or product/manufacturer specifications. When the tradesmen are given the drawings on site, it is common for drawings to be annotated with "refer to manufacturer specifications" and they will need to look these up anyway. When the participants in the laptop and HoloLens groups were asked if the technology would assist them in making decisions on site, they all said it would be unlikely that it would make a difference in comparison to using paper drawings. They reemphasised the issues with portability and that it is not as easy to carry a laptop or AR headset around on site as paper drawings are. Some of the participants mentioned that using technology can be difficult because of any glare on the screen.

The participants believed that for technology to be used on site, it would need to be robust and have a big display. Some of the participants believed that technology based plans could be useful for commercial construction but not residential as it is not nearly as complex. The HoloLens group said that it has the potential to be useful on site but would need to be developed more before it can be used. One situation where they thought it may be useful is to use it as a communication tool between the tradesmen and architects. A tradesman might find something that doesn't work on site and can communicate it back to the architect through the HoloLens. The architect could have the HoloLens feed on their computer and be able to change the drawings on a computer for it to realtime update on site.

The HoloLens participants responses varied in terms of whether they would be likely to use it on site. Initially, three of the participants said that they would be willing to use it if they were trained properly. However, once a participant said that they would not be willing to use it at all, the opinions of some of the other participants changed. In the end, three participants were not willing to use the HoloLens and two participants said they would. 
Table 7 - Advantages \& Disadvantages of Each System

\begin{tabular}{|c|c|c|}
\hline & ADVANTAGES & DISADVANTAGES \\
\hline $\begin{array}{l}\text { Paper } \\
\text { Drawings }\end{array}$ & $\begin{array}{l}\text { What everyone has } \\
\text { been taught to use } \\
\text { and has always } \\
\text { been used - } \\
\text { Everyone is } \\
\text { comfortable with it } \\
\text { Portable - } \\
\text { especially useful } \\
\text { when on top of } \\
\text { scaffolding etc. }\end{array}$ & $\begin{array}{l}\text { - Takes a longer time to get } \\
\text { revisions } \\
\text { - Sometimes not accurate to } \\
\text { scale } \\
\text { - Disintegrates in bad weather }\end{array}$ \\
\hline $\begin{array}{l}\text { Computer } \\
\text { Based }\end{array}$ & $\begin{array}{l}\text { - Once understood, it } \\
\text { is easy to } \\
\text { understand different } \\
\text { information in a } \\
\text { model }\end{array}$ & $\begin{array}{l}\text { - Risk of theft - can't leave } \\
\text { them on site } \\
\text { - Hard to get conservative } \\
\text { people to use } \\
\text { - Useless if it has a complex } \\
\text { interface }\end{array}$ \\
\hline HoloLens & $\begin{array}{l}\text { - Can solve issues } \\
\text { before starting on } \\
\text { site } \\
\text { - Would be more } \\
\text { useful if scaled 1:1 }\end{array}$ & $\begin{array}{l}\text { - } \text { Risk of theft } \\
\text { - } \text { Hard to get conservative } \\
\text { - } \text { Meople to use } \\
\text { going to site } \\
\text { - } \text { Cost of HoloLens }\end{array}$ \\
\hline
\end{tabular}





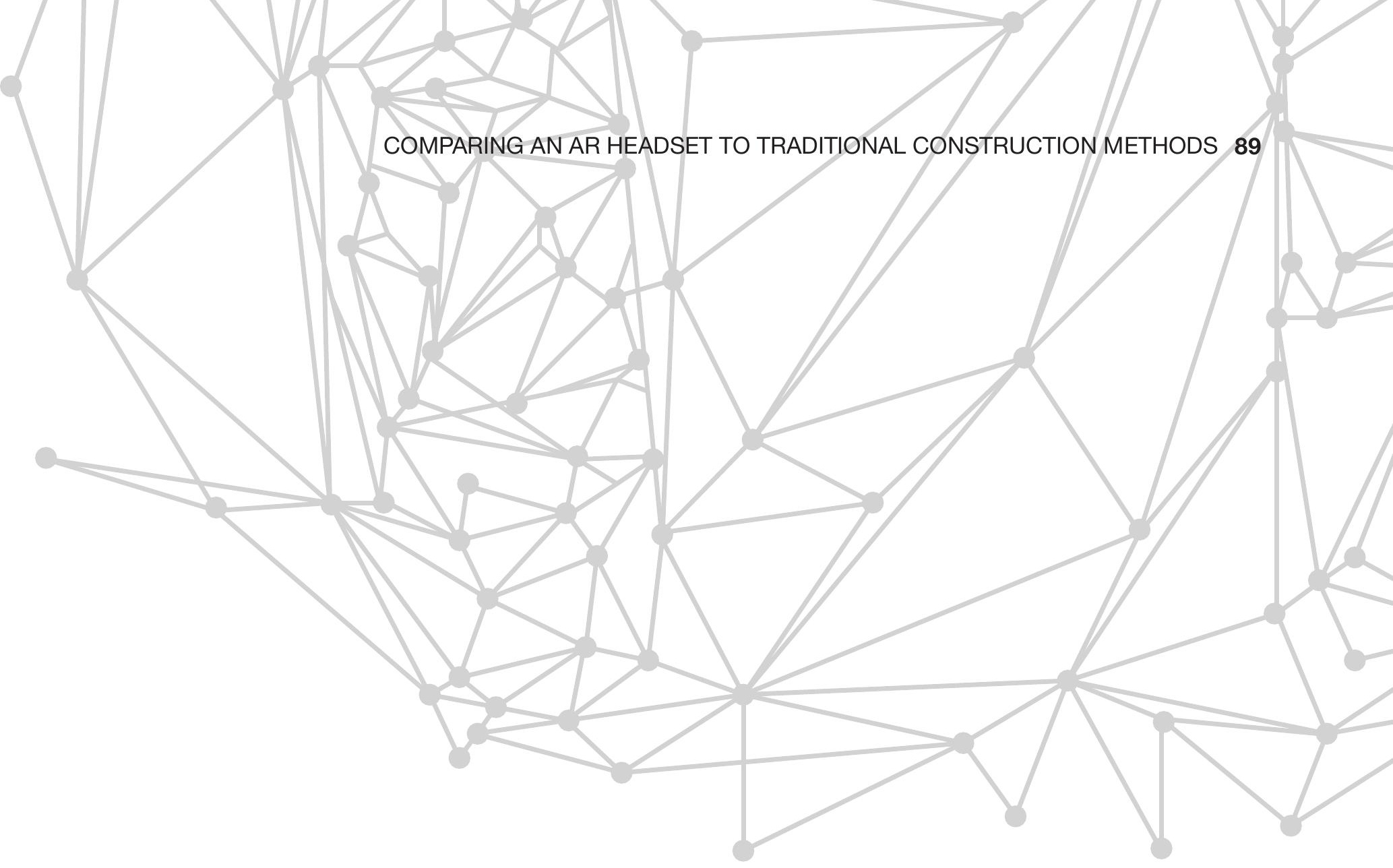

CHAPTER FIVE

DISCUSSION 



\subsection{CHAPTER INTRODUCTION}

This chapter discusses the results shown in Chapter 4 and presents an analysis of the results to address the research questions. As the results of the initial focus group were discussed in Chapter 4, only the experiments and postexperiment focus groups are discussed in this chapter. The experiments and post-experiment focus groups were analysed separately and integrated into the discussion.

As mentioned earlier, the purpose of the experiments was to quantify the effectiveness of $A R$ as an information retrieval tool in comparison to traditional paper drawing or computer-based methods. The experiments and focus groups were analysed in terms of effectiveness, efficiency and satisfaction. The combination of the experiments and focus groups provided a complementing result as they could answer the variables in both a measurable and subjective manner.

\subsection{EFFECTIVENESS}

The first variable's purpose was to measure the accuracy of each information retrieval system through the number of correct clash detection answers and compare them accordingly. The scores of each group determined the accuracy of each system.

Group 1 had a statistically low score as they failed to detect $60 \%$ of the clashes. Their score indicates that the paper drawings were unreliable for clash detection. It was pointed out that rather than collaborating around one drawing, the group opted to each look at an individual drawing. When looking at an individual drawing, this limited conversation and meant that collaboration with this system was at a minimum. If they chose to work together by looking at one drawing together, then their decisions may not only have been more accurate, but it may have sped up their decision making. This group also got distracted by the wording or colour coding of objects rather than focusing on clashes. They had to be reminded during the session that they were looking for mechanical clashes. This provided a significant limitation to this experiment group as some of their answers were considered invalid.

Group 2 (laptop) and Group 3's (HoloLens) scores were improved significantly by comparison to Group 1's scores. Group 2 and Group 3 both had effective collaboration skills as they were genuinely interested in the technology and only 
had one view of the building for the group unlike Group 1. As these groups only had one view, it mean that they were forced to work together to achieve the task.

Group 3 provided slightly more accurate results than Group 2 by answering one more correct question than Group 2. This suggested that the HoloLens allowed the group to make more accurate clash detection decisions but not at a significant level of difference.

\subsection{EFFICIENCY}

The second variable's purpose was to measure and compare the time each group spent completing the experiment task. This was measured by the average time spent on each clash and the overall elapsed time of the experiment.

The experiment results in Chapter 4 showed that Group 1 was unable to solve all ten clashes in the 30-minute time-frame. Group 1 did not seem to improve with time as near the end of the experiment the time spent per each clash detection increased by approximately 3 minutes. The reason for this increase was that they had difficulty finding more clashes as time went on. One of the reasons why Group 1 may have taken longer than the other groups is because if they thought something might be a clash, then they would need to refer to other drawings to confirm their answer. Finding the other relevant drawings could take more time and visually understanding how the elements connect proved to be some difficulty. As Group 1 struggled considerably, the total experiment times varied significantly across the groups.

Conversely to the first group, Group 2 and 3 had no trouble in identifying the ten clashes within the given time-frame. Given that the participants in these groups had no prior experience with viewing plans on computer-based systems or AR technology, this was an interesting result. One would expect that with the lack 
of familiarisation that they would have completed the task with a much slower time. The reason why the participants may have been able to solve the task faster in both these mediums could be the increased awareness of technology and the simplification of the user interfaces.

Between Group 2 and Group 3, the results showed that Group 2 was the most efficient group as they collected ten clashes in just over 15 minutes. This was almost half the time that Group 1 spent trying to detect all of the clashes. As laptop technology is more familiar to the participants than AR technology, the users may have been able to adapt faster to solve the tasks. Group 2 spent an average of 32 seconds per clash during their first four answers. Their time per clash increased slightly after this because they were spending more time discussing a clash before confirming it as an answer.

In saying this, Group 3's overall time was not far behind Group 2 as they detected the clashes with a difference of just under 3 minutes. It is possible that the HoloLens could produce a fast time if the users were more aware of the technology. When the participants of Group 3 began using the HoloLens, there was an initial shock and excitement of the technology. This could have meant that they were distracted from completing the task at hand. This was an interesting observation as Group 2 was not as shocked by the use of the laptop for completing the task. Although, this could be due to computers emerging more on site already. Other factors that could have contributed to the time were that the HoloLens stream to the laptop was lagging, and there was a considerably long time to understand how to use the HoloLens. The time lag between the image on the HoloLens and on the laptop screen was out of the researcher's control, but it could have been more stable if multiple HoloLens were used. Even though there was an explanation before the experiment began, the participants still took a long time to understand controls. While using the HoloLens, it also took the participants a significant amount of time to understand how to go back to the menu to turn off the visibility of objects.

Overall, the HoloLens has the potential to be efficient, but the laptop was the most efficient system in these experiments as it allowed the participants to make faster decisions. For the HoloLens to become more efficient, there would need to be more training for how to use the HoloLens, and the technology would need to be improved to allow for a more collaborative environment. 


\subsection{SATISFACTION}

The third variable's purpose was to explore each group's opinions on the allocated information retrieval system to determine if it could meet the user's expectation's and be perceived as useful.

The results from the focus group discussions showed that the participants' views were similar across all groups. The discussions were also comparable to the initial focus group as the participants in all groups mentioned that paper drawings are useful because everyone has been taught that way. The paper drawings were perceived to be more useful as not only is everyone comfortable with using paper drawings in the industry but that they are easily portable and have less associated risk. With a laptop or HoloLens, there is a higher risk of theft or damage that could ultimately result in a higher cost of operation. Some technology was still considered necessary as they would need it for details or specifications. More disadvantages than advantages were mentioned for both the laptop and the HoloLens.

Although the opinion on paper drawings was repeated across multiple sessions, it may not be reflecting the real experience of each participant. A participant that might have a higher role than someone else in the group could have been less likely to accept using technology, and this could have influenced less experienced participant's opinions. This was exhibited when the HoloLens participants were asked if they would be willing to use AR in the future. The participant's opinions changed when someone disagreed with the technology. This shows that the participants may not have wanted to give their true opinion.

Overall, the focus groups concluded that paper drawings were the preferred medium for information retrieval, but they could be enhanced with the use of some technology. 

COMPARING AN AR HEADSET TO TRADITIONAL CONSTRUCTION METHODS 97

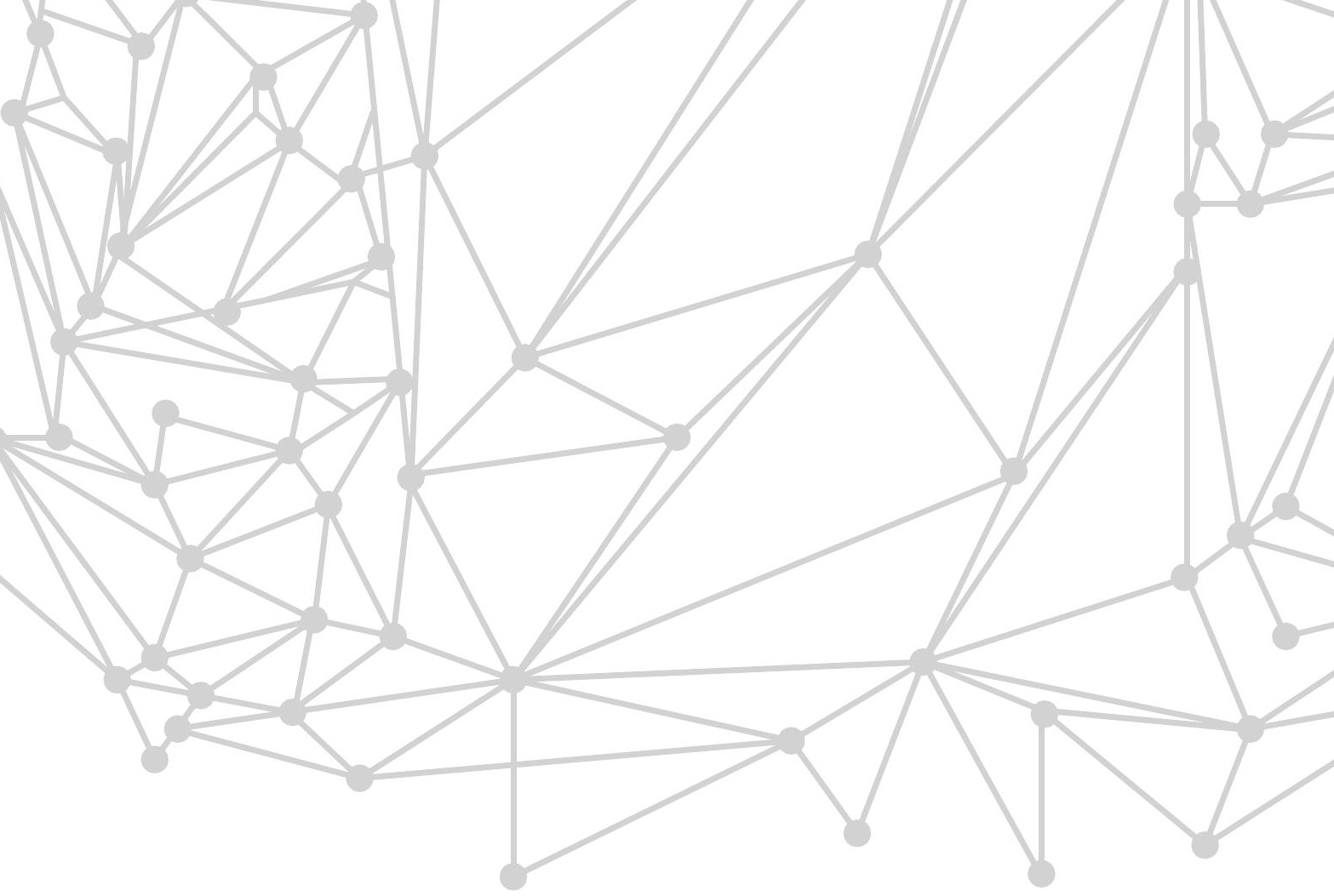

CHAPTER SIX

SUMMARY \& CONCLUSIONS 



\subsection{CHAPTER INTRODUCTION}

In the final chapter, the research is summarised in detail. First, the chapter reviews the research in its entirety, then the limitations of the research are presented, and finally the future research options are discussed.

The goals of this study were to determine what extent AR could provide a more effective system for information retrieval in comparison to traditional paper or computer-based methods; and to determine the relative advantages and disadvantages of using the Microsoft HoloLens on construction sites. The research objectives are reviewed following the completion of the research. In reviewing each objective, the thesis can be assessed in terms of achieving the research aim.

\subsection{REVIEW OF THESIS}

The first objective of this research was to critically assess previous literature about BIM and its implementation, precedent AR applications and studies to identify background information, and the technological requirements and characteristics of integrating BIM and AR technology.

A comprehensive literature review confirmed that BIM has many beneficial qualities but they are not being used to their full potential and there are currently no appropriate tools to make use of BIM on site. After examining background information of Augmented Reality in the construction industry, the review determined that there was limited studies that could prove the effectiveness of integrating BIM and AR. The review also concluded that because the detailed studies were completed several years ago and technology had developed significantly since then, systems such as the Microsoft HoloLens needed to be validated.

A three-phase mixed method approach was used for this research. A combination of focus groups and experiments were designed as the research instruments for the research to successfully test the overall aim of the research.

An initial focus group session aimed to identify common issues that arise during the construction stage of a project and understand how construction industry professionals work together to solve them. The focus group session with five construction industry professionals found common issues that arise during the 
construction stage of project to inform the design of the succeeding experiments and focus groups. Clash detection was identified as a reoccurring issue amongst the professionals with MEP services causing the most difficulty.

MEP services were a common issues because of their complex nature and if these clashes are not identified early enough they can cause significant disadvantages in terms of time and cost for the project. This focus group session also changed the scope of the participants for the experiments by suggesting that tradesmen should be the main participants due to their lack of training of software and interpretation of three-dimensional models. This focus group also acted as a test for how to run the subsequent focus group sessions. The importance of successful focus groups was highlighted through the controlling of the focus group discussion and the timing of recruiting participants. At times, the conversation from the audio recording was confusing as participants would speak over each other. The focus group rules should be re-emphasised before the focus group starts and the researcher should interrupt the conversation if there is overlap of speech. It cannot be stressed enough how early recruitment should begin to ensure a sufficient number of participants. However, despite identifying this after the initial focus group session, it proved to be difficult to recruit participants for the experiments because of the busy time of year for the construction industry. In an ideal world, the experiment dates would be changed to a time that was more suitable for the industry. Although, due to the thesis time-constraints, it was necessary for the experiments to be conducted during December.

From the results of the literature review and the initial focus group session, the framework for a Microsoft HoloLens application was developed to satisfy the third research objective and to aid in satisfying the fourth research objective. Due to the researcher's limited knowledge in coding, thesis time constraints and the need for a simple application design, the application was designed with only one capability. A Revit to HoloLens workflow was outlined to produce a 3D model of a building with the ability to toggle the visibility of building elements.

Continuing from the previous research objective, the next part of the research methodology aimed to demonstrate AR's potential in comparison to other systems through experiments and focus group sessions. The experiments employed three different information retrieval methods to compare and evaluate quantitative data through a clash detection task. Fifteen builders were divided 
equally into three sessions to use either the two-dimensional paper drawings, a three-dimensional model on a laptop, or a Microsoft HoloLens to complete the task. The focus group sessions enhanced the experiment results by providing a qualitative analysis of the experiment participants experiences and opinions with each information retrieval method.

After reviewing the success of each research objective, the research questions had to be reviewed to determine if this research was successful.

$R Q$ \#1: To what extent can Augmented Reality provide a more effective system for productivity and information retrieval in comparison to traditional paper or computer-based methods?

$R Q$ \#2: What are the relative advantages and disadvantages of using a Microsoft HoloLens for information retrieval on construction sites?

After collecting the data of the experiments and focus groups, this research found that the Microsoft HoloLens was not the fastest method of information retrieval for clash detection. However, it was considered to be the most effective system for accurate clash detection. There were several factors that contributed to this.

AR has the potential to provide an overall more effective system for information retrieval and clash detections only to a certain extent. The HoloLens is considered to be relatively new technology and it's use is considered to have some significant benefits. The experiments revealed that the Microsoft HoloLens was effective in accurately detecting clashes. However, the focus group discussions revealed that the technology may not be advanced enough to be used on site. This is however a subjective opinion and it leaves the question of whether the HoloLens disadvantages are related to the technology itself or the user. Until the users are willing to use technology, it will not be perceived as a completely effective tool. The Microsoft HoloLens needs to prove itself as useful to the industry through further testing and development of industry specific applications and training.

When analysing the usability of each information retrieval system, the results could draw the conclusion that a combination of these systems could be useful. Although the experimental results suggested that the laptop and HoloLens 
were the most useful systems, the focus group discussion stipulated that paper drawings were the more preferred information retrieval method. This does, however, not take into consideration of the conservative nature of participants. Many of the participants felt that the paper drawings were useful because they had been trained with $2 \mathrm{D}$ drawings. It could suggest that they were unwilling to step out of their comfort zone and accept using technology because it would mean that they would have to re-learn everything. If the participants had been trained with the technology in the first place, then it is possible that their views in the focus group discussion would have been different. As the experiment results indicated that technology was more useful for information retrieval than 2D paper drawings, it could mean that the main issue for implementing such technology is the underlying user acceptance issues.

This research aimed to determine what extent Augmented Reality could provide a more effective system for information retrieval in comparison to traditional paper or computer-based methods. It also aimed to establish the relative advantages and disadvantages of using a Microsoft HoloLens for information retrieval. With reference to the research aim's, the HoloLens can be useful for accuracy and has the potential to be an effective tool for clash detection in comparison to traditional methods. The advantages of this system are that it can provide a better visual understanding of buildings than traditional paper methods, and that users can effectively collaborate together to solve more accurate clash detections. The disadvantages were evident through the lagging of the streaming and the user acceptance towards the technology. However, as the technology develops, these disadvantages could cease to exist.

Based on the above statements, the thesis has achieved its aim. This research provided a good starting point for future research to develop the use of the Microsoft HoloLens for the construction industry. The thesis resulted in a hypothesis rather than a verified result and did not provide a detailed solution to integrating $\mathrm{AR}$ and BIM to facilitate construction on-site.

\subsection{LIMITATIONS}

Limitations identified by this research should be taken into consideration if exploring similar research in the future. The three major obstacles that were encountered in this research were the lack of knowledge around coding, the difficulty in recruiting participants, and general time constraints. 
language. This created a complex study for the researcher that could have been done with ease if there was some prior experience. The learning process for coding had to be factored in so that the experiments could be performed, otherwise the methodology of the study would have to be adjusted.

Even though this was a mixed methods study, it provided primarily qualitative results. The experiments were conducted in December, which was a particularly busy time for contractors due to the Christmas break approaching. The limited availability of participants made it difficult to gain a large participant population and a small window of opportunity to conduct the experiments.

The time available for this thesis was also a contributing factor to the lack of quantitative data. If the thesis time-frame was longer than 12 months, then the experiments could have been planned for a more suitable time to recruit more participants. Additionally this would mean that the researcher had more time to develop knowledge around coding.

If the researcher had an extensive knowledge of AR and the C\# language, more participants that were available, and a longer time-frame then this study could have been predominantly quantitative. It could have included an iterative testing and developing process. For example, the researcher could have designed the application with more features and higher-quality and tested it in cycles, developing it after each experiment.

\subsection{FUTURE RESEARCH RECOMMENDATIONS}

Future research should hopefully lead to the implementation of AR and the use of the Microsoft HoloLens on construction sites. Contextual factors should be taken into consideration, and it is recommended that future research should test the use of the Microsoft HoloLens in a pilot study on site. This is so the behaviour of users can be studied in the real environment.

However, until there is a better understanding of the use of AR in the construction industry, the research should remain in controlled environments. As this research was a single usability test, future studies should use this research as a basis for continued usability development. AR user training should also be examined to determine the best approach for implementation. With user capabilities being one of the downfalls of using AR, research should look at how applications can be designed for ease of use. 



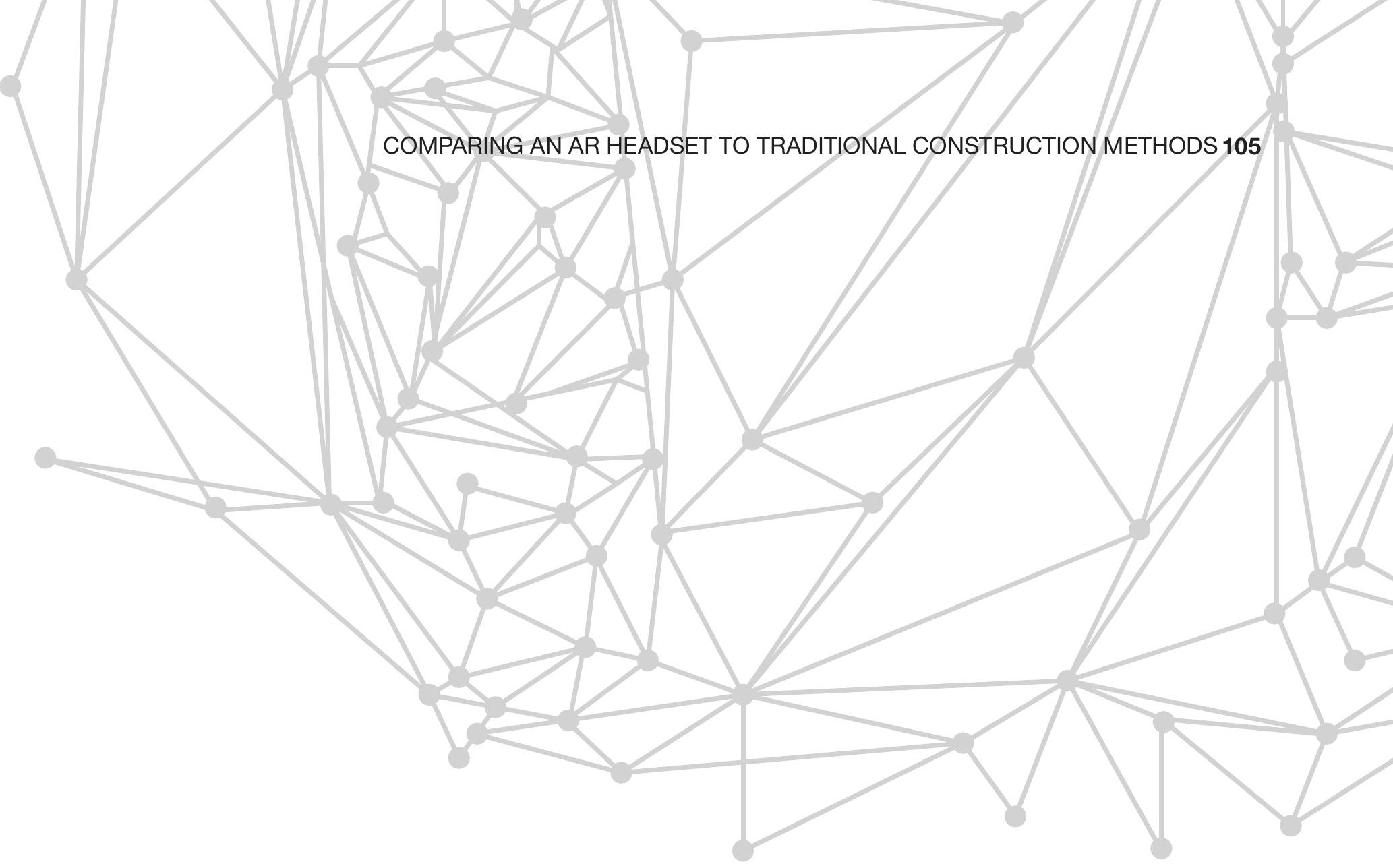

REFERENCES 



\section{REFERENCES}

Barbour, R. (2007). Doing Focus Groups. Thousand Oaks, CA: SAGE Publications, Inc.

Barnum, C.M. (2010). Usability Testing Essentials. Burlington, MA: Morgan Kaufmann.

BIM Acceleration Committee [BAC]. (2016). New Zealand BIM Handbook, November 2016: A Guide to Enabling BIM on Building Projects.

BIM Acceleration Committee [BAC]. (2017). BIM in New Zealand - an industry wide view 2017 (Report No. 4). Retrieved from: https://www.eboss. co.nz/assets/Uploads/BIM-Benchmark-Survey-2017.pdf

Bråthen, K., \& Moum, A. (2016). Bridging the gap: bringing BIM to construction workers. Engineering, Construction and Architectural Management, 23(6), 751764.

Chu, M., Matthews, J., \& Love, P.E.D. (2018). Integrating Mobile Building Information Modelling and Augmented Reality Systems: An experimental study. Automation in Construction, 85, 305-316.

Courage, C., \& Baxter, K. (2005). Understanding your Users: A practical guide to user requirements, methods, tools and techniques. San Francisco, CA:

Morgan Kaufmann Publishers.

Creswell, J. (2014). Research Design: Qualitative, Quantitative, and Mixed Methods Approaches (4th ed.). Thousand Oaks, CA: SAGE Publications, Inc. Creswell, J., \& Plano Clark, V. (2011). Designing and Conducting Mixed Methods Research (2nd ed.). Thousand Oaks, CA: SAGE Publications, Inc. Davis, F.D. (1989). Perceived usefulness, perceived ease of use and user acceptance of information technology. MIS Quarterly, 13(3), 319-340.

Davis, P. (2011). Introducing Autodesk ${ }^{\circledR}$ Revit $\circledast$ Architecture 2012: Autodesk ${ }^{\circledR}$ Official Training Guide. Indianapolis, IN: Wiley Publishing, Inc.

Etikan, I., Musa, S.A., \& Alkassim, R.S. (2016). Comparison of Convenience Sampling and Purposive Sampling. American Journal of Theoretical and Applied Statistics, 5(1), 1-4.

Eynon, J. (2016). Construction Manager's BIM Handbook. Chichester, UK: John Wiley \& Sons.

Ghaffarianhoseini, A. [Ali], Tookey, J., Ghaffarianhoseini, A. [Amirhosein], Naismith, N., Azhar, S., Efimova, O., \& Raahemifar, K. (2017). Building Information Modelling (BIM) uptake: Clear benefits, understanding its implementation, risks and challenges. Renewable and Sustainable Energy Reviews, 75, 1046-1053. 
Gheisari, M., Williams, G., Chen, P.J., \& Irizarry, J. (2014). BIM2MAR: An efficient BIM translation to mobile augmented reality applications. Journal of Management in Engineering, 31(1).

Grand Valley State University (2018). Atomic Object Technology Showcase

- 7 Things about Microsoft HoloLens. Retrieved from: https://www.gvsu.edu/ cms4/asset/7E70FBB5-0BBC-EF4C-A56CBB9121AECA7F/7 things about microsoft hololens.pdf

Hennick, M.M. (2014). Understanding Focus Group Discussions (1st ed.). USA: Oxford University Press.

Hodgson, S. (2018). vNEXT Task: HoloLens Gesture Support \#2630. Retrieved from: https://github.com/Microsoft/MixedRealityToolkit-Unity/issues/2630

Krueger, R.A. (2006). Analyzing Focus Group Interviews. Journal of Wound, Ostomy and Continence Nursing, 33(5), 478-481.

Kumar, R. (2014). Research Methodology: a step-by-step guide for beginners (4th ed.). Thousand Oaks, CA: SAGE Publications, Inc. International Organisation of Standardisation [ISO]. (2016). Building information models - Information delivery manual - Part 1: Methodology and format (ISO Standard No. 29481-1:2016). Retrieved from: https://www.iso.org/ obp/ui/\#iso:std:iso:29481:-1:ed-2:v1:en

International Organisation of Standardisation [ISO]. (2018). Ergonomics of human-system interaction - Part 11: Usability: Definitions and concepts (ISO Standard No. 9241-11:2018). Retrieved from: https://www.iso.org/obp/ ui/\#iso:std:iso:9241:-11:ed-2:v1:en

Jana, A., Sharma, M., \& Rao, M. (2017). HoloLens BluePrints. Retrieved from: https://www.oreilly.com/library/view/hololens-blueprints/9781787281943/cover. xhtml

Johnson, R.B., Onwuegbuzie, A.J., \& Turner, L.A. (2007). Towards a Definition of Mixed Methods Research. Journal of Mixed Methods Research, 1, 112-133.

Latiffi, A.A., Brahim, J., \& Fathi, M.S. (2014). The Development of Building Information Modeling (BIM) Definition". Applied Mechanics and Materials, 567, 625-630.

Liamputtong, P. (2011). Focus Group Methodology: Principles and Practices (1st ed.). Thousand Oaks, CA: SAGE Publications, Ltd.

Lucas, R. (2016). Research Methods for Architecture. London: Laurence King Publishing.

Matějka, P., \& Tomek, A. (2017). Ontology of BIM in a Construction Project Life Cycle. Procedia Engineering, 196, 1080-1087. 
Microsoft. (2018a). BIM Holoview App. Retrieved from: https://www.microsoft. com/en-nz/p/bim-holoview/9pm707h5x8bt?activetab=pivot:overviewtab\# Microsoft. (2018b). Fit Your HoloLens. Retrieved from: https://support. microsoft.com/en-sg/help/12632

Microsoft. (2018c). Health \& Safety. Retrieved from: https://www.microsoft. com/en-nz/hololens/legal/health-and-safety-information

Microsoft. (2018d). HoloLive App. Retrieved from: https://www. microsoft.com/en-nz/p/hololive/9pjg9mdw3gls?cid=msft_web collection\&activetab=pivot\%3Areviewstab

Microsoft. (2018e). Trimble Connect App. Retrieved from: https://www. microsoft.com/en-nz/p/trimble-connect/9nh8t4jnx7cp?activetab=pivot:overviewt ab\#

Microsoft. (2018f). Use Gestures. Retrieved from: https://support.microsoft. com/en-gb/help/12644/hololens-use-gestures

Miettinen, R., \& Paavola, S. (2014). Beyond the BIM Utopia: Approaches to the Development and Implementation of Building Information Modelling. Automation in Construction, 43, 84-91.

Newnham, J. (2017). Microsoft HoloLens By Example. Retrieved from: https:// www.oreilly.com/library/view/microsoft-hololens-by/9781787126268/

Odom, J. (2017). HoloLens Beginner's Guide. Retrieved from: https://learning. oreilly.com/library/view/hololens-beginners-guide/9781786464729/

Redmond, R., \& Curtis, E. (2009). Focus groups: principles and process. Nurse Researcher, 16(3), 57-69.

Royal Institute of Chartered Surveyors [RICS]. (2016). International BIM Implementation Guide (1st ed.). Retrieved from: https://www.rics.org/oceania/ upholding-professional-standards/sector-standards/construction/internationalbim-implementation-guide/

Rubenstone, J. (2016). How Mixed Reality May Change Construction Work. Engineering New-Record (ENR), 277(16), 20-24.

Ryan, R.A. (2007). Enhancing 3D Models with Urban Information: A case study involving local authorities and property professionals in New Zealand: Quantifying the benefits of 3D over alternative 2D systems. (Master of Building Science thesis, Victoria University of Wellington, Wellington, New Zealand).

Retrieved from: http://hdl.handle.net/10063/1162

Sanchez, A.X., Hampson, K.D., \& Vaux, S. (2016). Delivering Value with BIM: A Whole-Of-Life Approach. New York, USA: Routledge.

Saunders, M., Lewis, P., \& Thornhill, A. (2009). Research Methods for Business Students (5th ed.). Harlow, Essex: Pearson Education Ltd. 
Sun, C., Jiang, S., Skibniewski, M.J., Man, Q., \& Shen, L. (2015). A literature review of the factors limiting the application of BIM in the construction industry. Technological and Economic Development of Economy, 1-14.

Taylor, A.G. (2016). Developing Microsoft HoloLens Apps Now. Retrieved from: https://www.oreilly.com/library/view/develop-microsoft-hololens/9781484222027/ A394081 1 En 12 Chapter.html

Tommelein, I.D., \& Gholami, S. (2012). Root Causes of Clashes in Building Information Models. In I.D. Tommelein \& C.L. Pasquire (Eds.), Proceedings of the 20th Annual Conference of the International Group for Lean Construction. San Diego, CA: Montezuma Publishing.

Vaai, J. (2014). 4D Building Information Modelling With Augmented Reality on Mobile Devices to Support Construction Management: Applications and key performance criteria from a stakeholder perspective (Master of Building Science thesis, Victoria University of Wellington, Wellington, New Zealand). Retrieved from: http://researcharchive.vuw.ac.nz/xmlui/handle/10063/3596

Vass, S., \& Gustavsson, T.K. (2017). Challenges when implementing BIM for industry change. Construction Management and Economics, 35(10), 597-610. Vroegop, D. (2017). Microsoft HoloLens Developer's Guide. Retrieved from: https://www.oreilly.com/library/view/microsoft-hololensdevelopers/9781786460851/

Wang, X., \& Chong, H-Y. (2015). Setting new trends of integrated Building Information Modelling (BIM) for the construction industry. Construction Innovation, 15(1), 2-6.

Wang, X., Kim, M-J., Love, P.E.D., \& Kang, S-C.J. (2013). Augmented Reality in built environment: Classification and implications for future research. Automation in Construction, 32, 1-13.

Washington University in St. Louis (2018). Fossett Laboratory for Virtual Planetary Exploration - Fossett Lab Resources. Retrieved from: https:// virtualplanet.wustl.edu/resources/

Wei, A. N., \& Othuman Mydin, M.A. (2017). Potential and Benefits of Buildling Information Modeling (BIM) During Pre-Construction, Construction and Post Construction Stage. Analele Universităţii "Eftimie Murgu" Reşiţa: Fascicola I, (1), 429-438.

Yeh, K.C., Tsia, M.H., \& Kang, S.C. (2012). On-site building information retrieval by using projection-based augmented reality. Journal of Computing in Civil Engineering, 6(3), 342-355.

Zaher, M., Greenwood, D., \& Marzouk, M. (2018). Mobile Augmented Reality Applications for Construction Projects. Construction Innovation, 18(2), 152-157. 


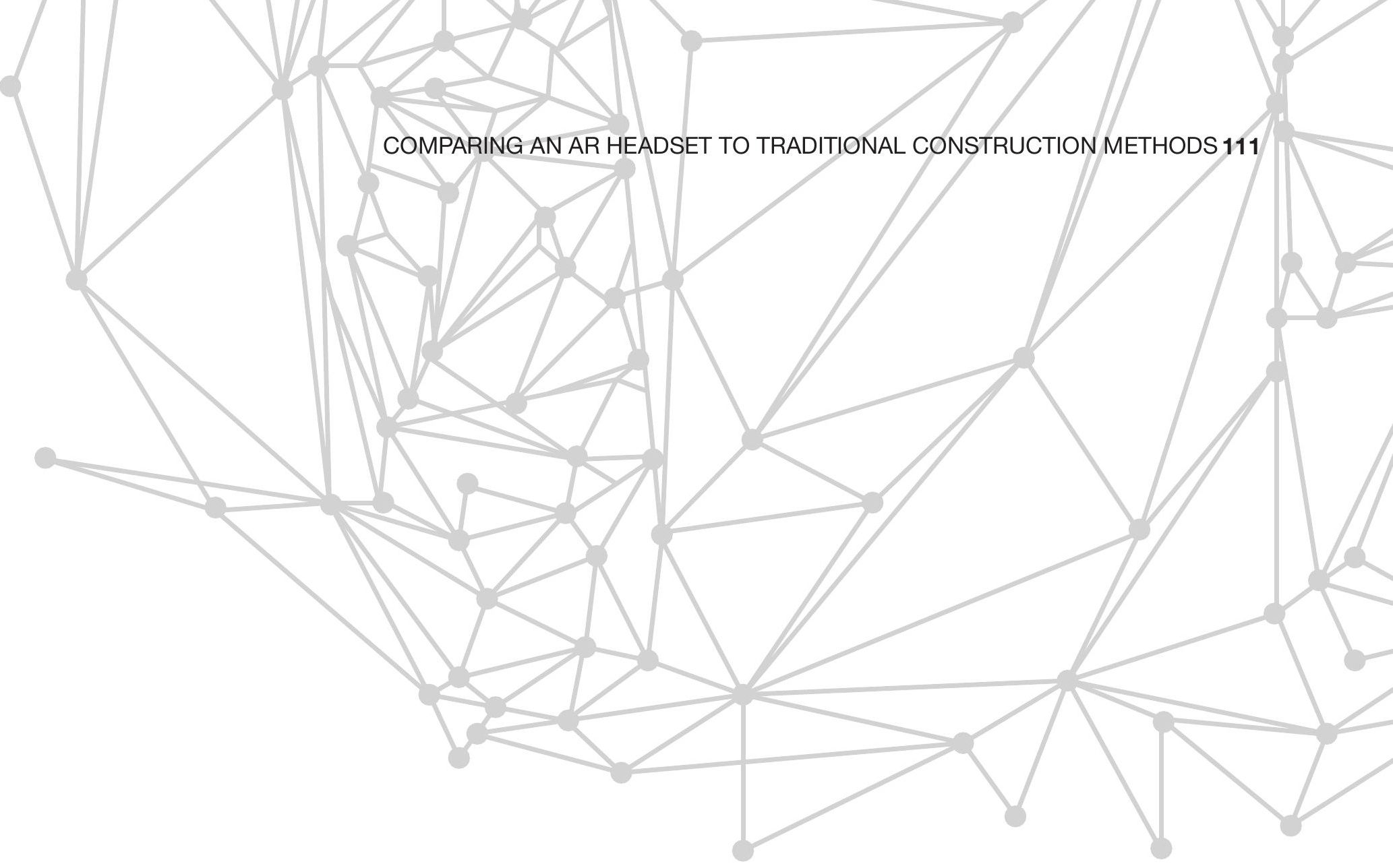





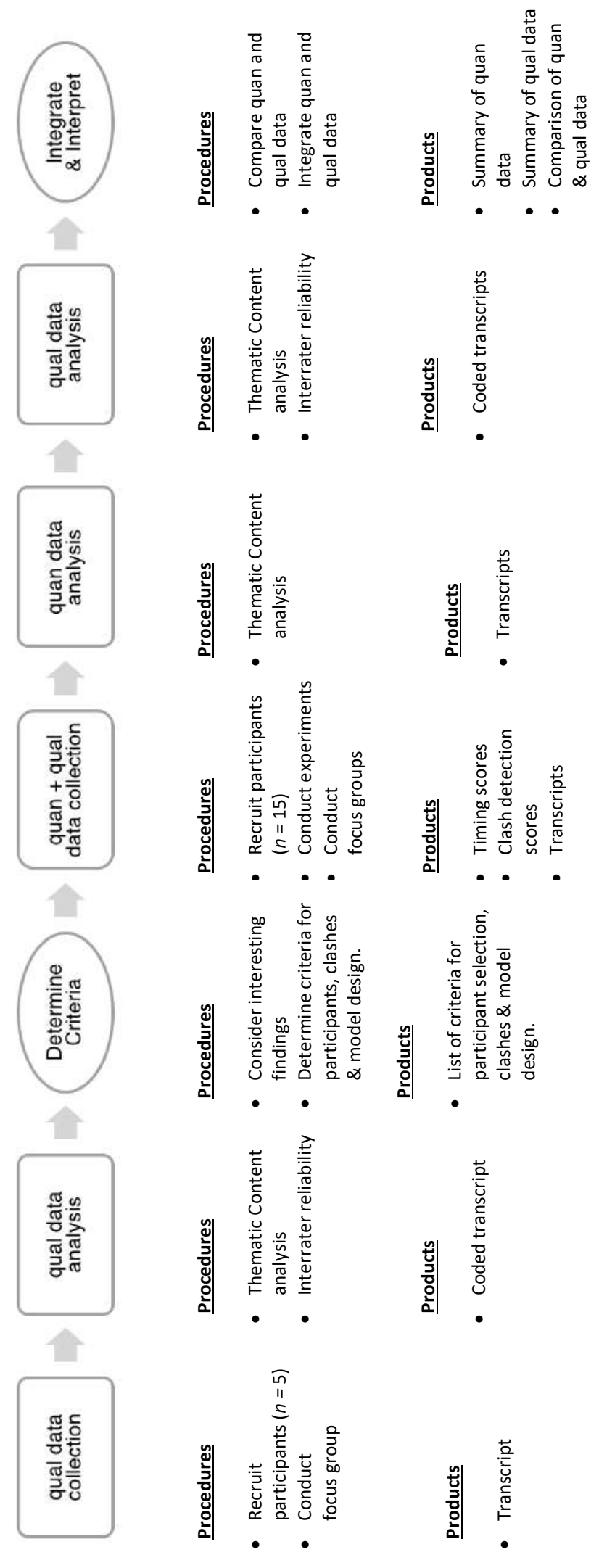




\section{APPENDICES}




\section{APPENDIX B - HEALTH SCREENING QUESTIONNAIRE}

\section{HEALTH SCREENING FOR HOLOLENS PARTICIPANTS}

If you experience any of the following medical conditions, you may not be eligible to participate:

$\begin{array}{ll}0 & \text { Migraine headaches } \\ 0 & \text { Motion sickness } \\ 0 & \text { Inner ear disorder } \\ 0 & \text { Binocular disorder } \\ 0 & \text { Fear of heights } \\ 0 & \text { Epilepsy/Seizures } \\ 0 & \text { Eye problems } \\ 0 & \text { Any other serious health concerns }\end{array}$

During the experiment you may experience symptoms of physical discomfort such as the following:

o Nausea

- Motion sickness

o Dizziness

o Disorientation

o Headache

o Fatigue

o Eye strain

o Dry eyes

o Drowsiness

You are free to stop the experiment at any time before or during the experiment. It is recommended that you avoid any potentially dangerous activities after taking part in the experiment, like driving or operating heavy machinery. It is also recommended that you arrange transportation ahead of time or use public transport to get to and from the experiment. If you cannot arrange transport, a taxi chit will be provided to transport you home safely. First aid support will be provided of you experience any symptoms of physical discomfort during the experiment.

If you experience any of the medical conditions, please inform the researcher before agreeing to participate. The level of your medical condition will dictate whether or not you are eligible to participate. 
116 APPENDICES 


\section{APPENDIX C - INITIAL FOCUS GROUP INFORMATION SHEET}

\section{INFORMATION SHEET FOR FOCUS GROUP PARTICIPANTS}

You are invited to take part in this research. Please read this information before deciding whether to take part. If you decide to participate, thank you. If you decide not to participate, thank you for considering this request.

\section{Who am I?}

My name is Tayler Hubber-Davis and I am a Masters student in Building Science at Victoria University of Wellington. This research project is work towards my thesis.

\section{What is the aim of the project?}

This project investigates how to combine Augmented Reality (AR) with Building Information Modelling (BIM) to facilitate on-site construction. This research aims to determine if Augmented Reality is more effective for information retrieval than two-dimensional or three-dimensional drawings. This is to demonstrate AR's potential through a comparative study, and to make future recommendations for the use of $A R$ in the construction industry.

This research has been approved by the Victoria University of Wellington Human Ethics Committee [ResearchMaster application reference \#0000026115].

\section{What will I be asked to do?}

You have been invited to participate because are a current employee in the New Zealand construction industry. If you agree to take part you will be part of a focus group at Te Aro Campus, Victoria University of Wellington. I will ask you and other participant's questions about how you use building information systems such as two-dimensional paper drawings, BIM, etc. in your workplaces to retrieve information about projects. The focus group will take 1 hour. I will audio record the focus group with your permission and write it up later. You will be provided with morning tea before the session. If you use public transportation the costs will be reimbursed to you after the session.

The information shared during the focus group is confidential. That means after the focus group, you may not communicate to anyone, including family members and close friends, any details about the focus group. 
You can withdraw from the focus group at any time before the focus group begins. You can also withdraw while the focus group it is in progress. However, it will not be possible to withdraw the information you have provided up to that point, as it will be part of a discussion with other participants.

\section{What will happen to the information I give?}

This research is confidential. This means that the researcher named below will be aware of your identity but the research data will be combined and your identity will not be revealed in any reports, presentations, or public documentation. However, you should be aware that in small projects your identity might be obvious to others in your community.

Only my supervisors and I will listen to the audio recording of the focus group. The focus group summaries and any recordings will be kept securely and destroyed on 25th February 2019.

\section{What will the project produce?}

The information from my research may be used in a Masters thesis, a BUILD magazine article, AND a paper/presentation at a conference. The audio recording will not be used in my thesis, articles, presentations or conferences. However, the information from the recording may be used.

\section{If you accept this invitation, what are your rights as a research participant?}

You do not have to accept this invitation if you do not want to. If you do decide to participate, you have the right to:

- choose not to answer any question;

- withdraw from the focus group while it is taking part however it will not be possible to withdraw the information you have provided up to that point;

- ask any questions about the study at any time;

- read over and comment on a written summary and the audio recording of the focus group;

- be able to read any reports of this research by emailing the researcher to request a copy. 
If you have any questions or problems, who can you contact?

If you have any questions, either now or in the future, please feel free to contact either:

\section{Student:}

Name: Tayler Hubber-Davis

University email address:

hubbertayl@myvuw.ac.nz

\section{Supervisor:}

Name: Kevin Sweet

Role: Architecture Programme Director

School: School of Architecture

Phone: 044634717

Email: Kevin.Sweet@vuw.ac.nz

\section{Human Ethics Committee information}

If you have any concerns about the ethical conduct of the research you may contact the Victoria University HEC Convenor: Dr Judith Loveridge. Email hec@ vuw.ac.nz or telephone +64-4-463 6028. 


\section{CONSENT TO PARTICIPATE IN FOCUS GROUP}

This consent form will be held until 25th February 2019.

Researcher: Tayler Hubber-Davis, School of Architecture, Victoria University of Wellington.

- I have read the Information Sheet and the project has been explained to me. My questions have been answered to my satisfaction. I understand that I can ask further questions at any time.

- I agree to take part in an audio recorded focus group discussion immediately following the experiment.

- I have read the Focus Group Rules and agree to comply with these rules during and after the focus group session.

I understand that:

- I acknowledge that I am agreeing to keep the information shared during the focus group confidential. I am aware that after the focus group, I must not communicate to anyone, including family members and close friends, any details about the focus group.

- I can withdraw from the focus group while it is in progress for any given reason. However, it will not be possible to withdraw the information I have provided up to that point as it will be part of a discussion with other participants.

- The identifiable information I have provided will be destroyed on 25th February 2019.

- Any information I provide will be kept confidential to the researcher and the supervisor.

- I understand that the results may be used for a Masters thesis, a BUILD magazine article, and a conference presentation.

- My name will not be used in reports, nor will any information that would identify me. However, I acknowledge that I will be identified by my role.

- I would like to receive a copy of the audio recording: $\square$ Yes $\square$ No

- I would like a summary of the focus group: $\quad \square$ Yes $\square$ No

I consent to:

- Being audio recorded during the focus group session

Signature of participant:

Name of participant:

Date:

Email: 


\section{APPENDIX D - EXPERIMENTS \& FOCUS GROUP INFORMATION SHEET}

INFORMATION SHEET FOR EXPERIMENT \& FOCUS GROUP PARTICIPANTS

You are invited to take part in this research. Please read this information before deciding whether or not to take part. If you decide to participate, thank you. If you decide not to participate, thank you for considering this request.

Who am I?

My name is Tayler Hubber-Davis and I am a Masters student in Building Science at Victoria University of Wellington. This research project is work towards my thesis.

What is the aim of the project?

This project investigates how to combine Augmented Reality (AR) with Building Information Modelling (BIM) to facilitate on-site construction. This research aims to determine if Augmented Reality is more effective for information retrieval than two-dimensional or three-dimensional drawings. This is to demonstrate AR's potential through a comparative study, and to make future recommendations for the use of $A R$ in the construction industry.

This research has been approved by the Victoria University of Wellington Human Ethics Committee [ResearchMaster application reference $\# 0000026115]$.

What will I be asked to do?

If you agree to take part, I will ask you to complete a brief Health Screening Questionnaire to prove that you are fit to partake in this study. I will then ask you to wear a Microsoft HoloLens (AR headset) that will show you virtual elements and used to complete specific tasks. You will be working in a team of 4-8 people and I will observe and record your actions. These tasks will be timed. During the experiment, you will be required to complete an individual quiz answering the questions related to the task. These questions will be based around information you can view in the AR model. With your permission, the study will be video recorded via a camera and tripod. A summary will be written up later, which you are welcome to review and comment if you wish. You can choose to not complete any tasks or stop the experiment at any time, without giving a reason. Following this experiment, you will be asked to take part in a focus group discussion. I will ask you and other participants questions about your experience using the Microsoft HoloLens to retrieve information about buildings. I will audio record the focus group with your permission and write it up later. 
Will the experiment involve discomfort for me? If so, what will be done to rectify it?

Participation in the study may cause drowsiness and/or symptoms of motion sickness. We ask that if you are experiencing any symptoms of nausea to tell us and we can stop the experiment. We will stop the experiment at the first signs of discomfort. If you do experience nausea, then you will be monitored until you return to normal. This should be a short period of time. We will provide further support if necessary. We recommend that you avoid any potentially dangerous activities like driving or operating heavy machinery for 2 hours after taking part in this experiment. We encourage you to organise public transportation or an alternative transportation option after the experiment. You will be reimbursed the cost of taking public transportation.

\section{How much of my time will I need to participate in this study?}

The experiment will take a maximum of 2 hours, which includes the experiment ( 1 hour including briefing) and the focus group discussion (1 hour). If you have used the Microsoft HoloLens, you will be required to stay behind for 15 minutes to be observed.

\section{What will happen to the information you give?}

This research is confidential ${ }^{1}$. This means that the researcher named below will be aware of your identity but the research data will be combined and your identity will not be revealed in any reports, presentations, or public documentation.

As other participants will be involved with this research, this means after the study, you may not communicate to anyone, including family members and close friends, any details about the experiment or focus group study. Any transcripts, summaries and recordings will be kept securely and destroyed on 25th February 2019.

\section{Can I withdraw from the study?}

Participation is entirely voluntary for both the experiment and focus group and you are not obliged to be involved. If you do participate, you can withdraw from the study by contacting me at any time before 25th of February 2019. If you withdraw, the information you provided will be destroyed or returned to you. You can withdraw from the experiment and focus group at any time before the ${ }^{1}$ Confidentiality will be preserved except where you disclose something that causes me to be concerned about a risk of harm to yourself and/or others. 
experiment or focus group begins. You can also withdraw while the experiment or focus group is in progress. However, it will not be possible to withdraw the information you have provided up to that point as it will be part of a discussion with other participants.

\section{What will the project produce?}

The information from my research may be used in a Masters thesis, a BUILD magazine article, AND a paper/presentation at a conference.

If you accept this invitation, what are your rights as a research participant? You do not have to accept this invitation if you don't want to. If you do decide to participate, you have the right to:

- $\quad$ ask for the camera recorder to be turned off at any time during the experiment;

- $\quad$ withdraw from the study before 25th February 2019;

- $\quad$ ask any questions about the study at any time;

- receive a copy of your video recording;

- read over and comment on a written summary of your experiment;

- be able to read any reports of this research by emailing the researcher to request a copy.

\section{If you have any questions or problems, who can you contact?}

If you have any questions, either now or in the future, please feel free to contact either:

\section{Student:}

Name: Tayler Hubber-Davis

University email address:

hubbertayl@myvuw.ac.nz

\section{Supervisor:}

Name: Kevin Sweet

Role: Architecture Programme Director

School: School of Architecture

Phone: 044634717

Email: Kevin.Sweet@vuw.ac.nz

\section{Human Ethics Committee information}

If you have any concerns about the ethical conduct of the research you may contact the Victoria University HEC Convenor: Dr Judith Loveridge. Email hec@ vuw.ac.nz or telephone +64-4-463 6028. 


\section{CONSENT TO PARTICIPATE IN EXPERIMENT AND FOCUS GROUP}

This consent form will be held until 25th February 2019.

Researcher: Tayler Hubber-Davis, School of Architecture, Victoria University of Wellington.

- I have read the Information Sheet and the project has been explained to me. My questions have been answered to my satisfaction. I understand that I can ask further questions at any time.

- I have completed a health screening questionnaire honestly.

- I have read the experiment procedures and agree to comply with these rules during and after the focus group session.

- I agree to take part in a video recorded and observational experiment.

- I have read the Focus Group Rules and agree to comply with these rules during and after the focus group session.

- I agree to take part in an audio recorded focus group discussion immediately following the experiment.

I understand that:

- I acknowledge that I am agreeing to keep the information shared during the experiment and focus group confidential. I am aware that after the experiment and focus group, I must not communicate to anyone, including family members and close friends, any details about the focus group or experiment.

- I may experience some discomfort during the experiment but I can stop the experiment at any time and without giving reason.

- I may feel drowsy during or after the experiment, and that I should avoid any potentially dangerous activities after taking part in the experiment, like driving or operating heavy machinery.

- I can withdraw from the focus group or experiment while it is in progress for any given reason. However, it will not be possible to withdraw the information I have provided up to that point as it will be part of a discussion with other participants.

- The identifiable information I have provided will be destroyed on 25th February 2019.

- Any information I provide will be kept confidential to the researcher and the supervisor.

- I understand that the results may be used for a Masters thesis, a BUILD magazine article, and a paper/presentation at a conference. 
- My name will not be used in reports, nor will any information that would identify me.

- I would like a copy of the video and audio recording of my experiment:

$\square$ Yes $\square$ No

- I would like a summary and transcript of the experiment and focus group:

$\square$ Yes $\square$ No

- I would like to receive a copy of the final report and have added my email address below. $\square$ Yes $\square$ No

I consent to:

o Experiencing virtual elements in an AR environment using the Microsoft HoloLens

o Potentially exposing myself to experiencing physical discomfort

- Completing a short health screening questionnaire before the experiment

o Being video recorded and observed during the experiment

- Being audio recorded during the focus group session

o Remaining behind for 15 minutes to be observed after using the Microsoft HoloLens

Signature of participant:

Name of participant:

Date:

Email: 
APPENDICES 


\section{APPENDIX E - FOCUS GROUP RULES}

\section{FOCUS GROUP RULES}

You are invited to take part in this research. Please read this information before deciding whether to take part. If you decide to participate, thank you. If you decide not to participate, thank you for considering this request.

Ground rules are established for the focus group to ensure the discussion is a safe space for focus group participants by establishing shared expectations and a positive tone/structure for the discussion. You must comply with these rules during and after the focus group session.

\section{Ground Rules:}

1. The information shared in this meeting is confidential. You should not discuss the opinions and comments made by other focus group participants with anybody outside this room. We would like you and others to feel comfortable when sharing information.

2. You do not need to agree with others, but you should listen respectfully as others share their views.

3. We would like to hear a wide range of opinions: please speak up on whether you agree or disagree.

4. There are no right or wrong answers, every person's experiences and opinions are important.

5. The meeting is audio recorded, therefore, please one person speak at a time.

6. Please turn off your phones. 
APPENDICES 


\section{APPENDIX F - INITIAL FOCUS GROUP QUESTION GUIDE}

1. What is your name? And a description of the participant's "typical" day at work. i.e. what are the tasks that you complete in your role?

2. What visual tools do you use on your projects currently? Paper drawings, BIM model, etc. How do you use them?

3. Do you find that you have to change the model/drawings during the construction stage of a project? If so, approximately how often do you do this?

4. What are common issues that you run into with your projects while on site?

5. How do you fix these issues? How do you work with others to fix these issues?

6. What do you imagine technology could do to help your projects?

7. Do you have any other general comments about this discussion or topics relating to the focus group session? 
APPENDICES 


\section{APPENDIX G - POST EXPERIMENT FOCUS GROUP QUESTION GUIDE}

1. What are the overall benefits of using the resource?

2. What are the overall drawbacks of using the resource?

3. Did you find it easy to work together to identify the issues in the building using this resource and how confident were you that your answers were correct?

4. How does this resource compare with the way you currently use visual tools on site?

5. If using the laptop or HoloLens - do you think this resource would assist you and save time in your decision making?

6. If using the laptop or HoloLens - how willing would you be to use this resource during the construction stage of your project?

7. What would make you more likely to use the resource?

8. Do you have any other general comments to make about today's experiment? 
APPENDICES 


\section{APPENDIX H - EXPERIMENT ANSWER SHEET}

There are a minimum of $\mathbf{1 0}$ clashes in the drawings/model. The clashes are mainly mechanical based, however there are some structural clashes. An example of a clash could be a duplicate or intersecting building element. You are required to identify as many clashes as you can within a 30-minute timeframe.

1.

2.

3.

4.

5.

6.

7.

8.

9.

10. 


\section{APPENDICES}




\section{APPENDIX I - MODEL LEGENDS}

\section{HoloLens Model MEP Legend:}

Pipes - Stormwater, Condensate, Sanitary, Gas etc.

Ducts - Supply Air, Outside Air, Toilet Exhaust, Kitchen Exhaust, Fan Coil Units etc.

Fire Systems - Sprinklers, Sprinkler Pipes, Smoke Detectors etc.

Water Pipes -Hot Water, Chilled Water, Domestic Cold Water etc.

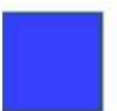

Cable Trays

\section{Paper/Laptop MEP Legend:}

\section{Paper/Laptop Fire Legend:}

Supply Air Duct

Return Air Duct

Supply Air Duct - Outside Air

Stormwater Pipes

Cable Trays

Gas Pipes and Valves

Witchen Exhaust Ducts

Toilet Exhaust Ducts

Sanitary Pipes

Chilled Water Pipes - Flow

Chilled Water Pipes - Return

Hot Water Pipes - Flow

Hot Water Pipes - Return

Condensate Pipes

Structural Stee
Fire Alarm Speaker

S Smoke Detector

Sprinkler Pendant

Upright Sprinkler

Pendant

Concealed Sprinkler Pendant

Threaded Reducing

Elbow

Threaded Reducing Tee

Sprinkler Pipe 